\title{
ss
}

\section{Le Cirad en 2006}
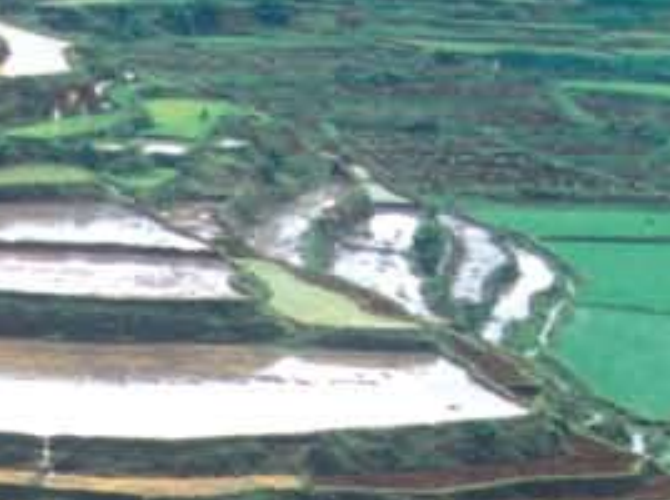

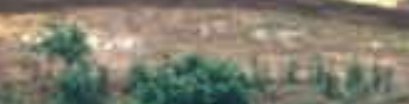

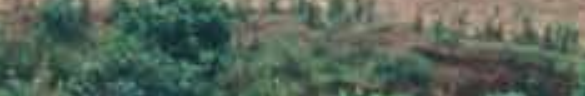

$=\frac{20}{20}$

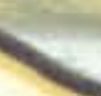

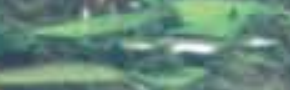

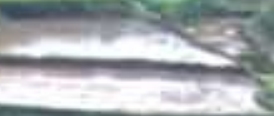
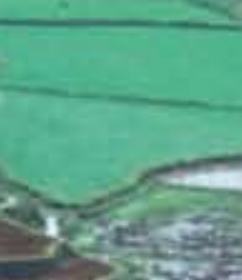

trextess.s.

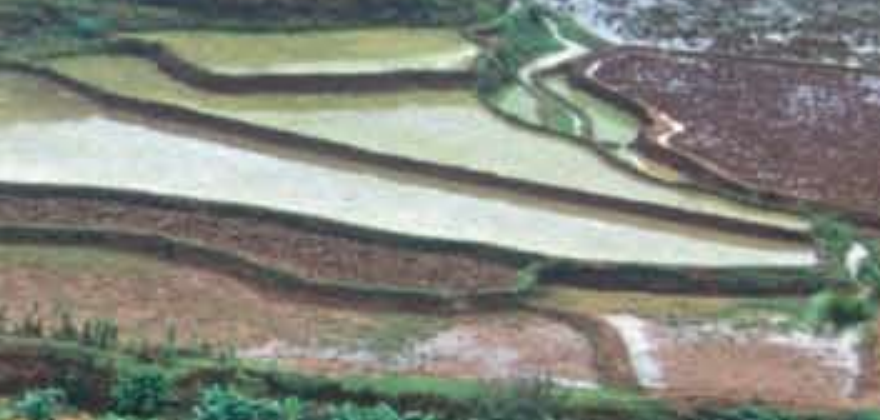

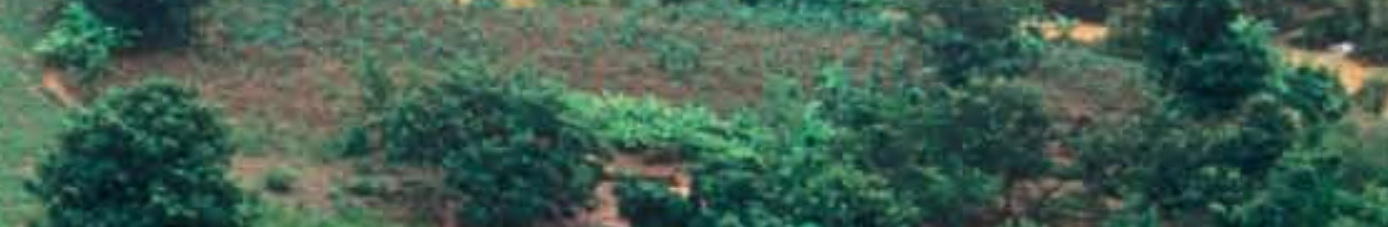
8.

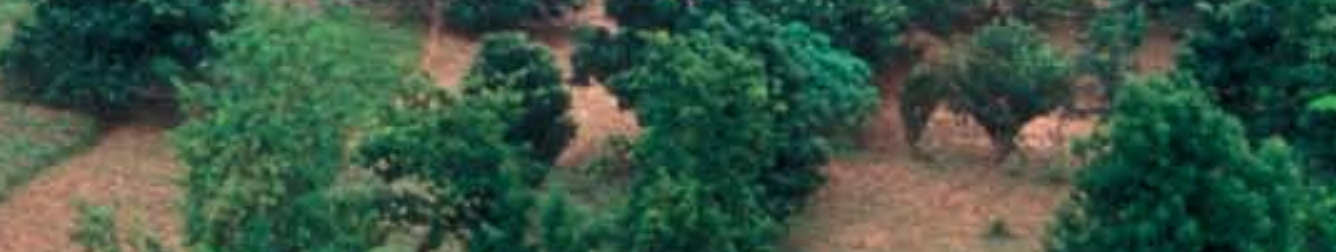

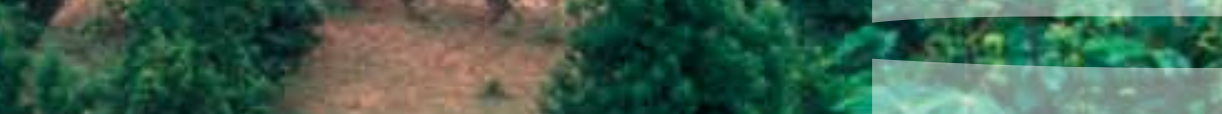

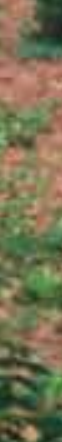

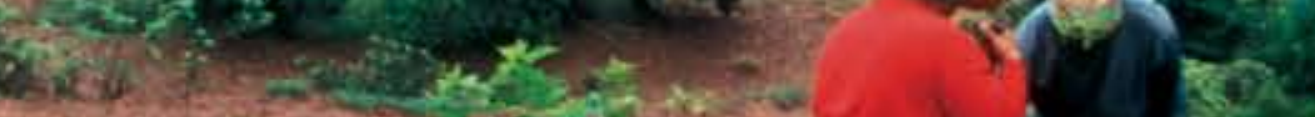

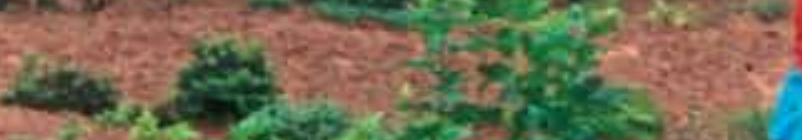

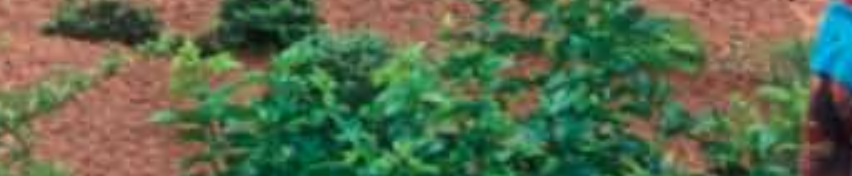

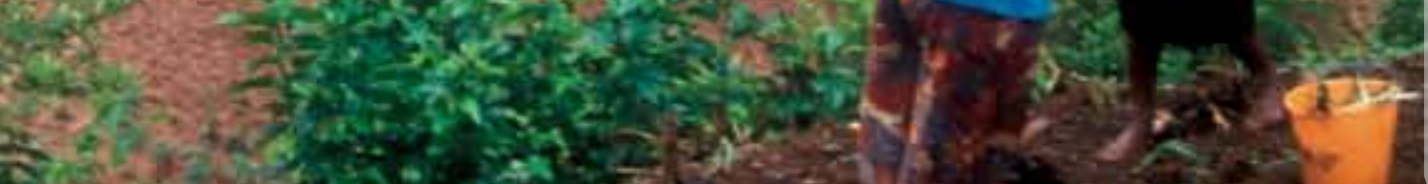




\section{Le Cirad en 2006}


LeCirad, Centre de coopération internationale en recherche agronomique pour le développement, est l'institut français de recherche agronomique au service du développement des pays du Sud et de l'outre-mer français. Il intervient dans l'ensemble des régions tropicales et subtropicales en privilégiant la recherche en partenariat.

Sa mission est de contribuer au développement durable de ces régions par des recherches, des expérimentations, des formations et la diffusion de l'information scientifique et technique. Ses compétences relèvent des sciences du vivant, des sciences humaines et des sciences de l'ingénieur, appliquées à l'agriculture, à l'alimentation, à la gestion des ressources naturelles et aux sociétés.

Le Cirad comprend trois départements de recherche : Systèmes biologiques (Bios), Performances des systèmes de production et de transformation tropicaux (Persyst), Environnements et sociétés (Es). Il est organisé en cinquante-neuf unités : trente-deux unités propres de recherche (Upr), quatre unités de service (Us), vingt unités mixtes de recherche (Umr) et trois unités de recherche en partenariat (Urp).

Il emploie 1825 personnes, dont 856 cadres scienifiques. Son budget opérationnel s'élève à 203 millions d'euros.

(C) Cirad, juin 2007 


\section{Avant-propos}

L'agriculture est désormais reconnue comme l'un des facteurs clés du développement, comme en témoignent les orienLtations actuelles de la Banque mondiale ; elle fournit un emploi à près de la moitié de la population active mondiale, participe à la gestion harmonieuse des paysages et contribue à la préservation des ressources. Ces fonctions font, plus que jamais, de la recherche agronomique une nécessité.

Cette recherche est aujourd'hui confrontée à de nouveaux défis. Selon la Fao, les disparités ne cessent de s'accentuer : dans un monde globalement plus riche, la sous-alimentation progresse - elle touche plus de 800 millions de personnes - et sa répartition devient préoccupante. La fourniture par l'agriculture d'énergie et de biomatériaux, actuellement à l'ordre du jour, risque encore d'amplifier les tensions pour l'utilisation de l'espace agricole. La prégnance des risques planétaires que font courir les maladies émergentes se confirme avec la crise de la grippe aviaire, et les attentes des décideurs et de la société vis-à-vis de la recherche sont ici particulièrement fortes. Quant au Sud, avec lequel le Cirad entretient des relations étroites et continues, il se caractérise par des disparités croissantes, entre les pays et en leur sein, de sorte que la notion de Sud recouvre une pluralité de situations. Pays riches, pays pauvres, pays émergents, tous sont invités à rechercher des solutions aux grands problèmes planétaires.

Au printemps 2006, leurs ministères de tutelle ont demandé au Cirad et à l'Inra d'élaborer une stratégie commune en vue de « constituer une offre élargie de compétences en agronomie et gestion des ressources renouvelables en direction des pays en voie de développement ». Des résultats importants ont déjà été obtenus. L'accord avec le Groupe consultatif pour la recherche agricole internationale (Gcrai), signé en octobre 2006, a pour objectif de renforcer les synergies entre le système international et le Cemagref, le Cirad et l'Inra, afin de répondre aux objectifs du Millénaire pour le développement, prônés par les Nations unies, particulièrement celui de lutter contre la pauvreté dans un processus de développement durable. Associé au World Vegetable Center (Avrdc) et à la Société internationale des sciences horticoles (Ishs), le Cirad a lancé, en mars 2006, I'Initiative horticole mondiale afin de rendre plus efficace et plus équitable la recherche horticole pour le développement.

En 2006, la recherche agronomique à Montpellier a été reconnue comme l'un des treize domaines d'excellence français, avec la labellisation en tant que Réseau thématique de recherche avancée (Rtra) du projet porté par le Cirad, l'Inra et Montpellier SupAgro. Centré sur les sciences du végétal, du gène au système, ce réseau croise les approches biotechnique et socio-économique sur des problématiques tempérées, méditerranéennes et tropicales. Ouvert à toute la communauté scientifique montpelliéraine et à ses partenaires, ce réseau rassemble 500 chercheurs et enseignants de haut niveau. II bénéficie de moyens nouveaux, qui lui permettront de confirmer son rôle de premier plan sur la scène internationale. Le Cirad et l'Inra ont, par ailleurs, lancé la prospective Agrimonde, qui sera conduite sur deux ans.

A la fin de l'année, le Cirad a adapté son organisation et renouvelé sa gouvernance, en maintenant les unités de recherche au cœur de son activité. Le nombre de ses départements a été réduit et leur nature scientifique réaffirmée. Chaque département est centré sur un ensemble spécifique d'objets et de questions : le gène et l'organisme, végétal ou animal, pour le département Systèmes biologiques; les systèmes de production et de transformation pour le département Performances des systèmes de production et de transformation tropicaux ; la gestion des ressources et les dynamiques territoriales pour le département Environnements et sociétés. La stratégie scientifique occupe désormais une place prépondérante ; elle est définie, de manière collégiale, par le directeur général, le directeur de la recherche et de la stratégie et les directeurs des départements. Au directeur de la recherche et de la stratégie sont également rattachées les directions régionales afin que prévale une seule logique de programmation, qui prenne en compte simultanément les dimensions scientifiques, partenariales et géographiques. Enfin, l'année 2007 verra le lancement du groupement d'intérêt public Initiative française pour la recherche agronomique internationale, outil commun de réflexion sur la programmation à l'échelle internationale du Cirad et de l'Inra.

Les résultats présentés dans ce rapport témoignent de manière concrète des travaux scientifiques du Cirad, mais aussi de ses activités dans les domaines de la formation et de l'information. Exigence fondatrice pour l'établissement, le partenariat y tient une place essentielle. C'est ainsi qu'au fil des années le Cirad dessine le paysage de ses recherches et de ses compétences, au service de son engagement pour le développement.

Patrice Debré

Président du conseil d'administration
Gérard Matheron

Directeur général 


\section{Sommaire}

Avant-propos

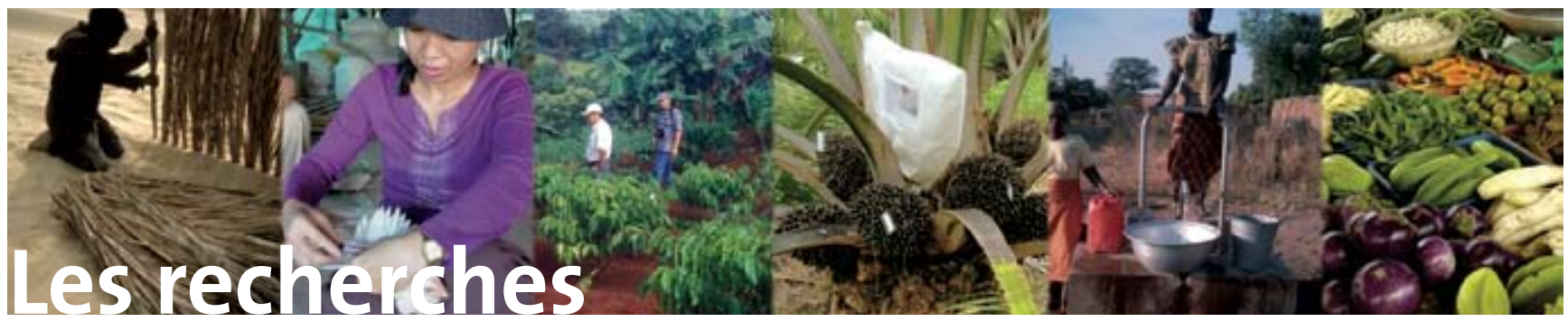

\section{Connaître •••}

-. OryGenes DB, à la découverte de la fonction des gènes chez le riz

-.. Des gènes impliqués

dans la qualité du café

Le paradoxe du café

-. - Le charbon de la canne à sucre :

diversité du champignon

et génétique de la résistance

-. Images et arôme de vanille

- - La silice renforce la résistance de la canne à sucre au foreur des tiges

-. Paysages à risque et comportement des glossines: les bases de la lutte antivectorielle

.. Une table de composition en polyphénols des fruits et légumes

\section{Préserver ॰००}

๑०० Les variétés locales de riz en Guinée : diversité, dynamique et conservation

○०० Agroforesterie et caféiculture : produire mieux et durablement

००० Les plantes envahissantes : une menace pour la biodiversité à la Réunion
๑०० L'avenir de l'agriculture irriguée en Méditerranée

La gouvernance de l'eau

๑०० La production porcine dans le delta du fleuve Rouge

๑०० Sauvegarder les espèces animales menacées au Vietnam

o o o Kassa, de nouvelles questions de recherche sur l'agriculture de conservation

Approches biologiques du sol

w o o Des formations sur l'impact de la gestion des matières organiques

o o o s L'observatoire, support de l'action collective

(o o o Ranema, un module de formation en épidémiologie à distance

a o o Cultiver dans les villes :

une réponse à l'urbanisation

1 o o c Le libre accès

à la connaissance scientifique

Les éditions Quae, la nouvelle maison d'édition du Cirad 


\section{Innover}

... Un diagnostic universel et précoce du dépérissement bactérien de l'anthurium

-. Culture in vitro du palmier à huile :

un procédé de seconde génération Une filiale pour exploiter un champ semencier de palmiers à huile en Thaïlande

- - Le contrôle génétique du sexe

chez les tilapias

.. Peste bovine et peste des petits ruminants :

I'ARN interférent au cœur

$d^{\prime}$ un futur traitement

42

.. Les indications géographiques

dans les pays émergents

\section{Anticiper $\square$}

- - Agrimonde : agricultures

et alimentations du monde en 2050

- - Les maladies émergentes :

un défi pour la recherche

Risques phytosanitaires émergents :

le Huanglongbing des agrumes

\section{Les indicateurs}

Les moyens humains et l'évolution

des compétences

La politique scientifique et partenariale

La valorisation

Les moyens financiers $\quad 58$

La politique de la qualité

Le Cirad dans le monde 

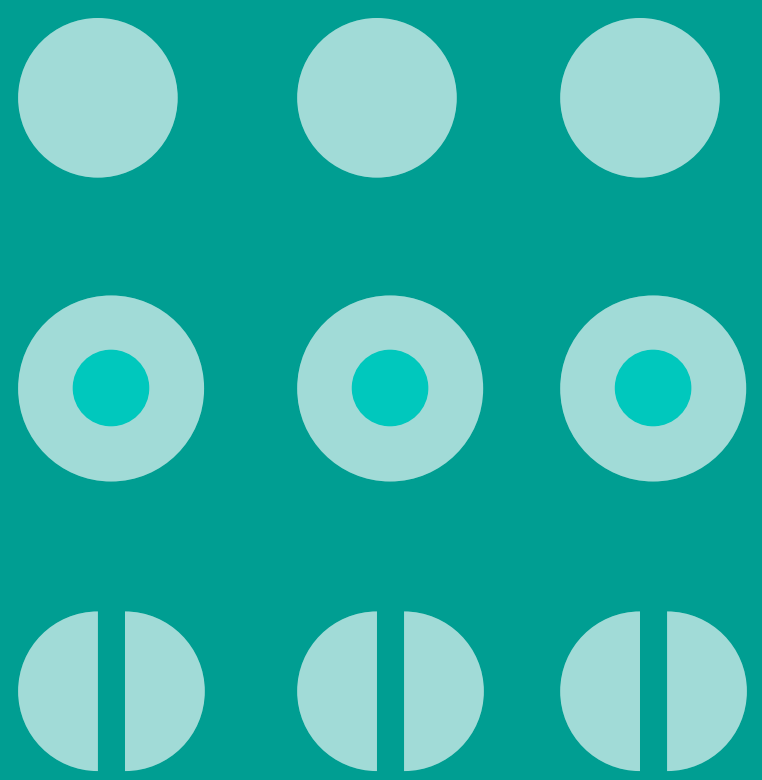

\section{Les recherches}
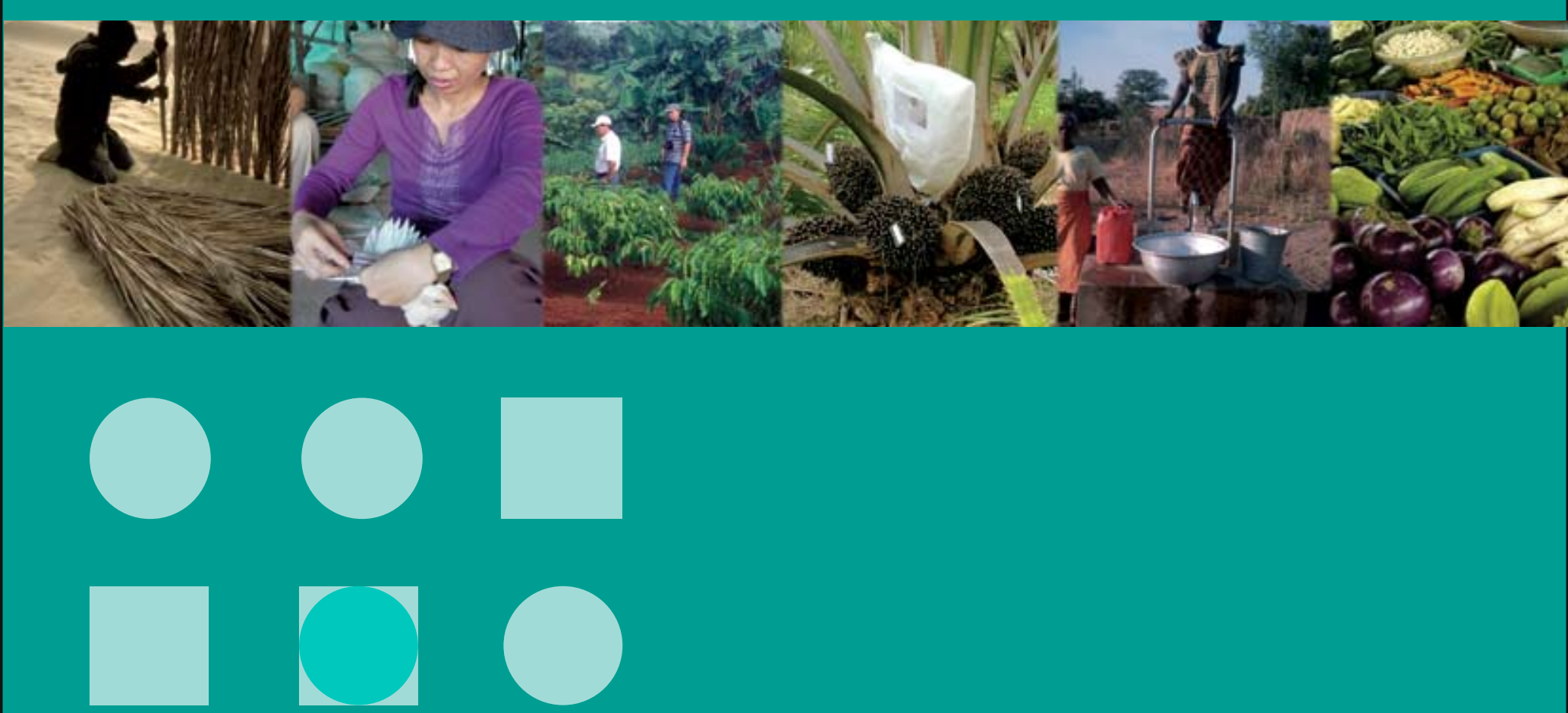


\section{Connaître •.•}

\section{•• OryGenesDB, à la découverte de la fonction des gènes chez le riz}

La séquence complète du génome du riz est désormais connue. Elle comporte de 40000 à 60000 gènes. Il s'agit maintenant d'en déterminer la fonction biologique : c'est le domaine de la génomique fonctionnelle. Pour faciliter cette étude, une base de données vient d'être créée par le Cirad. Elle regroupe l'ensemble des informations génomiques essentielles sur le riz, en particulier les séquences adjacentes (FST) aux sites d'intégration d'éléments mutagènes présents dans les collections de mutants d'insertion. Ces étiquettes permettent d'accéder à la fonction des gènes en reliant directement gène et phénotype, dans une démarche de génétique inverse.

\begin{abstract}
Outre son intérêt agricole, le riz présente l'avantage de posséder un petit génome et des similarités de séquences et d'organisation génique avec les autres céréales, qui en font une plante modèle pour étudier les monocotylédones. Le séquençage complet de son génome s'est achevé en décembre 2004. Il révèle une abondance inattendue de gènes, de I'ordre de 40000 à 60 000, alors qu'on en compte seulement 27000 chez Ara-
\end{abstract}

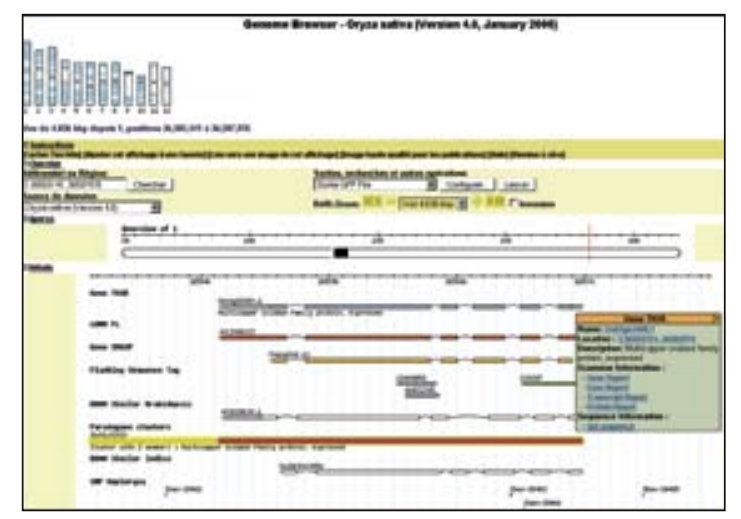

Une interface graphique qui permet de naviguer le long du génome. bidopsis thaliana, l'espèce modèle pour les dicotylédones. II s'agit maintenant de déterminer la fonction biologique de tous ces gènes : $c^{\prime}$ est le domaine de la génomique fonctionnelle.

\section{L’apport de la génomique}

Pour déterminer cette fonction, plusieurs études fondées sur la mutagenèse insertionnelle ont été entreprises. Cette méthode permet d'insérer, au hasard dans le génome, un fragment d'ADN repérable, I'ADN-T ou ADN de transfert (ou un élément transposable). Lorsque celui-ci s'intègre dans un gène, il peut en altérer la fonction et provoquer la modification du caractère correspondant. Le gène muté est localisé grâce à l'élément inséré, et sa fonction est identifiée grâce au caractère affecté. Le repérage systématique des sites d'insertion se fait par séquençage à grande échelle à partir des éléments mutagènes intégrés.
Une collection de 30000 lignées d'insertion d'ADN-T et 40000 FST (flanking sequence tag) ont ainsi été produits au Cirad dans le cadre du projet Génoplante. Parallèlement, d'autres collections de mutants ont été créées par différents laboratoires internationaux. Pour exploiter ces informations, une base de données intégrative, OryGenesDB, qui regroupe l'ensemble de ces ressources ainsi que les données génomiques essentielles sur le riz, a été conçue.

\section{Un système complet d'information}

L'objectif du système d'information OryGenesDB est de permettre aux généticiens moléculaires de trouver rapidement des mutants d'insertion pour des gènes d'intérêt et de récupérer le maximum d'annotations liées à ces gènes par une démarche de génétique inverse, de la séquence au phénotype. 


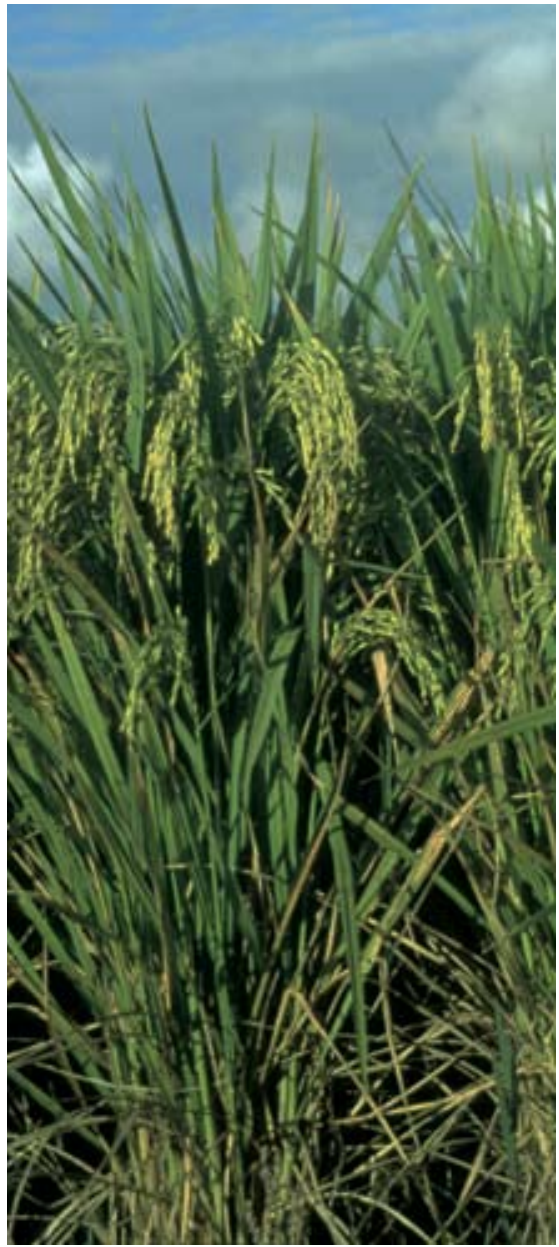

Le riz, une plante modèle pour étudier les monocotylédones. () J.E. Taillebois/Cirad.

Le cœur du système est constitué par le logiciel générique Genome browser, une application web de visualisation d'annotations génomiques. II offre une interface graphique conviviale, qui permet de naviguer le long du génome et de visualiser facilement l'ensemble des annotations génomiques disponibles. Le référentiel du système correspond aux pseudo-molécules, ou chromosomes, du riz issues du site de I'institut de recherches génomiques (Tigr). Outre les FST, différentes informations, comme les ADNc pleine longueur, les groupes de séquences exprimées de plusieurs céréales (blé, maïs, orge, sorgho, canne à sucre), les marqueurs moléculaires et des données d'expression, y ont été intégrées sous la forme de couches d'annotations. Des outils complémentaires ont été développés pour faciliter la recherche et la visualisation des informations : recherche par numéro d'accession, par mots clés, par domaine protéique conservé ou encore par homologie de séquence. Le résultat de la recherche peut ensuite être archivé sous la forme d'un fichier Excel.

\section{Un outil incontournable pour explorer la fonction des gènes}

Afin de simplifier et $d^{\prime}$ intensifier les analyses fonctionnelles du génome du riz, deux autres bases de données, développées en parallèle, vont être reliées à OryGenesDB. Oryza Tag Line (OTL) est le versant phénotypique de la base OryGenesDB. Elle référence I'ensemble des données morphologiques et physiologiques recueillies sur les lignées $d^{\prime}$ insertion $d^{\prime} A D N-T$. La connexion de ces deux bases permettra d'identifier rapidement l'effet d'une mutation dans un gène donné en recherchant les caractéristiques morphologiques et physiologiques des plantes correspondantes. Enfin, pour exploiter la masse d'informations réunies sur Arabidopsis thaliana, une nouvelle base de données, Greenphyl, a été créée. Elle permet de classer l'ensemble des séquences provenant du riz et d'Arabidopsis en familles puis de déterminer, à l'aide d'un outil automatique, les équivalents fonctionnels les plus probables chez les deux espèces.

OryGenesDB est maintenant la base de données centrale pour I'analyse fonctionnelle des gènes du riz au Cirad. Elle est largement utilisée par la communauté internationale. Sa puissance et sa simplicité d'utilisation devraient en faire un outil incontournable pour explorer la fonction des gènes d'intérêt agronomique chez les autres céréales.

- Christophe Périn, Gaëtan Droc, Pierre Larmande, Emmanuel Guiderdoni, Manuel Ruiz, Brigitte Courtois,

Umr Polymorphismes d'intérêt agronomique (Pia)

christophe.perin@cirad.fr

\section{Partenaires}

Wageningen, University and Research Centre, Plant Research International (Pays-Bas). Le développement d'OryGenesDB a été financé par la Commission européenne (projet Cereal gene tag CT-2001-01453) et le Challenge Programme Generation (projet Rice stress mutants).

\section{Bibliographie}

Antonio B.A., Buell C.R., Yamazaki Y., Yap I., Perin C., Bruskiewich R., 2007. Informatics resources for rice functional genomics. In : Rice functional genomics: challenges, progress and prospects, Upadhyaya N.M. (éd.). New York, Springer, p. 365-406.

Droc G., Ruiz M., Larmande P., Pereira A., Piffanelli P., Morel J.B., Dievart A., Courtois B., Guiderdoni E., Périn C., 2006. OryGenesDB: a database for rice reverse genetics. Nucleic Acids Research, 34 : D736-D740.

Enckevort L.J.G., Droc G., Piffanelli P., Greco R., Gagneur C., Weber C., González V.M., Cabot P., Fornara F., Berri S., Miro B., Lan P., Rafel M., Capell T., Puigdomènech P., Ouwerkerk P.B.F., Meijer A.H., Pe E., Colombo L., Christou P., Guiderdoni E., Pereira A., 2005. EU-OSTID: a collection of transposon insertional mutants for functional genomics in rice. Plant Molecular Biology, 59: 99-110.

Yuan Q., Ouyang S., Wang A., Zhu W., Maiti R., Lin H., Hamilton J., Haas B., Sultana R., Cheung F., Wortman J., Buell C.R., 2005. The institute for genomic research Osa1 rice genome annotation database. Plant Physiology, $138: 18-26$.

\section{Site}

http://orygenesdb.cirad.fr 


\title{
•• Des gènes impliqués dans la qualité du café
}

\author{
Le saccharose est un composé essentiel de la qualité organoleptique du café. Une équipe du \\ Cirad et de l'institut agronomique brésilien du Paraná vient d'identifier les gènes responsables \\ de l'accumulation de ce sucre dans les grains. Un pas de plus vers la production d'un café \\ d'excellence.
}

Pour maintenir leurs revenus, les planteurs doivent plus que jamais miser sur la production d'un café de qualité. Or, I'amélioration de la qualité du café à la tasse passe par une meilleure connaissance des processus biologiques — floraison, maturation du fruit — qui déterminent les caractéristiques du produit final. Certains composés, comme les sucres, les lipides et la caféine, sont connus pour leur implication dans la qualité du café. Le saccharose, en particulier, est considéré comme un composé essentiel de la qualité organoleptique : sa dégradation lors de la torréfaction produit en effet plusieurs précurseurs d'arômes et de flaveurs.

\section{Une enzyme responsable de l'accumulation du saccharose}

Depuis 2001, le Cirad et I'institut agronomique brésilien du Paraná mènent des recherches sur la maturation du grain de caféier. En partenariat avec I'université de Campinas, au Brésil, ils ont caractérisé les enzymes clés du métabolisme du saccharose au cours du développement du grain, à partir de techniques de biologie moléculaire et de biochimie.

Ces travaux ont montré qu'une enzyme, la synthétase de saccharose, est responsable de l'accumulation de ce sucre dans les grains de café Arabica. Contrairement à d'autres plantes, la participation des invertases à ce métabolisme est mineure. La synthétase de saccharose existe sous la forme d'au moins deux protéines proches et de même fonction biologique — des isoformes — mais qui sont codées par deux gènes distincts : Sus 1 et Sus2.

L'expression de ces gènes a été analysée au sein des différents tissus du fruit en développement (pulpe, périsperme, albumen, grain). L'accumulation du saccharose dans les grains en fin de maturation, avant la récolte, est contrôlée par I'isoforme Sus2. L'isoforme Sus1, quant à elle, semble être impliquée dans la dégradation du saccharose et donc dans la production d'énergie. Son expression est en effet toujours détectée durant les phases précoces de division et d'expansion cellulaire des jeunes tissus.

\section{Des marqueurs précoces de la qualité}

Dans une seconde phase, la diversité nucléotidique de ces gènes a été étudiée afin d'expliquer la variabilité de la teneur en saccharose des grains entre les espèces de Coffea ou au sein $d^{\prime}$ une même espèce. Les gènes ont été cartographiés et testés quant à leur implication dans cette variabilité. Ils constitueront des marqueurs précoces du contenu en saccharose, et donc de la qualité du café produit.

Première application de ces résultats : une étude des relations entre l'ombrage, connu pour accroître la qualité du café, et les enzymes du métabolisme du saccharose. Un essai au champ révèle ainsi que la synthétase de saccharose et la phosphate synthétase de saccharose, une autre enzyme du métabolisme du saccharose, présentent des activités plus élevées dans les grains de caféiers cultivés à l'ombre que dans ceux cultivés en plein soleil. Dans le cas de la synthétase de saccharose, cette activité est corrélée avec l'augmentation de l'expression du gène Sus2, qui a été observée dans les grains des plants ombragés. Cependant, la teneur finale en saccharose des grains n'est pas plus élevée sous ombrage : la qualité du café pourrait alors résulter d'une réorientation du métabolisme glucidique vers la synthèse $d^{\prime}$ autres composés, comme les lipides, susceptibles d'y être également impliqués.

- Thierry Leroy, Pierre Marraccini, David Pot, Umr Polymorphismes d'intérêt agronomique (Pia) thierry.leroy@cirad.fr

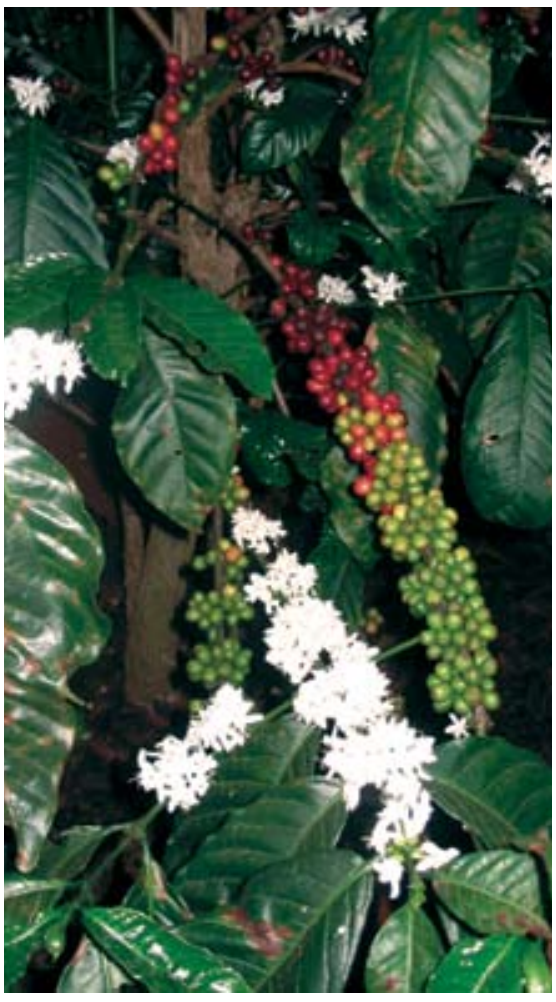

Le saccharose accumulé dans les grains est l'un des composés organoleptiques du café. $\odot$ P. Marraccini/Cirad. 


\section{Partenaires}

Ambassade de France au Brésil, Consórcio Brasileiro de Pesquisa e Desenvolvimento do Café (Cbpdc, Brésil), Empresa Brasileira de Pesquisa Agropecuária (Embrapa, Brésil), Instituto Agronômico do Paraná (lapar, Brésil), université de l'Etat de Londrina (Brésil), université de Campinas (Unicamp, Brésil).

\section{Bibliographie}

De Castro R., Marraccini P., 2006. Cytology, biochemistry and molecular changes during coffee fruit development. Brazilian Journal of Plant Physiology, 18 : 175-199.

Geromel C., Ferreira L.P., Cavalari A.A., Pereira L.F.P., Guerreiro S.M.C., Vieira L.G.E., Leroy T., Pot D., Mazzafera P., Marraccini P., 2006. Biochemical and genomic analysis of sucrose metabolism during coffee (Coffea arabica) fruit development. Journal of Experimental Botany, $57: 3243-3258$.

Leroy T., Marraccini P., Dufour M., Montagnon C., Lashermes P., Sabau X., Ferreira L.P., Jourdan I., Pot D., Andrade A.C., Glaszmann J.C., Vieira L.G.E., Piffanelli P., 2005. Construction and characterization of a Coffea canephora BAC library to study the organization of sucrose biosynthesis genes. Theoretical and Applied Genetics, $111: 1032-1041$.

Leroy T., Ribeyre F., Bertrand B., Charmetant P., Dufour M., Montagnon C., Marraccini P., Pot D., 2006. Genetics of coffee quality. Brazilian Journal of Plant Physiology, 18 : 229-242.

\section{Le paradoxe du café}

Cet ouvrage part d'un constat. Les échanges internationaux ont fortement progressé ces deux dernières décennies et représentent une source importante de revenus pour les pays en développement. Pourtant, si nombre d'entre eux sont depuis longtemps producteurs et exportateurs de produits tropicaux, ils sont toujours aussi pauvres.

A partir de l'étude de la « chaîne globale de valeur » du café, les auteurs considèrent de manière nouvelle le problème du développement des pays exportateurs de produits de base. Ils analysent ainsi le paradoxe du café — la coexistence d'un boom du café dans les pays consommateurs et d'une crise du café dans les pays producteurs - et prouvent que le paradoxe du café existe parce que le café que les agriculteurs vendent et celui que les consommateurs achètent sont de plus en plus différents. Les consommateurs ne payent pas une qualité matérielle, mais plutôt des attributs symboliques. Et tant que les caféiculteurs et leurs organisations ne contrôleront pas, au moins en partie, cette production « immatérielle», ils continueront d'être faiblement rémunérés. Au-delà de l'étude de cas, cet ouvrage contribue à un profond renouvellement de l'analyse de la filière.

\section{- Benoit Daviron, Upr Normes et régulation des marchés agricoles benoit.daviron@cirad.fr}

\section{Bibliographie}

Daviron B., Ponte S., 2005. The coffee paradox: global markets, commodity trade and the elusive promise of development. Londres, Zed Books, 296 p.

Daviron B., Ponte S., 2006. La paradoja del café: mercados globales, comercio de bienes primarios y la esquiva promesa del desarrollo. Bogotá, Fedecafé de Colombia, Fondo Nacional Cafetero, International Coffee Organisation, $288 \mathrm{p}$.

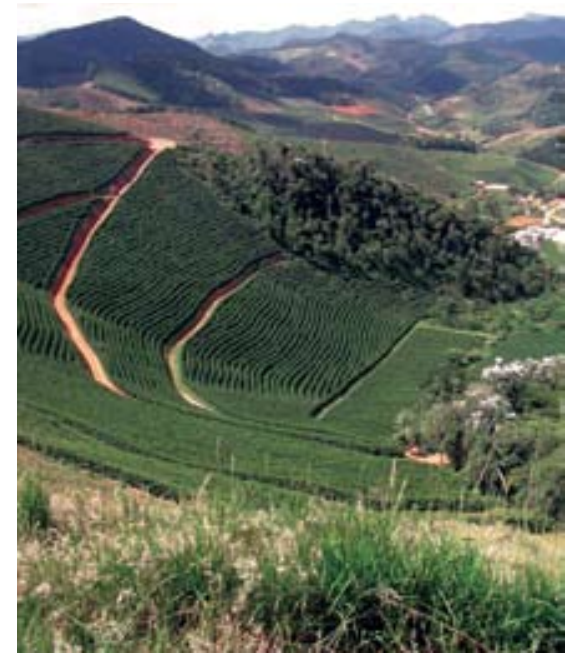

Champs de Coffea arabica cultivés en escalier, Esperito Santo, Brésil. @ P. Marraccini/Cirad.

\title{
- • - Le charbon de la canne à sucre : diversité du champignon et génétique de la résistance
}

\begin{abstract}
Le charbon est une maladie présente dans toutes les zones de culture de la canne à sucre, à I'exception de la Papouasie-Nouvelle-Guinée, qui est pourtant le berceau de l'espèce ancestrale domestiquée, Saccharum officinarum. Des études permettent désormais de mieux cerner la diversité génétique de ce champignon et le déterminisme génétique de la résistance de la canne.
\end{abstract}

Le charbon de la canne à sucre est une maladie due au champignon Ustilago scitaminea, dont la diversité génétique se révèle extrêmement faible en dehors de I'Asie. La lutte contre cette maladie peut s'appuyer sur la sélection de variétés résistantes, mais le déterminisme génétique de cette résistance n'est pas connu. Pour identifier les régions chromosomiques impliquées, une nouvelle stratégie a été mise en œuvre. Elle se fonde sur l'étude des associations entre marqueurs et résistance, qui s'avère particulièrement prometteuse. 


\section{Une lignée unique à l'origine de la maladie en dehors de l'Asie}

Le charbon de la canne à sucre se manifeste par la formation d'un sore charbonneux en forme de fouet à l'extrémité des tiges infectées, qui peut libérer de grandes quantités de spores. La structure particulière de la diversité génétique de ce champignon a été étudiée, à l'échelle mondiale, grâce aux marqueurs microsatellites. II apparaît que l'essentiel de cette diversité est détecté dans certaines populations du continent asiatique. La diversité génétique des populations provenant des continents américain et africain est, en revanche, extrêmement faible et toutes les souches non asiatiques étudiées sont issues d'un même génotype.

Ces résultats suggèrent que les flux géniques entre continents sont rares puisqu'une lignée unique, originaire d'Asie, s'est répandue à travers le monde, probablement par le transport accidentel de boutures infectées. En dehors de I'Asie, I'utilisation de variétés résistantes devrait donc constituer une stratégie durable et efficace pour combattre la maladie. En Asie, compte tenu de la variabilité du pathogène, il serait intéressant de mieux caractériser les sources de résistance disponibles, en particulier celles de l'espèce sauvage S. spontaneum.

\section{Repérer les associations entre marqueurs et résistance}

Les variétés modernes de canne à sucre résultent de quelques hybridations interspécifiques réalisées entre $S$. officinarum et $S$. spontaneum au début du $x x^{\mathrm{e}}$ siècle, en Inde et en Indonésie, dont les produits ont ensuite été entrecroisés moins d'une dizaine de fois pour aboutir à ces variétés. II y a donc eu un fort effet de fondation, susceptible d'entraîner du déséquilibre de liaison. Ce déséquilibre de liaison, qui mesure I'association non aléatoire entre allèles

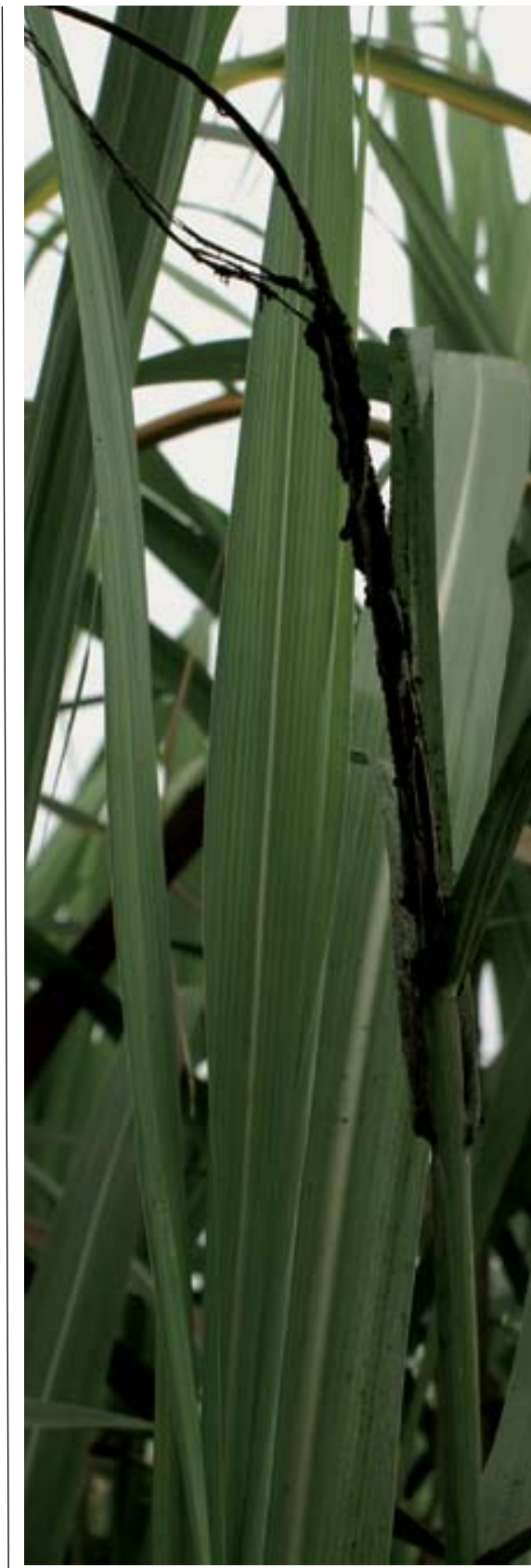

Le charbon de la canne à sucre se manifeste par la formation d'un sore charbonneux en forme de fouet à l'extrémité des tiges. (c) J.-C. Girard/Cirad.

à des locus distincts, est plus ou moins fort chez les plantes cultivées selon I'histoire de leur domestication et leur régime de reproduction. Chez la canne à sucre, ce fort déséquilibre de liaison a été confirmé en suivant le comportement de marqueurs AFLP (amplified fragment length polymorphism), dont la position sur les cartes génétiques de référence est connue : des associations significatives entre marqueurs peuvent être détectées jusqu'à des distances de plus de 20 cM, même si l'intensité moyenne du déséquilibre chute considérablement lorsque la distance génétique entre les marqueurs dépasse 5 cM. La structure de ce déséquilibre de liaison permet donc d'envisager de localiser des gènes d'intérêt en analysant les associations entre marqueurs et caractères sur l'ensemble du génome.

C'est sur la base de ce constat que le déterminisme génétique de la résistance au charbon a été exploré dans une population de cultivars constituée de deux sous-populations, I'une très résistante et l'autre très sensible au charbon. L'étude des associations entre la présence ou l'absence des marqueurs et la résistance a permis de mettre en évidence des régions chromosomiques liées à la résistance. Certaines d'entre elles correspondent à des QTL (quantitative trait loci) détectés lors d'une étude de cartographie génétique réalisée parallèlement sur un croisement contrôlé entre un cultivar résistant ( $R$ 570) et un clone sensible (MQ 76-53).

Les études d'associations apparaissent particulièrement prometteuses chez la canne à sucre. Elles viennent compléter les approches par QTL, qui se révèlent délicates chez cette plante hautement polyploïde.

- Louis-Marie Raboin, Laurent Costet, Umr Peuplements végétaux et bioagresseurs en milieu tropical (Pvbmt),

Jean Carlier, Umr Biologie et génétique des interactions pour la protection intégrée (Bgpi),

Jérôme Pauquet, Angélique D'Hont, Umr Polymorphismes d'intérêt agronomique (Pia) louis-marie.raboin@cirad.fr

\section{Partenaires}

Centre d'étude, de recherche et de formation (Cerf, Réunion), Centro de Investigación de la Caña de Azúcar de Colombia (Cenicana, Colombie), Compagnie sucrière sénégalaise (Sénégal), Cooperativa de Produtores de Cana-de-Açúcar, Açúcar e Álcool do Estado 
de São Paulo (Copersucar, Brésil), Hawaii agriculture Research Center (Hawaii), GPM Sugar Group (Indonésie), Japan International Research Center for Agricultural Sciences (Jircas, Japon), Mauritius Sugar Industry Research Institute (Msiri, Maurice), Mitr Phol Sugarcane Research Center (Thaïlande), Philippine Sugar Research Institute Foundation (Philippines), Société nationale sucrière (Sosuco, Burkina Faso), South African Sugar Research Institute (Sasri, Afrique du Sud), Texas Agricultural Experiment Station (Etats-Unis), Uttar Pradesh Council of Sugarcane Research (Inde).

\section{Bibliographie}

Raboin L.M., 2005. Génétique de la résistance au charbon de la canne à sucre causé par Ustilago scitaminea Syd. : caractérisation de la diversité génétique du pathogène, cartographie de QTL dans un croisement biparental et étude d'associations dans une population de cultivars modernes. Thèse de doctorat, AgroM, Montpellier, $119 \mathrm{p}$.

Raboin L.M., Oliveira K.M., Le Cunff L., Telismart H., Roques D., Butterfield M., Hoarau J.Y., D'Hont A., 2006. Genetic map- ping in sugarcane, a high polyploid, using bi-parental progeny: identification of a gene controlling stalk colour and a new rust resistance gene. Theoretical and Applied Genetics, 112 : 1382-1391.

Raboin L.M., Selvi A., Miranda Oliveira K., Paulet F., Calatayud C., Zapater M.F., Brottier P., Luzaran R., Garsmeur O., Carlier J., D'Hont A., 2007. Evidence for the dispersal of a unique lineage from Asia to America and Africa in the sugarcane fungal pathogen Ustilago scitaminea. Fungal Genetics and Biology, 44 : 64-76. (doi:10.1016/j.fgb.2006.07.004).

\title{
•• Images et arôme de vanille
}

\begin{abstract}
Au cours de la maturation du fruit, la glucovanilline accumulée dans la gousse de vanille encore verte est hydrolysée par une glucosidase, qui libère l'arôme de vanille. Mais la localisation de ces deux composés au sein de la gousse fait l'objet de controverses. Grâce à l'imagerie cellulaire et aux nouvelles techniques de déconvolution spectrale, il est désormais possible d'identifier précisément in situ ces deux métabolites. Et d'envisager à terme d'améliorer les procédés de traitement après récolte de la gousse.
\end{abstract}

L'imagerie cellulaire connaît aujourd'hui une véritable révolution liée à l'essor des techniques de marquage in situ et à l'évolution des performances des microscopes, qui s'est considérablement accélérée au cours des dix dernières années. Il est en effet désormais possible d'analyser la composition spectrale de la lumière de chaque pixel d'une image. La déconvolution spectrale, à la base de cette analyse, fait appel à des algorithmes puissants qui permettent de décomposer un spectre d'émission complexe en spectres élémentaires enregistrés comme témoins. Au départ, ce système a été développé pour les biologistes

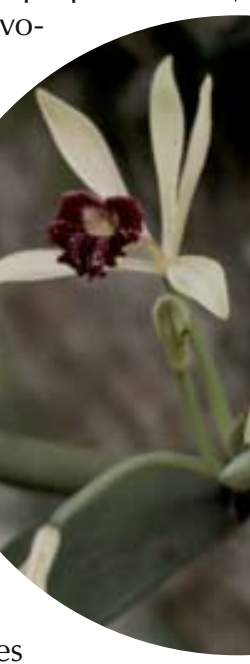

qui souhaitaient suivre, dans un même tissu, plusieurs protéines marquées avec des tags de couleur différente.

Au sein du plateau d'histocytologie et d'imagerie cellulaire végétale, cette technique a été utilisée pour localiser in situ des métabolites secondaires de la gousse de vanille, présentant des différences de fluorescence : la vanilline et son

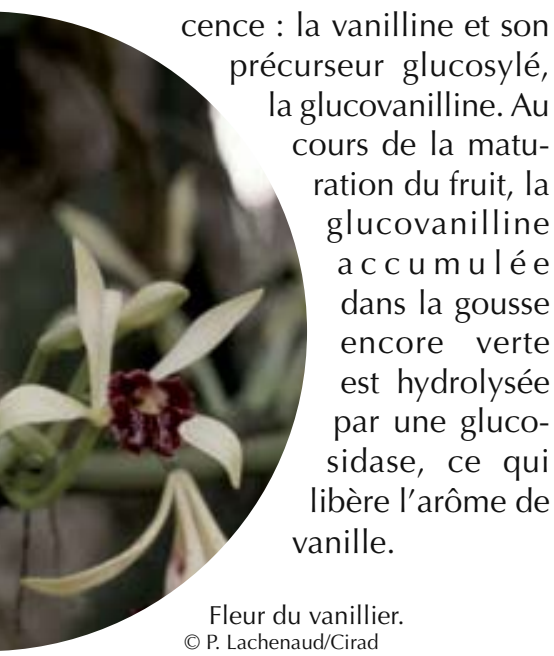

\section{Localiser précisément la vanilline dans la gousse}

Des poudres de vanilline et de glucovanilline purifiées ont été observées au microscope confocal, et leurs spectres d'émission respectifs enregistrés. Ces spectres témoins ont été utilisés pour analyser la lumière de fluorescence d'une coupe de gousse et retrouver les pixels de l'image qui contiennent l'un ou l'autre des spectres ou les deux spectres superposés. Il a ainsi été possible de distinguer les zones de l'image et de la coupe qui correspondaient à la glucovanilline de celles qui correspondaient à la vanilline.

La glucovanilline s'accumule essentiellement dans la zone interne de la gousse et, plus précisément, dans les placentas, les papilles sécrétrices et autour des graines, dans la cavité de la gousse. La vanilline se retrouve dans les cellules des placentas et au voisinage des graines. Les expériences menées sur 


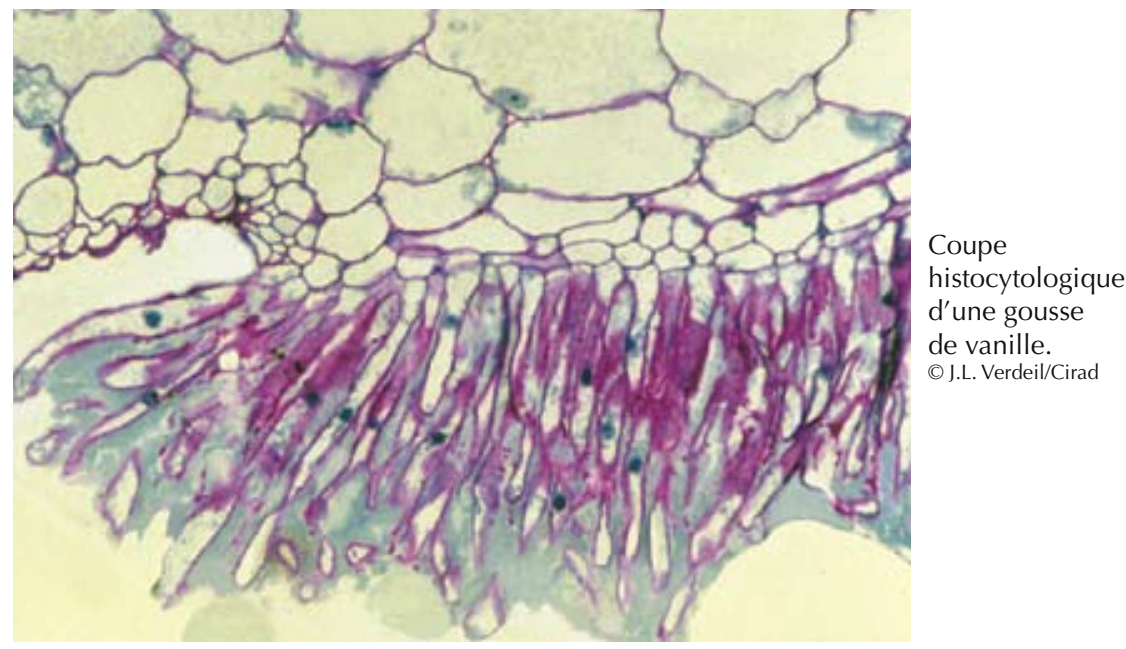

de nombreux témoins ont permis de confirmer cette localisation. Elles ont aussi mis en évidence la puissance de la déconvolution spectrale pour localiser in situ des métabolites secondaires, et les limites de cette technique.

Ces données expérimentales ouvrent des perspectives pour le contrôle des procédés de traitement après récolte de la gousse. En effet, le procédé utilisé dans les pays producteurs, qui est issu $d^{\prime}$ 'une longue tradition, est totalement empirique. Dans ces conditions, il est presque impossible de diagnostiquer correctement l'origine des défauts qualitatifs rencontrés. Ces travaux constituent une étape indispensable vers une meilleure compréhension de l'élaboration de la qualité de la vanille au cours de sa transformation.
- - Jean-Luc Verdeil, Umr Biologie du développement des espèces pérennes cultivées (Bepc),

Eric Odoux, Upr Qualité des aliments tropicaux

jean-luc.verdeil@cirad.fr

\section{Partenaires}

Centre national de la recherche scientifique (Cnrs, France), Institut national de la recherche agronomique (Inra, France),

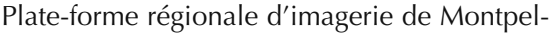
lier (Rio Imaging, http//mri.cnrs.fr).

\section{Bibliographie}

Odoux E., Escoute J., Verdeil J.L., Brioulet M., 2003. Localization of $ß$-D-glucosidase activity and glucovanillin in vanilla bean (Vanillia plantifolia Andrews). Annals of Botany, 92 : 437-444.

Odoux E., Escoute J., Verdeil J.L., 2006. The relation between glucovanillin, B-D-glucosidase activity and cellular compartmentation during the senescence, freezing and traditional curing of vanilla beans. Annals of Applied Biology, 149 : 43.

\section{- • La silice renforce la résistance de la canne à sucre au foreur des tiges}

Le foreur Eldana saccharina est l'un des principaux ravageurs des cultures de canne à sucre. Une étude menée par le Cirad et le Sasri, en Afrique du Sud, prouve que la silice joue un rôle dans la résistance de la canne à sucre en activant ses défenses naturelles et que ce rôle est plus marqué en cas de stress hydrique. Ces travaux ouvrent la voie à une nouvelle méthode de lutte agrobiologique.

Avec 20,4 millions d'hectares plantés en 2005, la culture de la canne à sucre occupe une place importante dans l'économie mondiale. Elle connaît un essor sans précédent avec la production de bioéthanol, un biocarburant dont la demande devrait progresser dans les années à venir. Les plantations subissent, cependant, les assauts de nombreux insectes. Et plusieurs espèces provoquent des dégâts importants sur la plante. C'est le cas notamment des lépidoptères foreurs comme Eldana saccharina (Pyralidae) dont la chenille creuse des galeries dans les cannes et provoque de ce fait des pertes en sucre et en biomasse. L'incidence économique est considérable : selon des estimations réalisées à la Réunion avec un autre foreur, une infestation où plus de $90 \%$ des cannes sont attaquées avec $20 \%$ d'entre-nœuds perforés occasionne jusqu'à 30 tonnes de pertes à I'hectare sur les variétés sensibles.

\section{Limiter les dégâts sur les variétés sensibles}

La lutte chimique contre ce type de ravageur est difficile dans la mesure où les larves et les chenilles responsables des dégâts sont protégées à l'intérieur des tiges. La lutte biologique, expérimentée depuis de nombreuses années sur E. saccharina, n'a pas donné de résultats probants. Les recherches se concentrent donc aujourd'hui sur 


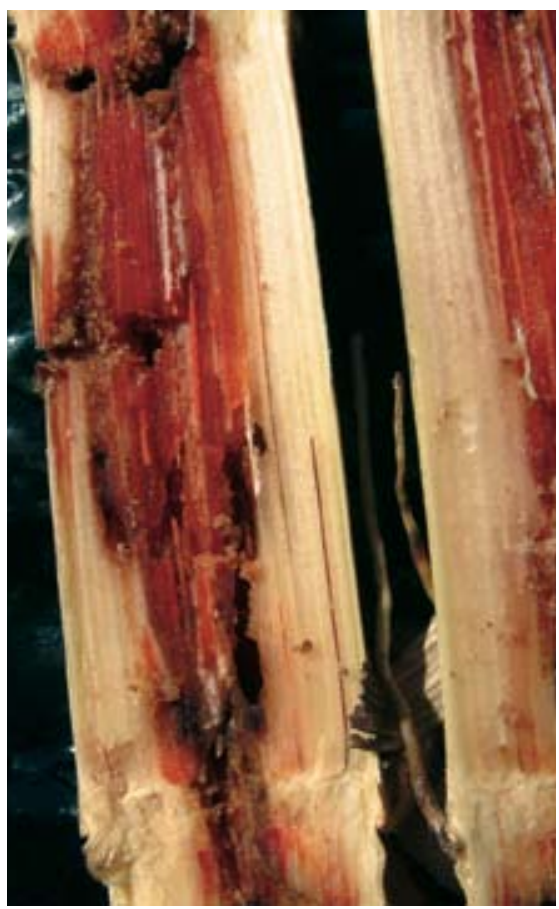

La chenille de Eldana saccharina creuse des galeries dans les cannes et provoque de lourdes pertes en sucre et en biomasse. o R. Goebel/Cirad.

I'identification des facteurs agronomiques qui freinent le développement du foreur. En partenariat avec le Sasri, I'institut sud-africain de recherche sur le sucre, le Cirad a mené, durant trois ans, un vaste programme de recherche en Afrique du Sud, I'un des principaux pays producteurs de canne à sucre.

Les résultats des expérimentations en serre et au laboratoire sont convaincants : I'apport de silice réduit de manière significative les dégâts, toutes variétés confondues, avec ou sans stress hydrique. Sur les variétés sensibles et en conditions de stress hydrique, les dégâts atteignent même des niveaux très faibles, équivalents à ceux mesurés chez les variétés résistantes quelles que soient les conditions hydriques. On estime aujourd'hui que l'action de la silice sur les variétés sensibles éviterait la perte de $20 \%$, voire $30 \%$, du rendement en sucre, sans compter les pertes en biomasse dues à l'insecte. En revanche, I'apport de silice ne modifie pas la dureté des tiges ni la qualité du sucre.

\section{Une nouvelle méthode de lutte agrobiologique}

Ce rôle actif de la silice soluble dans I'amélioration du système de défense de la plante pourrait s'expliquer, en cas de stress hydrique, par des modifications de la concentration et de la structure de la silice dans les tissus de la plante. Ces modifications entraîneraient une efficacité accrue de l'effet de barrière à la pénétration des larves, sans que la dureté des tissus soit modifiée. Selon une autre hypothèse, la silice pourrait renforcer l'expression des défenses naturelles de la plante, qu'elles soient chimiques ou physiologiques. Ces mécanismes de défense restent à élucider. Les expérimentations à venir, notamment dans le cadre d'une collaboration avec l'université du Kwazulu Natal, en Afrique du Sud, vont permettre d'étudier le rôle de la silice au sein même de la plante. II s'agira de localiser les dépôts de silice dans la tige qui interviennent dans le mécanisme de barrière et de déterminer la nature de cette barrière.

En Afrique du Sud, $60 \%$ des sols sont déficients en silice disponible pour la canne à sucre. (o) R. Goebel/Cirad.
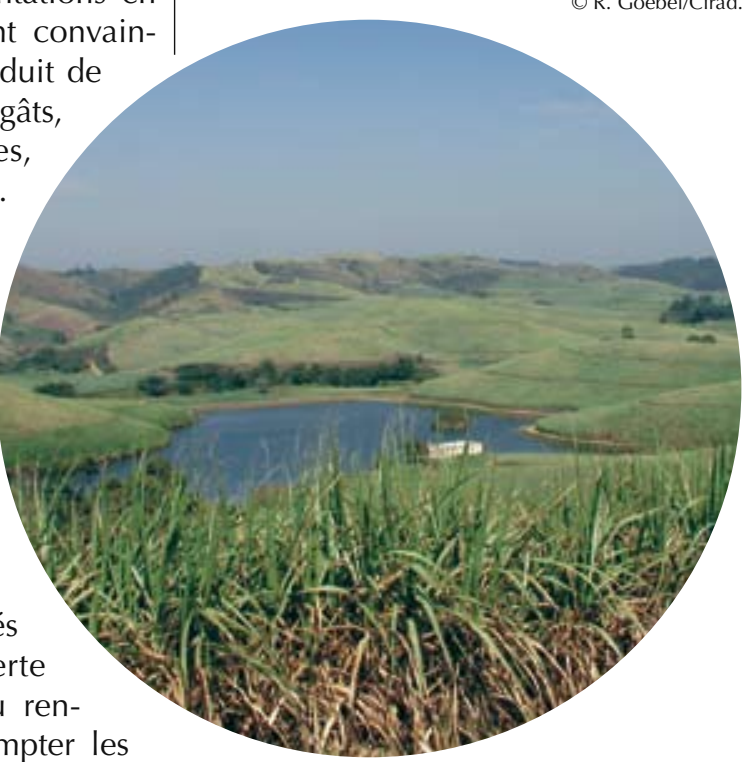

Ces résultats laissent espérer à terme I'utilisation généralisée de la silice dans le cadre de la lutte agrobiologique contre le foreur. Les producteurs des bassins canniers d'Afrique du Sud sont particulièrement concernés : dans cette région, $60 \%$ des sols sont déficients en silice disponible pour la plante. A cette déficience s'ajoute parfois un manque d'eau, qui aggrave les infestations du foreur. Des amendements en silicate de calcium pourraient permettre de mieux contrôler le ravageur en plein champ, y compris avec des variétés sensibles. Des essais au champ sont prévus en 2007 et 2008, avant la diffusion de cette méthode auprès des producteurs.

\section{Ce sujet de recherche a reçu le prix Kynoch de la meilleure contribution au congrès de la South African Sugar Technologists' Association en juillet 2006 à Durban, Afrique du Sud.}

\section{- François-Régis Goebel,}

Upr Systèmes canniers regis.goebel@cirad.fr

\section{Partenaires}

South African Sugar Research Institute (Sasri, Afrique du Sud), université de Witwatersrand (Afrique du Sud).

\section{Bibliographie}

Kvedaras O.L., Keeping M.G., Goebel R., Byrne M. Eldana saccharina Walker (Lepidoptera: Pyralidae) larval performance and stalk damage in sugarcane: influence of plant silicon and feeding site. International Journal of Pest Management (sous presse).

Kvedaras O.L., Keeping M.G., Goebel F.R., Byrne M. Water stress augments siliconmediated resistance of susceptible sugarcane cultivars synergy in resistance of sugarcane cultivars to the stalk borer, Eldana saccharina Walker (Lepidoptera: Pyralidae). Bulletin of Entomological Research (sous presse).

Kvedaras O.L, Keeping M.G., Goebel R., Byrne M., 2006. Silicon and water stress synergy in resistance of sugarcane cultivars to the stalk borer, Eldana saccharina (Lepidoptera: Pyralidae). Proceedings of the South African Sugar Technologists' Association, $80: 291-296$

Kvedaras O.L., Keeping M.G., Goebel R., Byrne M., 2005. Effects of silicon on the African stalk borer, Eldana saccharina (Lepidoptera: Pyralidae) in sugarcane. Proceedings of the South African Sugar Technologists' Association, $79: 359-362$. 


\title{
- - Paysages à risque et comportement des glossines : les bases de la lutte antivectorielle
}

\begin{abstract}
En Afrique subsaharienne, les trypanosomoses animales transmises par les glossines ont des conséquences économiques considérables sur l'élevage. Pour lutter contre ces maladies, il est indispensable de bien connaître l'écologie des glossines, en particulier les facteurs qui influencent leur capacité vectorielle. Des études, menées principalement au Burkina Faso, tentent de cerner ces facteurs.
\end{abstract}

\begin{abstract}
Au Burkina Faso, les trypanosomoses sont transmises principalement par deux espèces de glossines, qui vivent le long des cours d'eau : Glossina palpalis gambiensis et G. tachinoides. Les travaux sur les paysages à risque, mais aussi sur le mode d'alimentation des mouches, permettent de mieux cibler la lutte antivectorielle tant dans l'espace qu'à l'échelle de l'animal, et d'étendre à la lutte contre les glossines une technique utilisée pour les tiques.
\end{abstract}

\section{Identifier}

\section{les paysages à risque}

Une première série d'études a porté sur les relations entre les groupements végétaux ripicoles et l'abondance des glossines dans le Mouhoun, une région du nord-ouest du pays. Les paysages aux abords du fleuve ont fait l'objet d'une analyse par télédétection. Les cordons ripicoles étant des entités spatiales trop petites pour être analysées

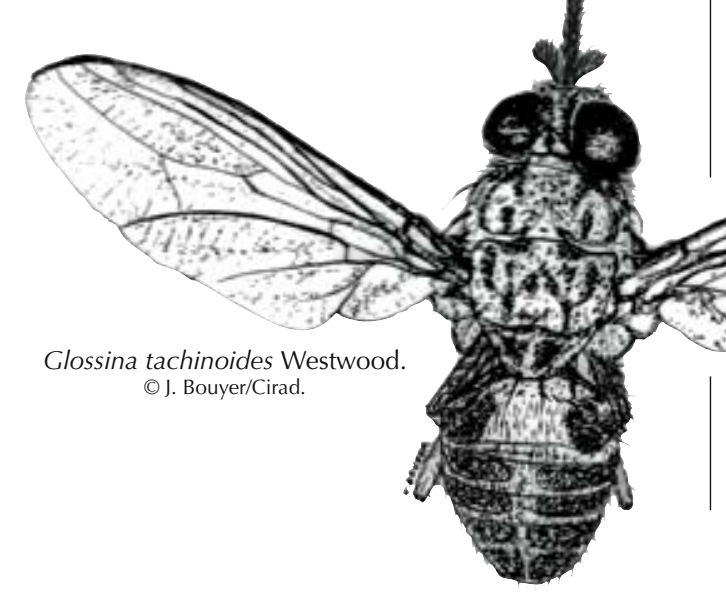

directement, ce sont les pixels environnants qui ont été examinés sur les images du satellite Landsat 7 TM (pixels à 30 mètres). Ils ont permis de déterminer certaines propriétés du cordon ripicole, comme sa dégradation ou son écotype, en identifiant des groupes de voisinage similaire, puis en les confrontant aux relevés de terrain. Le risque de transmission trypanosomienne cyclique y est ensuite estimé en calculant le taux $d$ 'inoculation entomologique, produit de la densité relative des vecteurs par le pourcentage de glossines infectantes. Cette analyse a permis de localiser le risque trypanosomien en considérant ces composantes principales de la capacité vectorielle sur I'ensemble de la boucle du Mouhoun, soit 702 kilomètres de réseau hydrographique. Elle a abouti à la définition de trois paysages à risque.

La saturation des espaces, avec l'augmentation de la densité animale et l'extension des cultures de rente, combinée à la réduction de la pluviosité est à l'origine d'une fragmentation toujours plus poussée des écosystèmes favorables aux glossines. Les cordons ripicoles constituent alors des

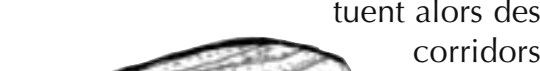
qui permettent aux mouches de circuler entre les zones favorables résiduelles, lesquelles se situent autour des zones protégées. Des études de dispersion - par marquage, lâcher et recapture —, de génétique des populations et de morphométrie géométrique permettent de quantifier ces flux et de mieux comprendre la structure des populations cibles, leur degré d'isolement et leur taille.

Ces études préalables à la lutte antivectorielle sont destinées aux grands projets de contrôle à l'échelle de populations entières, notamment dans le cadre de la Campagne panafricaine d'éradication des glossines et des trypanosomoses (Pattec). Elles permettent de circonscrire les opérations, mais aussi d'implanter des barrières pour isoler des sous-unités plus vulnérables, qui peuvent être attaquées séquentiellement.

\section{Comportement trophique et lutte antivectorielle}

L'étude des vecteurs eux-mêmes, en particulier de leur mode de nutrition, est à l'origine de la découverte de deux spécificités déterminantes pour l'épidémiologie et le contrôle des trypanosomoses. D'abord, l'existence d'un apprentissage, qui oriente les préférences trophiques vers le premier hôte rencontré. Cette découverte remet en cause les modèles épidémiologiques actuels, qui ne tiennent pas compte de ce phénomène et considèrent la préférence trophique des individus - l'une des composantes de la capacité vectorielle - comme constante. Ensuite, la confirmation d'un tropisme, qui pousse 
les glossines à attaquer l'extrémité des membres des bovins. Ce résultat a une application pratique immédiate : I'adaptation du pédiluve acaricideinsecticide avec la mise au point d'une lutte intégrée, à la fois contre la tique Amblyomma variegatum et contre les glossines, principaux vecteurs des zones subhumides d'Afrique de l'Ouest. Cette technique est actuellement implantée dans les zones périurbaines du Burkina Faso, et des pédiluves de démonstration vont être installés dans les pays voisins (Mali, Bénin, Ghana, Tchad, Cameroun, République centrafricaine). Au-delà des trypanosomoses, le comportement des glossines a également un impact sur l'épidémiologie de la maladie du sommeil, et une lutte antivectorielle centrée sur le traitement épicutané des porcs a été organisée en Guinée.

- Jérémy Bouyer, Laure Guerrini, François Roger, Laurence Vial, Upr Epidémiologie et écologie des maladies animales jeremy.bouyer@cirad.fr

Traitement des animaux par passage dans un pédiluve acaricide-insecticide, au Burkina Faso. ( ) J. Bouyer/Cirad.

\section{Partenaires}

Agriculture and Veterinary Information and Analysis (Avia-Gis, Belgique), Centre international de recherche-développement sur l'élevage en zone subhumide (Cirdes, Burkina Faso), Direction nationale de l'élevage (Guinée), Direction nationale de l'élevage (Sénégal), Institut de médecine tropicale (Imt, Belgique), Institut de recherche pour le développement (Ird, France), International Atomic Energy Agency (laea, Autriche), Pan African Tsetse and Trypanosomiasis Eradication Campaign (Pattec), Organisation des Nations unies pour l'alimentation et I'agriculture (Fao, Italie), Programme national de lutte contre la trypanosomiase humaine

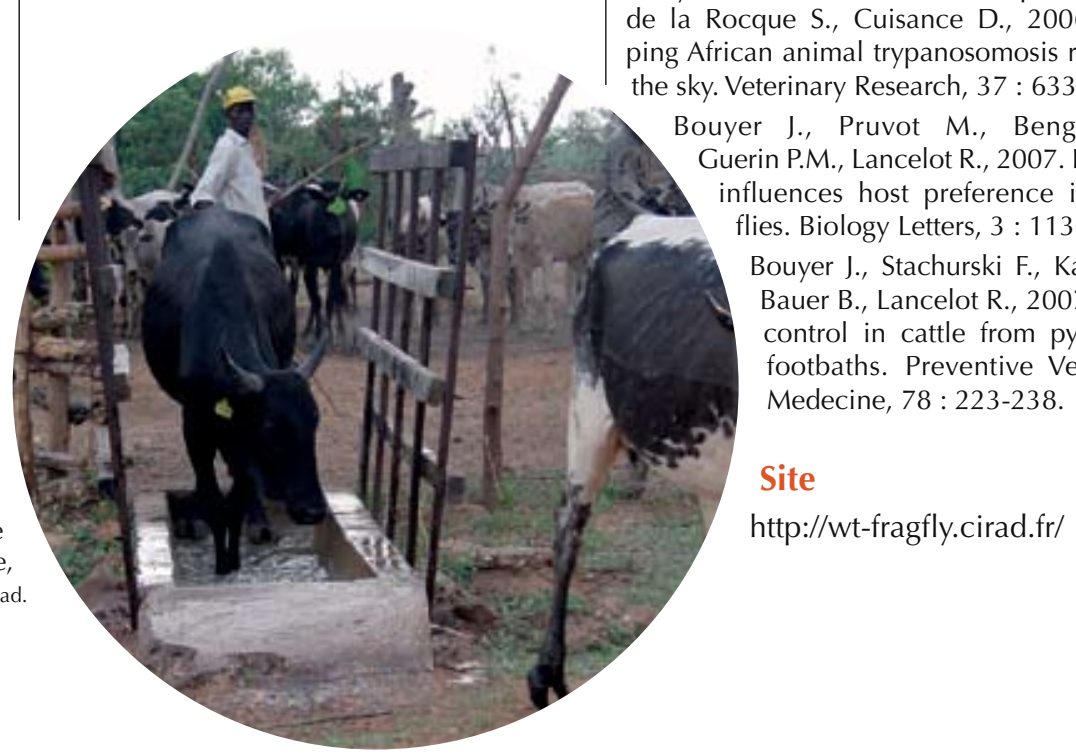

africaine (Pnltha, Guinée), Union économique et monétaire ouest-africaine (Uemoa), université de Neuchâtel (Suisse), université d'Oxford (Royaume-Uni).

Ces travaux ont été financés par Fragfly (Wellcome Trust), Saphyto, Ceva-santé animale, Bayer, I'laea, le Coraf et l'Uemoa.

\section{Bibliographie}

Bouyer J., 2006. Ecologie des glossines du Mouhoun au Burkina Faso : intérêt pour l'épidémiologie et le contrôle des trypanosomoses africaines. Thèse, université de Montpellier II, 212 p.

Bouyer J., Guerrini L., Desquesnes M., de la Rocque S., Cuisance D., 2006. Mapping African animal trypanosomosis risk from : 633-645.

Bouyer J., Pruvot M., Bengaly Z., Guerin P.M., Lancelot R., 2007. Learning in tsetse :113-116 ary

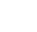

\title{
•• Une table de composition en polyphénols des fruits et légumes
}

\begin{abstract}
Les polyphénols, surtout présents dans les fruits et les légumes, suscitent un intérêt croissant pour leur rôle potentiel dans la prévention de certaines maladies. Mais aucune table de composition en polyphénols n'avait encore été établie pour les aliments consommés en France. Un vaste projet a été lancé afin de construire cette table, qui servira de base à l'étude de l'effet des polyphénols sur la santé.
\end{abstract}

Les polyphénols suscitent depuis une dizaine d'années un intérêt croissant de la part des nutritionnistes, des épidémiologistes, des industriels de l'agro- alimentaire et des consommateurs. Leur activité antioxydante, bien supérieure à celle des vitamines, pourrait jouer un rôle préventif dans nombre de maladies dégénératives comme les cancers et les maladies cardiovasculaires. Mais, jusqu'à présent, aucune étude globale des polyphénols présents dans les 


\title{
Préserver ॰००
}

\section{○ ० Les variétés locales de riz en Guinée : diversité, dynamique et conservation}

\begin{abstract}
La diversité génétique des plantes cultivées serait menacée par les pressions anthropiques et l'introduction de variétés améliorées. Les résultats d'une étude menée sur les variétés locales de riz en Guinée semblent contredire cette affirmation.
\end{abstract}

Moins d'espèces cultivées, moins de variétés cultivées par espèce, moins de diversité au sein de chaque variété : trois symptômes de l'érosion de la biodiversité. II est communément admis que I'utilisation massive de variétés améliorées à la place des variétés locales ainsi que les pressions anthropiques sont les principaux responsables de cet appauvrissement. Idée reçue ou réalité ? Seul un suivi de l'évolution des ressources génétiques des espèces cultivées permettrait de répondre à cette question. Un tel suivi a été réalisé sur les variétés locales de riz en Guinée, I'un des réservoirs de la diversité génétique des deux espèces de riz cultivées : Oryza glaberrima, l'espèce africaine, et $O$. sativa, I'espèce asiatique. Les variétés locales de riz sontelles en train de disparaître ? Quelles sont les stratégies à mettre en œuvre pour les conserver? Depuis 2000, le Cirad et ses par- tenaires africains mènent des recherches afin de répondre à ces questions.

\section{Une diversité stable, voire en légère croissance}

La diversité génétique d'échantillons collectés en 2003 dans six villages de Guinée maritime a été comparée, à l'aide de marqueurs moléculaires, à celle d'échantillons prélevés par une mission de prospection réalisée, en 1980, dans ces mêmes villages et conservés en chambre froide à Montpellier. Par ailleurs, des enquêtes ont été réalisées dans près de 1680 exploitations réparties dans 79 villages, afin d'inventorier, à l'échelon national, les variétés utilisées par les paysans entre

Champ d'une variété locale de riz pluvial. o M.B. Barry.
1996 et 2001. Les résultats obtenus vont à l'encontre de la vision alarmiste d'une érosion génétique. De 1980 à 2003, le nombre de variétés de riz et la diversité génétique sont stables, voire en légère augmentation. Sur la période 1996-2001, le nombre de variétés a progressé de $10 \%$.

\section{Une diversité typique de l'agriculture de subsistance}

Le nombre de variétés varie 1 à 15 par exploitation et de 4 à 40 par village, selon les régions, mais les variétés locales sont toujours majoritaires à plus de $80 \%$. Cette diversité variétale permet à chaque village de faire face aux variations des conditions agroécologiques et à la diversité des usages du riz. Cependant, près de $90 \%$ des variétés inventoriées sont cultivées par un petit nombre de paysans, et se trouvent donc fortement menacées de disparition. Autre fait important : chaque variété locale est elle-même la somme d'un grand nombre de lignées pures, et, pour une même variété, la proportion de ces lignées varie d'une 
ferme à l'autre. Cette structure multilignée s'explique par la gestion paysanne des variétés de riz, qui se caractérise par l'échange et le renouvellement fréquents des variétés et des semences ainsi que par des pratiques culturales et de production de semences qui favorisent les mélanges et les recombinaisons génétiques.

\section{Une diversité qui ne peut être conservée que sur place}

Pour ce qui est de la préservation de la diversité des variétés locales, une conservation in situ, à la ferme, compatible avec le développement agricole, semble la seule option réellement efficace. En effet, il serait impossible d'échantillonner toutes les lignées qui composent chaque variété locale et de les conserver ex situ, dans une cryobanque par exemple. Pour organiser une telle conservation, les chercheurs ont étudié la répartition de la diversité à plusieurs échelles — région, village, ferme, champ - en utilisant des descripteurs allant des noms vernaculaires aux marqueurs moléculaires. Les résultats montrent qu'un seul village peut contenir l'équivalent de $70 \%$ de la diversité régionale. $\mathrm{A}$ un niveau plus fin d'analyse, une grande exploitation peut renfermer $50 \%$ de la richesse génique d'un village. Ainsi, avec un petit nombre de villages et d'exploitations agricoles, la diversité génétique de toute une région, telle que la Guinée maritime, peut être couverte. A terme, un tel dispositif pourrait s'étendre à tout le pays.

\section{○ ० Nourollah Ahmadi, Upr Création} variétale et peuplements de riz nourollah.ahmadi@cirad.fr

\section{Partenaires}

Centre du riz pour l'Afrique (Adrao, Bénin), Institut de recherche agronomique de Guinée
(Irag, Guinée), Institut de recherche pour le développement (Ird, France).

\section{Bibliographie}

Barry M.B., 2006. Diversité et dynamique des variétés locales de riz $(O$. sativa et $O$. glaberrima) en Guinée : conséquences pour la conservation des ressources génétiques. Thèse de doctorat, Ecole nationale supérieure agronomique de Rennes, $170 \mathrm{p}$.

Barry M.B., Diange A., Sogbossi M.J., Pham J.L., Diawara S., Ahmadi N. Recent changes in varietal diversity of rice in Guinea. Plant Genetic Resources, Characterization and Utilisation (sous presse).

Barry M.B., Pham J.L., Noyer J.L., Courtois B., Billot C., Ahmadi N., 2007. Genetic diversity of the two cultivated rice species $(O$. sativa and O. glaberrima) in maritime Guinea: evidence for interspecific recombination. Euphytica, $154:$ 127-137.

Barry M.B., Pham J.L., Noyer J.L., Courtois B., Billot C., Ahmadi N. Genetic ecogeographical distribution of rice (O. sativa and O. glaberrima) genetic diversity in Maritime Guinea based on molecular markers: implications for in situ genetic resource conservation. Plant Genetic Resources, Characterization and Utilisation (sous presse).

\title{
๑०० Agroforesterie et caféiculture : produire mieux et durablement
}

\begin{abstract}
Comment résister aux crises du café sans forcément produire plus ? En produisant mieux et en misant sur la qualité. Tel est le principal résultat de Casca, projet d'envergure mené en partenariat par le Cirad en Amérique centrale. Il a fourni les bases scientifiques d'une meilleure gestion des systèmes agroforestiers à base de caféiers, de la promotion d'un café de qualité et de l'amélioration des revenus des producteurs.
\end{abstract}

\begin{abstract}
En Amérique centrale, le café est le principal produit d'exportation depuis plus de cent ans. Sa culture contribue au revenu de près de 300000 producteurs. Mais, à partir de 1999, la filière a dû faire face à une crise majeure : en raison de la surproduc-

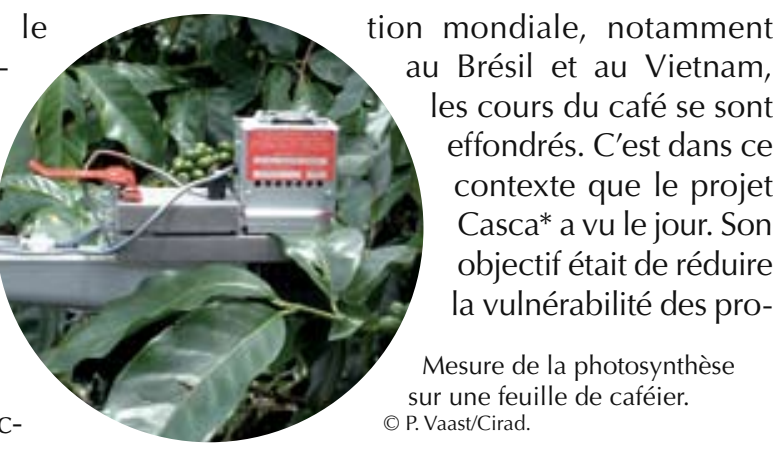

ducteurs face aux fluctuations des prix. Mené par le Cirad et quatre partenaires - le Catie, le Ceh, Promecafé et I'Una - il a mobilisé plus de 25 chercheurs et 35 étudiants, dont 25 Latinoaméricains, durant cinq ans.

Dans cette région, environ $70 \%$ des plantations sont conduites en association avec des arbres d'ombrage et des degrés d'intensification divers. Cepen- 


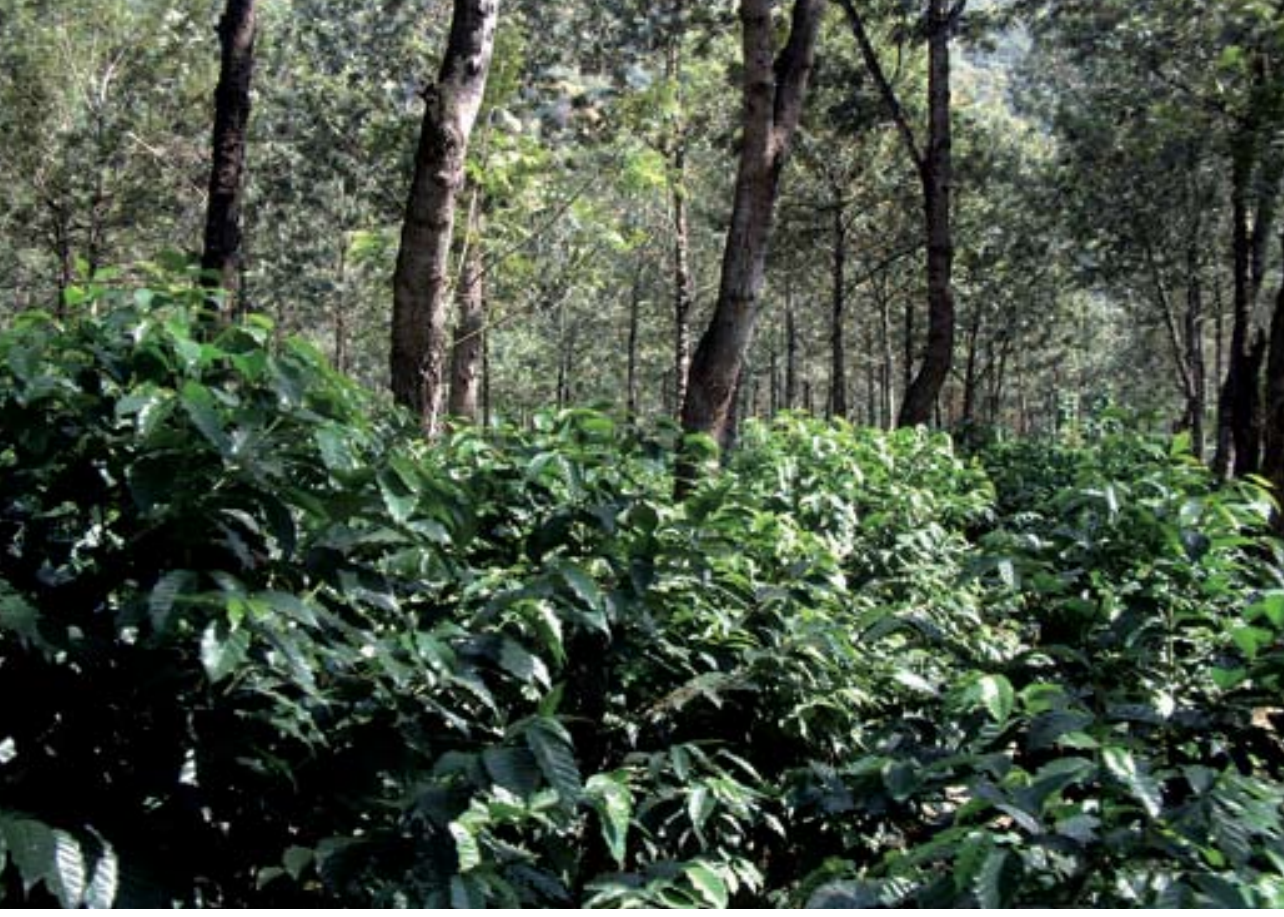

Dans les systèmes agroforestiers, la production est moindre mais de meilleure qualité : caféiers sous Gravilea robusta. ( $)$ P. Vaast/Cirad.

dant, la tendance de ces trente dernières années a été à la modernisation de la caféiculture : les pratiques culturales ont été intensifiées et l'ombrage a été réduit. Or, pour mieux vivre de leur travail, les producteurs doivent désormais miser sur la qualité de leur café, sur la diversification de leur revenu et sur la valorisation des services environnementaux qu'ils rendent grâce aux systèmes agroforestiers. Face à cette situation, il était donc nécessaire de proposer des alternatives viables à la monoculture intensive afin de promouvoir des pratiques de gestion durables.

Durant les cinq années du projet, des données ont été collectées au sein d'environ 900 exploitations de trois pays : Costa Rica, Guatemala et Nicaragua. Plusieurs grands axes de recherche ont été explorés, notamment l'effet des pratiques agroforestières sur la culture du caféier, l'impact de la caféiculture sur l'environnement et, finalement, l'amélioration des revenus des producteurs.

\section{Un café \\ de meilleure qualité}

En général, les producteurs connaissent les espèces forestières à associer aux caféiers mais la gestion qu'ils leur appliquent est déficiente : la densité des arbres est rarement adaptée à l'ombrage nécessaire au bon développement végétatif et à la production des caféiers; la fertilisation ne correspond pas toujours aux besoins des caféiers et des arbres d'ombrage. Les chercheurs ont donc développé des modèles qui doivent permettre de décider des espèces et des densités d'arbres en fonction du besoin en lumière des caféiers. Ils ont également évalué l'impact de l'ombrage sur la physiologie et la qualité du café, notamment sur la photosynthèse, I'allocation du carbone entre production et développement végétatif, la floraison et la charge en fruits. L'ombrage joue un rôle similaire à celui de l'altitude, en fournissant un microenvironnement favorable à la croissance des baies. Il retarde la maturation de la pulpe, augmente ainsi la taille des grains et améliore la qualité de la boisson. La production est moindre en quantité mais plus stable année après année et de meilleure qualité.

\section{Un compromis entre production et protection de l'environnement}

Les plantations de caféiers, qui couvrent un million d'hectares en Amérique centrale, ont également un impact sur l'en- vironnement à grande échelle. Elles se situent souvent au sein d'écosystèmes de montagne très fragiles, dans le corridor biologique mésoaméricain, où la biodiversité est particulièrement forte. Afin de quantifier cet impact, les effets des arbres d'ombrage et de leur mode de gestion sur la fertilité des sols et la disponibilité en azote pour le caféier ont été évalués. Les chercheurs ont identifié les pratiques de fertilisation permettant un compromis entre production et protection de l'environnement. Ils ont montré qu'en diminuant les besoins en engrais les systèmes agroforestiers contribuent à réduire les pertes de nitrates par drainage et donc la contamination des nappes phréatiques. Par ailleurs, I'introduction de l'arbre dans les systèmes caféiers accroît le stock de carbone dans la biomasse, la litière au sol et dans le sol, contribuant ainsi à la séquestration du carbone.

\section{Des sources de revenus diversifiées}

Enfin, les chercheurs se sont penchés sur les revenus des producteurs. L'objectif était de simuler les effets de plusieurs scénarios de culture et leurs conséquences sur les coûts de production du café et sur la viabilité économique des exploitations. Les simulations mettent en évidence la contribution majeure du bois d'œuvre et du bois de feu, en particulier dans les régions de basse altitude : le bois fournit entre $10 \%$ et $50 \%$ des revenus des caféiculteurs au Costa Rica et au Guatemala. Les revenus peuvent aussi être améliorés par la certification et la labellisation des productions (café durable, biologique, etc.), mais la mise aux normes techniques et les processus de certification entraînent des coûts supplémentaires.

Ces résultats seront approfondis grâce à un nouveau projet, Cafnet**, qui vient de débuter. Il concerne l'Amérique centrale, l'Afrique de l'Est et l'Inde, et vise à promouvoir les systèmes agroforestiers à base de caféiers pour les biens et les services environnementaux qu'ils procurent. Il devrait permettre d'amé- 
liorer les capacités d'organisation et de commercialisation des coopératives et $\mathrm{d}^{\prime}$ adapter les itinéraires techniques aux modes de certification du café, qui se sont multipliés ces dernières années.

○ $\circ$ Philippe Vaast, Jean-Michel Harmand, Upr Fonctionnement et pilotage des écosystèmes tropicaux plantés philippe.vaast@cirad.fr jean-michel.harmand@cirad.fr

\section{Partenaires}

Asociación Nacional del Café (Anacafé, Guatemala), Centre for Ecology and Hydrology (Ceh, Royaume-Uni), Centro Agronómico Tropical de
Investigación y Enseñanza (Catie, Costa Rica), Instituto del Café de Costa Rica (Icafé, Costa Rica), Programa Cooperativo Regional para el Desarrollo Tecnológico y la Modernización de la Caficultura de Centroamérica (Promecafé, Guatemala, Costa Rica), Universidad Nacional Agraria (Una, Nicaragua).

* Casca (Sustainability of Coffee Agroforestry Systems in Central America: coffee quality and environmental impacts).

** Cafnet (Connecting, enhancing and sustaining environmental services and market values of coffee agroforestry in Central America, East Africa and India).

Site

http://www.casca-project.com

\section{Bibliographie}

Franck N., Vaast P., Génard M., Dauzat J., 2006. Soluble sugars mediate sink feedback down-regulation of leaf photosynthesis of Coffea arabica in the field. Tree Physiology, $26: 517-525$.

Vaast P., Bertrand B., Guyot B., Génard M., 2006. Fruit thinning and shade influence bean characteristics and beverage quality of coffee (Coffea arabica L.) under optimal conditions. Journal of Science of Food and Agriculture, 86 : 197-204.

Van Kanten R.F., Vaast P., 2006. Coffee and shade tree transpiration in suboptimal, lowaltitude conditions of Costa Rica. Agroforestry Systems, $67: 187-202$.

\title{
○०० Les plantes envahissantes : une menace pour la biodiversité à la Réunion
}

\begin{abstract}
Les invasions biologiques constituent une menace importante pour la biodiversité des espaces insulaires. A la Réunion, où le taux d'endémisme de la flore est particulièrement élevé, il est indispensable de protéger les formations naturelles contre les plantes introduites devenues envahissantes. Depuis les années 1990, le Cirad analyse les mécanismes de propagation de ces plantes, leur impact et les moyens de lutte. Pour fournir aux gestionnaires de l'environnement les moyens d'intervenir plus tôt et plus efficacement.
\end{abstract}

A la Réunion, le rythme d'introduction de plantes a connu une accélération sans précédent au cours des trente dernières années. Une centaine de ces plantes sont devenues envahissantes et menacent les formations naturelles. Parallèlement à la lutte chimique, mécanique et bientôt biologique, il est important d'intervenir en amont de l'invasion pour prévenir l'introduction des espèces potentiellement envahissantes ou réguler l'expansion des plantes déjà présentes.

\section{Intervenir en amont de l'invasion}

Des analyses, réalisées dans le cadre du projet européen Poseidom*, ont permis d'identifier une cinquantaine de plantes potentiellement envahissantes, qui doivent faire l'objet d'une interdiction d'introduction dans les départements d'outre-mer. Parmi les espèces ornementales cultivées dans les jardins des Hauts, 34 présentent une forte capacité d'invasion. La dynamique spatiale de ces invasions confirme l'intérêt d'intervenir précocement.

L'exemple de l'étang du Gol, qui était entièrement recouvert par un mélange de jacinthe d'eau (Eichhornia crassipes) et de laitue d'eau (Pistia stratiotes) début 2006, est particulièrement révélateur. En mars 2006, le passage du cyclone Diwa l'a nettoyé à plus de $99 \%$, par effet de chasse d'eau, en évacuant les plantes vers l'océan. Huit mois plus tard, il était à nouveau totalement envahi, au détriment de l'ensemble de l'écosystème aquatique. La production de biomasse de ces plantes aquatiques est estimée à 250 tonnes par hectare tous les 15 jours. Une telle dynamique exclut toute élimination mécanique et plaide en faveur d'une lutte biologique, qui a déjà fait ses preuves dans de nombreux pays tropicaux.

\section{Intégrer l'ensemble des compartiments du paysage}

Il apparaît aussi indispensable de prendre en compte les flux $d^{\prime}$ espèces entre les compartiments du paysage : forêts, 


\title{
○०० L'avenir de l’agriculture irriguée en Méditerranée
}

\begin{abstract}
Rare, salée, inégalement répartie, convoitée, l'eau constitue un enjeu majeur pour l'agriculture méditerranéenne. Dans le cadre du projet européen Wademed, un séminaire a permis de dresser un bilan de l'évolution de l'agriculture irriguée au Maghreb et d'explorer de nouvelles formes de coopération.
\end{abstract}

Tant dans les pays du Maghreb qu'en Europe, I'agriculture familiale a été marquée dans la seconde moitié du $\mathrm{xx}^{\mathrm{e}}$ siècle par une modernisation rapide dont l'irrigation a été l'un des grands vecteurs. Si les agriculteurs du nord de la Méditerranée ont pu produire plus et mieux à moindre coût, c'est principalement grâce à la structuration de la profession agricole. En Afrique du Nord, de nouvelles formes d'organisation professionnelle voient le jour, certaines sous l'impulsion de l'Etat, d'autres à partir d'initiatives locales.

Depuis 1995, le Cirad est engagé au Maghreb dans une coopération régionale, qui associe la recherche, les administrations en charge de la gestion de l'eau et le monde professionnel agricole. Dans le cadre du projet euro-

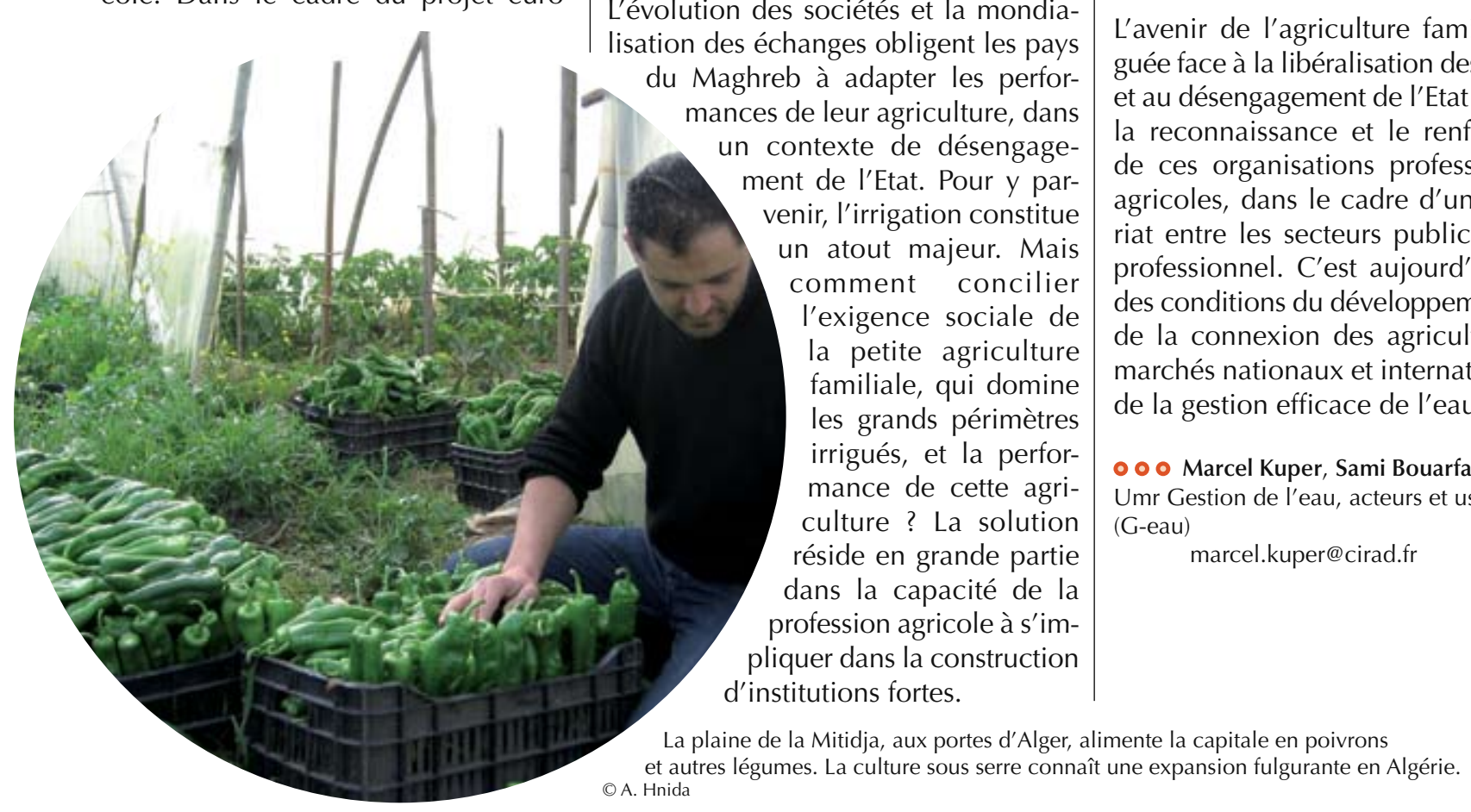

Les analyses ont, en effet, montré comment, en Tunisie, en Algérie et au Maroc, des coopératives et des associations s'investissent dans l'organisation des filières et dans la mise en place de services sociaux sur le territoire rural : aménagement des pistes, installation de dispensaires de proximité, création d'écoles maternelles, formation des fils et filles d'agriculteurs. Ces organisations professionnelles agricoles permettent aux agriculteurs de récupérer une plus grande part de la valeur ajoutée. Elles accompagnent les exploitations dans I'amélioration technique et économique de leurs performances et gèrent les infrastructures hydrauliques. Enfin, elles constituent une force de négociation face aux marchés, aux pouvoirs publics et aux collectivités territoriales.

\section{Renforcer l'organisation de la profession agricole}

L'évolution des sociétés et la mondiasation des échanges obligent les pays Maghreb à adapter les performances de leur agriculture, dans ment de l'Etat. Pour y parenir, I'irrigation constitue un atout majeur. Mais comment l'exigence sociale de la petite agriculture familiale, qui domine les grands périmètres irrigués, et la performance de cette agriculture ? La solution réside en grande partie profession agricole à s'impliquer dans la construction d'institutions fortes. 


\section{Partenaires}

Direction générale du génie rural (Tunisie), Ecole nationale d'agriculture de Meknès (Maroc), Escuela Técnica Superior de Ingenieros Agrónomos de Madrid (Espagne), Institut agronomique et vétérinaire Hassan II (lavh, Maroc), Institut national agronomique d'Alger (Inaa, Algérie), Institut national agronomique de Tunisie (Inat, Tunisie), Institut national de recherche en génie rural, eaux et forêts (Inrgref, Tunisie), Institut de recherche pour le développement (Ird, France), Institut de recherche pour I'ingénierie de l'agriculture et de l'environnement (Cemagref, France), Instituto Superior de Agronomia (Isa, Portugal), Institut für Umweltsystemforschung (Allemagne), université de Tunis (Tunisie).

\section{Bibliographie}

Séminaire «L'avenir de l'agriculture irriguée en Méditerranée », 6-10 novembre 2006, Cahors, France.

Hammani A., Kuper M., Debbarh A., 2005. La modernisation de l'agriculture irriguée : actes du séminaire euro-méditerranéen, 19-23 avril 2004, Rabat, Maroc. Projet Inco-Wademed. Rabat, lavh, 2 vol., 358 p., 368 p.

Site

www.wademed.net

\section{La gouvernance de l'eau}

Les principes d'une gestion durable de la ressource en eau sont des éléments essentiels de réponse aux problèmes de pauvreté et de sécurité alimentaire, mais ils s'avèrent souvent difficiles à mettre en pratique. Un ouvrage, Water governance for sustainable development, fait le point sur les récents changements intervenus dans la gouvernance, les institutions, l'économie et les politiques de ce secteur, en s'appuyant notamment sur des études réalisées en Afrique du Sud. Il examine comment ces éléments ont évolué, passant d'un pilotage centralisé par l'offre et d'une approche quantitative à une gestion de la demande, décentralisée et plus participative. Des études de cas permettent d'identifier les difficultés rencontrées dans la mise en œuvre des nouvelles politiques, difficultés souvent liées à la couverture des coûts, à l'allocation de la ressource entre secteurs et à la privatisation des services et de la gestion.

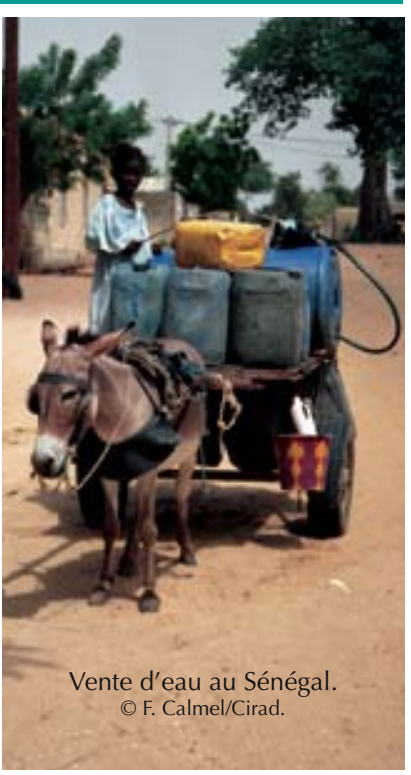

- ० Sylvain Perret, Umr Gestion de l'eau, acteurs et usages (G-eau) sylvain.perret@cirad.fr

\section{Bibliographie}

Perret S., Farolfi S., Rashid H., 2006. Water governance for sustainable development: Approaches and lessons from developing and transitional countries. Londres, Earthscan, Montpellier, Cirad, $296 \mathrm{p}$.

\section{○० La production porcine dans le delta du fleuve Rouge}

Le delta du fleuve Rouge, au Vietnam, est une vaste région d'agriculture intensive. L'essor des productions animales y est sans précédent et la production porcine est l'un des principaux maillons du développement économique. Mais cet élevage entraîne des risques de pollution de l'eau et des sols et peut avoir des répercussions sur la santé humaine. Comment gérer les impacts environnementaux de cette production tout en assurant la compétitivité des élevages? Et comment prendre en compte les contraintes spatiales et sociétales de ce type d'élevage dans les politiques de développement?

Peuplée de 18 millions d'habitants, à des densités record de plus de 1200 habitants au kilomètre carré, la région du delta du fleuve Rouge regroupe les activités économiques essentielles du nord du Vietnam. La forte croissance industrielle, agricole et démographique pèse aujourd'hui lourd sur ses ressources naturelles. C'est ainsi que, dans la majorité de ces provinces, les productions animales connaissent une croissance sans précédent. La production porcine est l'un des principaux maillons du développement économique — dans la province de Thai Binh, elle est passée de 700000 porcs en 2000 à 1,2 million en 2006. Cet essor répond à une forte demande de produits animaux, aussi bien à l'échelle locale qu'internationale. Les services agricoles de Thai Binh sont d'ailleurs en charge du programme 
national pour le développement de la production de viande de porc maigre. Ils prévoient de soutenir les 1600 fermes d'élevage et les 16400 exploitations familiales de la province pour atteindre 1,4 million de porcs en 2010 et produire 500000 tonnes de carcasses de qualité par an.

\section{Mieux gérer les déchets de l'élevage}

C'est dans ce contexte qu'un vaste projet, financé par l'Union européenne, a été mis en œuvre sur le développement de la production porcine, la gestion des déchets et la protection de l'environnement (E3P). Mené dans le cadre du Pôle de recherche sur l'intensification des systèmes d'élevage (Prise), en collaboration avec sept organismes d'Asie et d'Europe, il a abouti à un diagnostic multidisciplinaire de la situation de l'élevage et de la gestion des effluents produits dans la province de Thai Binh, ainsi qu'à la création d'une base de références locales très documentée.

Ce diagnostic s'appuie sur un ensemble d'analyses et d'enquêtes réalisées dans le cadre du projet : recueil de statistiques agricoles locales, typologie des élevages, évaluation de leur pression sur l'environnement, enquête sur la perception des acteurs. Un système d'information géographique et un outil de diagnostic agronomique ont été mis au point. Le premier permet de présenter, sous forme de cartes thématiques, les bilans régionaux en matières organiques, actuels ou prévisionnels, en fonction des scénarios de développement prévus pour 2010. Le second sert à évaluer les excédents en éléments fertilisants issus des déchets animaux à différentes échelles, les besoins en engrais des terres cultivées et les besoins en éléments nutritifs des étangs piscicoles. Ils ont permis de proposer des modes de gestion et de transformation des déchets qui préservent mieux l'environnement. L'utilisation de la modélisation pour le couplage de l'outil de diagnostic agronomique et du système d'information géographique constitue l'une des originalités des travaux réalisés.

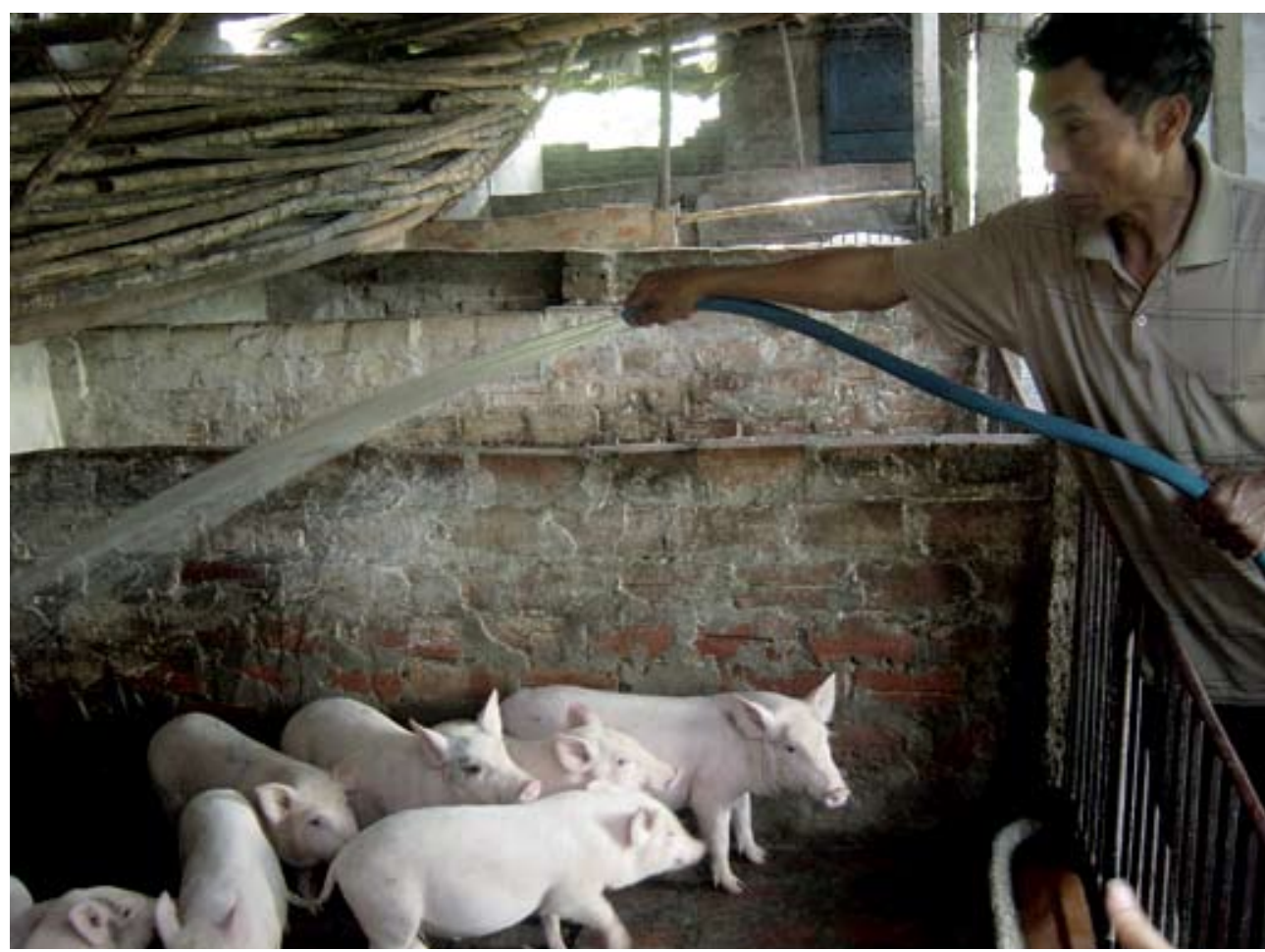

Lavage quotidien des cases dans un élevage porcin. ( ) V. Porphyre/Cirad.

\section{Des systèmes de traitement adaptés}

Ces résultats ont stimulé les demandes des acteurs du développement. Le comité populaire de Thai Binh souhaite maintenant construire des systèmes de traitement des déjections adaptés à la taille des exploitations agricoles. Un projet, qui débutera en 2007, portera sur les normes agronomiques permettant de mieux valoriser les matières organiques et sur les conditions d'émergence de filières de matières organiques transformées (énergie, compostage) et recyclées (agriculture, aquaculture). II concernera aussi la modélisation des flux de nutriments et de biomasse à l'échelle régionale, et comportera un volet d'accompagnement scientifique auprès des partenaires vietnamiens pour I'ensemble des questions d'interaction de l'environnement et de l'élevage.

๑ ० Vincent Porphyre, Upr Systèmes d'élevage et productions animales Jean-Michel Médoc, Upr Risque environnemental lié au recyclage vincent.porphyre@cirad.fr jean-michel.medoc@cirad.fr

\section{Partenaires}

Asian Institute of Technology (Ait, Thaïlande), Ayuda, Intercambio y Desarrollo de Asia (Aida, Espagne), Centre de télédétection et géomatique (Vtgeo, Vietnam), Délégation de la Commission européenne au Vietnam (Europe), Institut national de l'élevage (Niah, Vietnam), Institut national des sols et des fertilisants (Nisf, Vietnam), université agricole de Hanoi (Vietnam)

\section{Bibliographie}

Médoc J.M., Raimbault T., Ayache B., 2006. Assessment of the balance between livestock effluent production and nutrient demand by crops in a small agricultural area of the Reunion Island. In : 12th Ramiran international conference on technology for recycling of manure and organic residues in a whole-farm perspective, Aarhus, Danemark, 9-11 septembre 2006. Tjele, Dias, Dias Report, 122-123 : 65-67.

Porphyre V., Nguyen Que Coi (éd.), 2006. Pig production development, animal-waste management and environment protection: a case study in Thai Binh province, Northern Vietnam. Prise publications, $224 \mathrm{p}$.

Site

http://pigtrop.cirad.fr/en/worldwide/ asie_VN_Asiaproeco.htm 


\section{Sauvegarder les espèces animales menacées au Vietnam}

Dans les montagnes du Vietnam, le cheptel traditionnel et les bovidés sauvages sont longtemps restés isolés. Actuellement menacés par l'ouverture de ces régions, ils viennent de faire l'objet d'une vaste étude pluridisciplinaire, qui devrait déboucher sur des stratégies de valorisation et de conservation et permettre aux communautés rurales, en particulier aux femmes qui ont la charge du cheptel, de mieux vivre dans ces régions déshéritées.

Pour des raisons géographiques et historiques, les zones de montagne du Vietnam sont restées isolées pendant plusieurs décennies, et les espèces animales, domestiques et sauvages, qu'elles hébergent ont été préservées. Dans le cadre du projet Biodiva*, et en partenariat avec des institutions de recherche vietnamiennes, le Cirad mène, depuis 2004, plusieurs actions afin d'inventorier, de caractériser et de sauvegarder ces ressources génétiques animales aujourd'hui menacées. Ce projet pluridisciplinaire associe des activités de terrain et une approche plus fondamentale d'analyse génétique.

Pour évaluer la biodiversité des races domestiques endémiques, des inventaires ont été réalisés et 2000 questionnaires dépouillés. L'objectif était de définir les caractéristiques zootechniques des animaux, mais aussi les spécificités socio-économiques des systèmes d'élevage traditionnels. La caractérisation génétique, réalisée à I'aide d'outils moléculaires, a porté sur 7000 échantillons biologiques, géoréférencés et prélevés sur le cheptel lors des inventaires. Les données collectées ont été analysées grâce à un logiciel élaboré spécifiquement afin de permettre la cartographie thématique des populations animales.

\section{Aujourd'hui, le cerf Sika ne vit plus qu'en captivité}

Le cerf Sika (Cervus nippon) revêt une importance, à la fois économique et traditionnelle, majeure du fait de l'ex- ploitation du velours de ses bois pour la pharmacopée traditionnelle asiatique. L'espèce n'existe plus qu'en captivité et les risques de dérives génétiques dues à la consanguinité et aux croisements interspécifiques sont élevés. Des données concernant sa croissance et son alimentation, entre autres, ont été collectées et analysées à l'aide d'un logiciel conçu spécialement pour la gestion des cervidés. Elles serviront à établir un mode de gestion adapté pour l'élevage du Sika. Des ateliers villageois ont également permis de former plus d'un millier d'éleveurs aux bonnes pratiques de cet élevage.

\section{Le clonage reproductif contre l'extinction des grands bovidés sauvages}

Pour les populations résiduelles de grands bovidés sauvages, une double approche conservatoire a été mise en œuvre. En laboratoire, le clonage somatique est envisagé pour la conservation de deux espèces en voie d'extinction : le Saola (Pseudoryx nghetinhensis) et le Gaur (Bos gaurus). A I'heure actuelle, le clonage reproductif in vivo du Saola sur bovin est en passe de réussir avec la production de nombreux embryons.

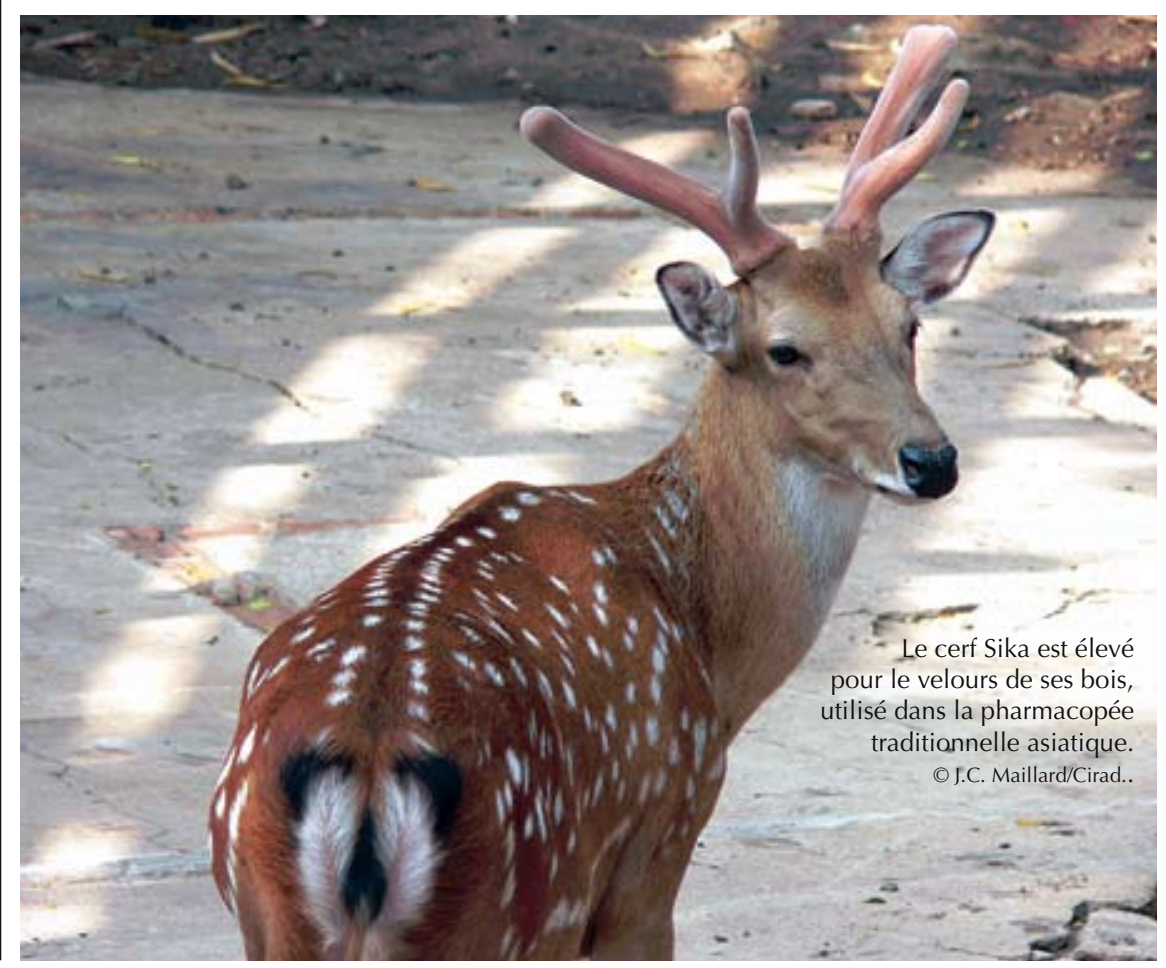


II reste à réaliser des tests préimplantatoires sur différentes espèces potentiellement receveuses. Néanmoins, des essais ont montré que les embryons se développent normalement jusqu'à vingt jours après leur implantation dans un utérus bovin. Cette approche, prometteuse, pourrait être étendue à d'autres espèces de bovidés menacées comme le Gaur.

L'approche in situ concerne le Gaur, le Banteng (Bos javanicus) et le buffle d'eau sauvage (Bubalus arnee), espèces très menacées au Vietnam. Il s'agit de définir des plans de gestion adaptés pour une bonne conservation de ces espèces. Pour cela, il est nécessaire de connaître les effectifs des troupeaux résiduels. Là encore, la démarche adoptée repose sur des outils moléculaires, une démarche plus classique n'étant pas possible du fait des effectifs trop réduits de ces espèces. Des prélèvements non invasifs $\mathrm{d}^{\prime} \mathrm{ADN}$ ont été réalisés à partir des fèces collectées sur le terrain avant d'être analysés. Des marqueurs génétiques individuels permettent ensuite d'estimer les paramètres démographiques de ces populations. La modélisation et l'analyse de leur viabilité permettront, à terme, de comprendre quels sont les paramètres démographiques à risque et quel est le moyen le plus efficace pour parvenir à une reconstitution des effectifs.

\section{Une stratégie de conservation étendue à toute la région}

Parallèlement à ces travaux, des projets pilotes locaux de conservation et de valorisation de cette diversité animale sont mis en place. Six microprojets ont déjà été identifiés ; ils concernent des populations animales intéressantes à divers titres : productivité, prolificité, adaptation à des milieux particuliers, résistance à certaines maladies, effectifs réduits, etc. Un autre microprojet concerne le développement de la filière d'élevage du cerf Sika dans les provinces de Nghe An et Ha Tinh, avec la mise en œuvre d'une unité pilote de production, de conditionnement et de commercialisation de produits dérivés (velours, viande...). Ces microprojets doivent être lancés en 2007.

Ces résultats revêtent un intérêt majeur pour toute la région. A terme, deux autres pays de la péninsule indochinoise, le Laos et le Cambodge, confrontés aux mêmes impératifs d'inventaire et de conservation de leur biodiversité animale, seront associés à cette initiative.

○ ० Jean-Charles Maillard,

Miguel Pedrono, Upr Gestion intégrée de la faune

jean-charles.maillard@cirad.fr

\section{Partenaires}

Académie des sciences et technologies (Vast, Vietnam), Centre national d'information scientifique et technologique (Cnist, Vietnam), Institut national de l'élevage (Niah, Vietnam), Institut national de la recherche agronomique (Inra, France), Parc national de Cat Tien (Vietnam).

* Biodiva (Conservation et valorisation de la biodiversité animale domestique et sauvage endémique des zones montagneuses du Vietnam)

\section{Bibliographie}

Berthouly C., Nhu Van T., Verrier E., Vu Chi C., Maillard J.C., 2006. Biometrical characterisation of the $\mathrm{H}^{\prime}$ mong cattle population in the northern mountainous areas of Vietnam. In : 8th world congress on genetics applied to livestock production, Belo Horizonte, Brésil, 13-18 août 2006.

Maillard J.C., Berthouly C., 2006. Development of in situ micro-projects in farm animal populations of the mountain regions of North of Viet-Nam (Biodiva project). In : Options and strategies for the conservation of farm animal genetic resources, 7-10 novembre 2005, Montpellier, France. Rome, Fao, p. 104-108.

Maillard J.C., Gonzalez J.P., 2006. Biodiversity and emerging diseases. Annals of the New York Academy of Sciences, Special Issue, 1081:1-16.

Rivière-Dobigny T., Pham Doan L., Pedrono M., Michaux J., Maillard J.C., 2006. Testing the reliability of molecular analyses from faecal DNA in two wild bovid species: Bos gaurus and Bos javanicus. In : Vle colloque du Bureau national des ressources génétiques $(\mathrm{Brg}), \mathrm{La}$ Rochelle, France, 3-4 octobre 2006.

Site

http://www.biodiva.org.vn

Le projet Biodiva devrait permettre, entre autres, de sauvegarder et de valoriser les races domestiques locales : bergère Tay et son troupeau de chèvres dans les montagnes, province de Ha Giang. (O).C. Maillard/Cirad.

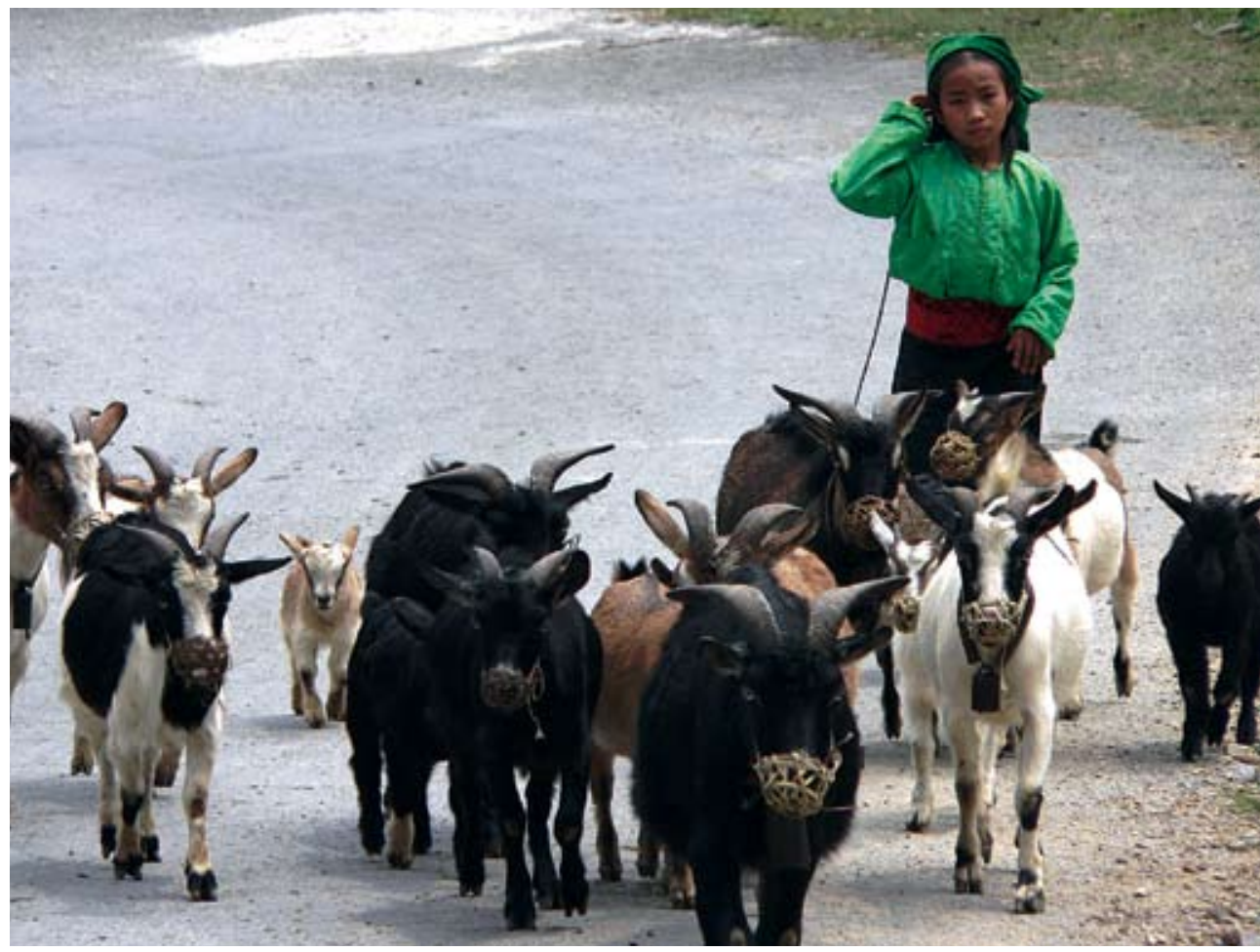




\title{
Partager
}

\section{- @ ¿ Kassa, de nouvelles questions de recherche sur l'agriculture de conservation}

\begin{abstract}
L'agriculture de conservation repose sur trois principes indissociables : la réduction, voire la suppression, du travail du sol, le maintien d'une couverture végétale et la rotation des cultures. Elle vise à mieux produire tout en préservant les ressources naturelles. Entre 2004 et 2006, le projet européen Kassa, coordonné par le Cirad, a permis de faire le point des connaissances dans ce domaine, en Europe, en Afrique du Nord, en Asie et en Amérique latine.
\end{abstract}

En 1990, moins de 10 millions d'hectares étaient cultivés dans le monde selon les principes de l'agriculture de conservation. On en compte aujourd'hui plus de 95 millions, dont 44 \% en Argentine, en Bolivie et au Brésil. En Inde et au Pakistan, les surfaces ainsi cultivées sont passées de 400000 hectares en 1998 à 2,2 millions d'hectares en 2005. En Estonie, en République tchèque, en Ukraine et au Maghreb, des systèmes inspirés de l'agriculture de conservation voient le jour. Mais si I'agriculture de conservation permet aux agriculteurs de réaliser des économies d'énergie, de machines et de temps de travail, son impact sur les rendements est variable et sa mise en œuvre dépend largement du contexte naturel,

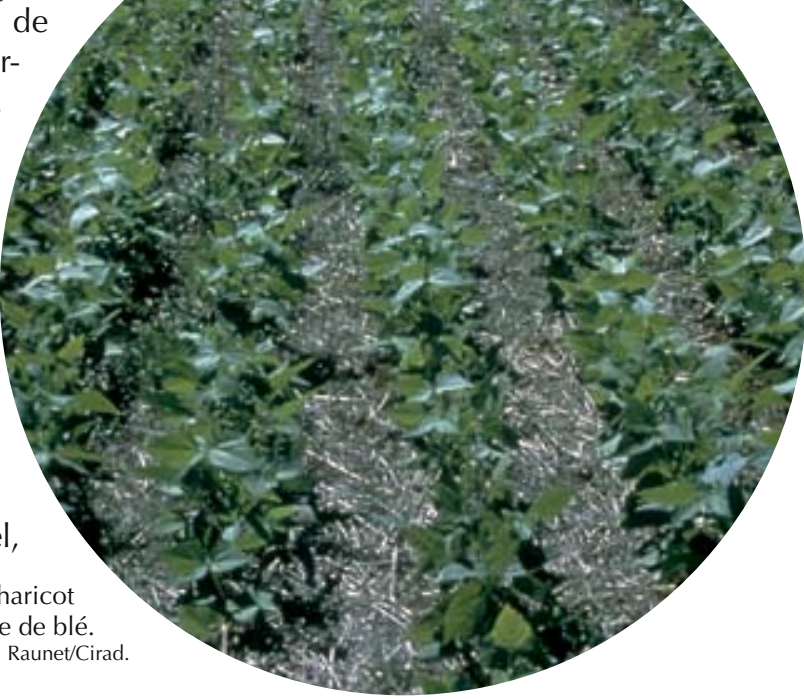
de 22 institutions, cinq organisations non gouvernementales et une entreprise issues de 18 pays à travers le monde, a permis de mieux cerner ses indications et ses limites.

\section{Une progression forte mais inégale}

De plus en plus d'agriculteurs, dans un nombre croissant de pays, adoptent l'agriculture de conservation. Cette progression est sensible dans les pays fortement producteurs et vendeurs d'Amérique et en Australie. L'Europe, en revanche, reste visiblement à la traîne. Quelles sont les causes de cette disparité ? Diverses contraintes dissuadent les agriculteurs de se lancer dans l'agriculture de conservation ou les poussent à n'utiliser qu'une partie de la technologie. Certains types de sols (sensibles au compactage, humides...) ou de climats (très humides, froids ou arides) ne favorisent pas cette pratique. Le couvert permanent et la rotation sont censés protéger le sol contre l'érosion et combattre les adventices et les maladies, mais ils entraînent parfois des surcoûts pour les agriculteurs : les plantes cultivées en rotation ne trouvent pas toujours de débouché sur le marché, la couverture favorise dans certains cas le développement de ravageurs et de 
maladies, d'où le recours parfois intensif aux pesticides, les plantes et variétés adaptées font encore défaut. En outre, dans des systèmes où le niveau de production est déjà très élevé, comme en Europe, I'introduction de I'agriculture de conservation ne modifie pas les rendements de manière significative et son seul avantage réside dans la réduction des coûts de production qu'elle entraîne. Enfin, I'absence de connaissances, de machines adaptées, de systèmes $d^{\prime}$ innovation permettant d'acquérir et de partager les savoirs et les savoir-faire entre les acteurs sont autant de handicaps.

\section{Des questions à approfondir}

Il reste donc à développer et à améliorer cette technique pour l'adapter aux différents contextes favorables. De plus, de nombreuses questions de recherche sont encore à approfondir comme l'impact de ces pratiques sur le fonctionnement biologique, structural et chimique des sols, sur les bilans du carbone et de l'azote et sur la fertilité du sol en général. Il s'agit également de mieux connaître les conséquences des polluants, des métaux lourds ou des pesticides sur la biodiversité et sur la qualité du sol, de l'eau et de la chaîne alimentaire. Il est en outre nécessaire de préciser les répercussions sociales et économiques de cette pratique. De façon plus générale, si les bénéfices à court terme sont assez parlants pour que l'agriculture de conservation trouve aujourd'hui sa place, de nombreuses questions restent en suspens quant à son impact, positif ou négatif, à plus long terme.

(1) (1) (1) Rabah Lahmar,

Umr Gestion de l'eau, acteurs et usages

(G-eau), Umr Fonctionnement

et conduite des systèmes de culture tropicaux et méditerranéens (System)

rabah.lahmar@cirad.fr

\section{Partenaires}

22 institutions, 5 organisations non gouvernementales et une entreprise dans 18 pays.

* Kassa (Knowledge Assessment and Sharing on Sustainable Agriculture).

\section{Bibliographie}

Lahmar R., 2006. Sharing knowledge on sustainable agriculture: concluding conference of the KASSA Project, 20-21 février 2006, Fondation universitaire, Bruxelles, Belgique.

Lahmar R., 2006. Opportunités et limites de l'agriculture de conservation en Méditerranée : les enseignements du projet Kassa. In : $3^{\text {e }}$ Rencontres méditerranéennes du semis direct, $23-$ 25 mars 2006, Saragosse, Espagne. Montpellier, Ciheam, Options méditerranéennes, Série A, Séminaires méditerranéens $n^{\circ} 69$, p. 11-18.

Lahmar R., 2006. Adoption of conservation agriculture in Europe: lessons of the KASSA project. In : Cost 634, conference on farm level adoption of soil and water conservation measures and policy implications in Europe, 1-3 octobre 2006, Wageningen, Pays-Bas.

Lahmar R., 2006. Sustaining conservation agriculture: lessons learned from the EU project KASSA. In : 2nd International rice congress, 9-13 octobre 2006, New Delhi, Inde.

\section{Site}

http://kassa.cirad.fr

\section{Approches biologiques du sol}

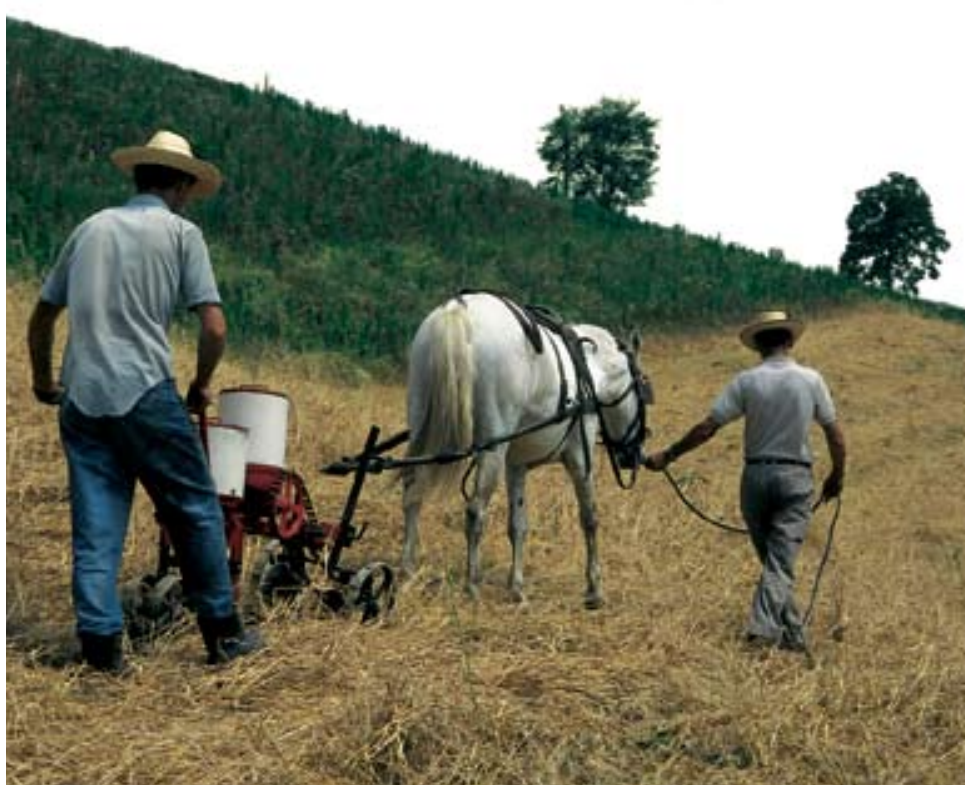

Plusieurs agronomes du Cirad ont participé à la conception et à la rédaction de l'ouvrage Biological approaches to sustainability soil systems, qui rassemble les expériences de 102 chercheurs de 28 pays sur les systèmes novateurs en agriculture de conservation et leurs implications en biologie des sols. Cinq chapitres présentent ainsi les résultats obtenus par le Cirad et ses partenaires, à Madagascar, au Brésil, au Vietnam et au Gabon, sur les systèmes de culture en semis direct sous couverture végétale permanente ainsi que les principes de ces systèmes, fondés sur la compréhension du fonctionnement des sols et privilégiant l'activité biologique.

(D) a (D) Olivier Husson, Lucien Séguy, Upr Systèmes de semis direct sous couverture végétale, Urp Systèmes de culture et rizicultures durables, Madagascar olivier.husson@cirad.fr

\section{Bibliographie}

Uphoff N., Ball A.S., Herren H., Husson O., Laing M., Palm C., Pretty J., Sanchez P., Sanginga N., Thies J., 2006. Biological approaches to sustainability soil systems. Boca Raton, CRC Press, $764 \mathrm{p}$. 


\title{
- o o Des formations sur l'impact de la gestion des matières organiques
}

\begin{abstract}
Dans les pays du Nord comme du Sud, l'intérêt pour le recyclage des matières organiques en agriculture ne cesse de croître. Mais comment évaluer l'impact agronomique et environnemental de cette pratique? Le Cirad et ses partenaires ont mis au point des indicateurs adaptés aux zones tropicales et des modèles de simulation fiables et faciles à utiliser. Afin de les diffuser, le Cirad a conçu une formation destinée aux pays du Sud, dont le contenu et le site d'intervention sont modulables.
\end{abstract}

Un cycle de formation sur l'impact agronomique et environnemental de la gestion des matières organiques vient d'être créé par le Cirad. II se propose de faire le point sur les techniques de valorisation des matières organiques en fonction des situations - secteur urbain, terroir, zone industrielle, région d'élevage intensif ou d'agriculture biologique - et d'examiner leurs atouts et leurs risques écologiques - qualité des eaux, transferts de polluants, évolution des sols, gaz à effet de serre et séquestration du carbone, charge minérale de certains effluents. Cette formation présente, en outre, des méthodes de mesure utilisables au champ et au laboratoire (matière organique, eau, sol, plante, gaz) et des indicateurs d'état et de prévision de la transformation des apports organiques. Son originalité réside dans la prise en compte des spécificités des pays du Sud, qu'il s'agisse des aspects logistiques, écologiques ou réglementaires, mais aussi des méthodes d'analyse et de mesure proposées, qui sont adaptées à un environnement technique limité.

Cette formation s'adresse aux chercheurs, ingénieurs, techniciens de l'agriculture et de l'environnement et, plus généralement, à toute personne en charge du développement agricole, agro-industriel ou de la protection de I'environnement. Elle alterne conférences, travaux dirigés et visites sur le terrain, et met l'accent sur l'échange d'expériences entre les participants et avec les formateurs.

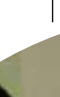

\section{1}

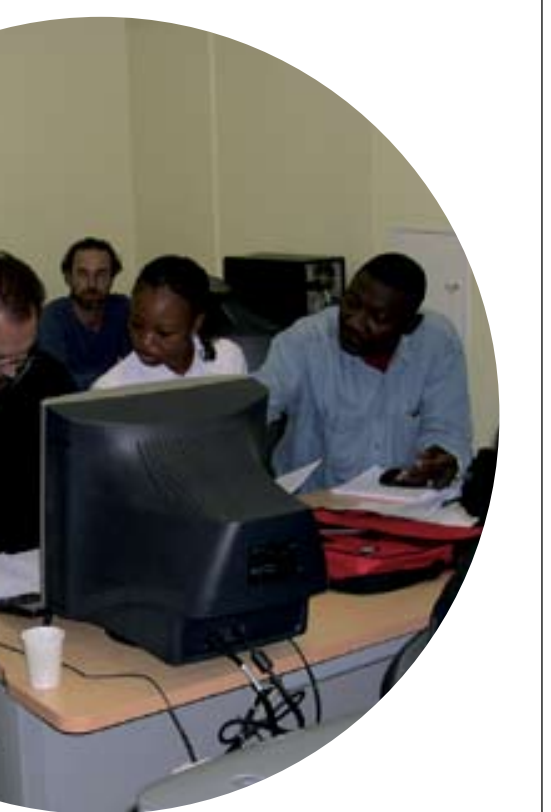

Une formation qui s'adresse aux chercheurs, ingénieurs et techniciens de l'agriculture et de I'environnement. (C R. Oliver/Cirad.

Une session pilote a été organisée en octobre 2006, à Montpellier, avec des intervenants du Cirad, de l'Inra et de I'Ird. Les participants venaient de Nouvelle-Calédonie, du Sénégal, du Mali, de Madagascar, du Cameroun et du Burkina Faso. Cette session a permis de préciser le cadre de ce cycle de formation. Les participants ont ainsi sou- ligné la nécessité d'une concertation, à I'échelon local, avec les acteurs de la gestion des matières organiques et ils ont mis l'accent sur la formation de formateurs et l'insertion de ce type de formation dans l'enseignement supérieur. Ils ont enfin déterminé deux niveaux de formation en fonction des publics : I'un, scientifique, vise l'enseignement et porte sur des thématiques ciblées (filière agricole, agriculture périurbaine, élevage...) et des outils techniques ; I'autre, plus général, concerne les décideurs et traite de la place de l'agriculture, des besoins énergétiques, des risques environnementaux, de la législation et du transfert des travaux de la recherche au développement.

(1) (1) (1) Francis Ganry, Upr Risque environnemental lié au recyclage, Florence Paulet, Appui au montage de projets de formation et d'enseignement francis.ganry@cirad.fr

\section{Partenaires}

Institut national de la recherche agronomique (Inra, France), Institut de recherche pour le développement (Ird, France).

\section{Bibliographie}

Chabalier P.F., Van de Kerchove V., Saint Macary H., 2006. Guide de la fertilisation organique à la Réunion. Saint-Denis, Cirad, Chambre d'agriculture de la Réunion, $302 \mathrm{p}$.

Ganry F., Barthès B., Gigou J., 2005. Les défis du maintien de la fertilité des sols tropicaux: cas de l'Afrique de l'Ouest. In : Sols et environnement : cours, exercices et études de cas ( $2^{\mathrm{e}}$ cycle, master, écoles d'ingénieurs, professionnels), Girard M.C. et al. Paris, Dunod, p. 583-607. 


\title{
め ๓ L'observatoire, \\ support de l'action collective
}

\begin{abstract}
L'information est un élément clé dans un monde agricole en pleine mutation. Pour coordonner les activités, pour mener des actions collectives et, plus globalement, pour gérer les territoires ruraux, il est indispensable de disposer d'une information partagée, fiable et actualisée. La mise en place d'un observatoire est l'occasion de rassembler et d'organiser cette information. Le Cirad a testé, en France, une nouvelle démarche qui permet de construire un tel observatoire.
\end{abstract}

L'avenir de l'agriculture, sa viabilité économique, son intégration dans un environnement fragilisé et ses relations avec la société civile sont actuellement des questions fondamentales pour l'ensemble des acteurs du monde rural, au Nord comme au Sud. Pour répondre à ces interrogations et accompagner les changements à venir, une information fiable et rationalisée s'avère essentielle.

Mais, selon les situations, cette information est riche ou lacunaire, dispersée, incomplète ou mal organisée : dans tous les cas, elle requiert au minimum une remise en forme. Pour organiser, partager et diffuser cette information, un nouveau concept a vu le jour : celui d'observatoire. Mais quelles sont les conditions, les modalités et les moyens à mettre en œuvre pour réaliser un observatoire? Comment le construire pour le rendre opérationnel ? A partir d'une série de mises en situation en France, le Cirad a pu tester et valider une démarche novatrice de création d'observatoires.

\section{Un observatoire, pour quoi faire?}

Un observatoire permet de mieux comprendre et gérer les relations entre l'agriculture et le territoire. C'est I'occasion pour les acteurs d'expliciter,

La fenaison sur le plateau de Millevaches : émergence de nouvelles pratiques, de nouveaux systèmes cultivés. (OY. Clouet/Cirad.

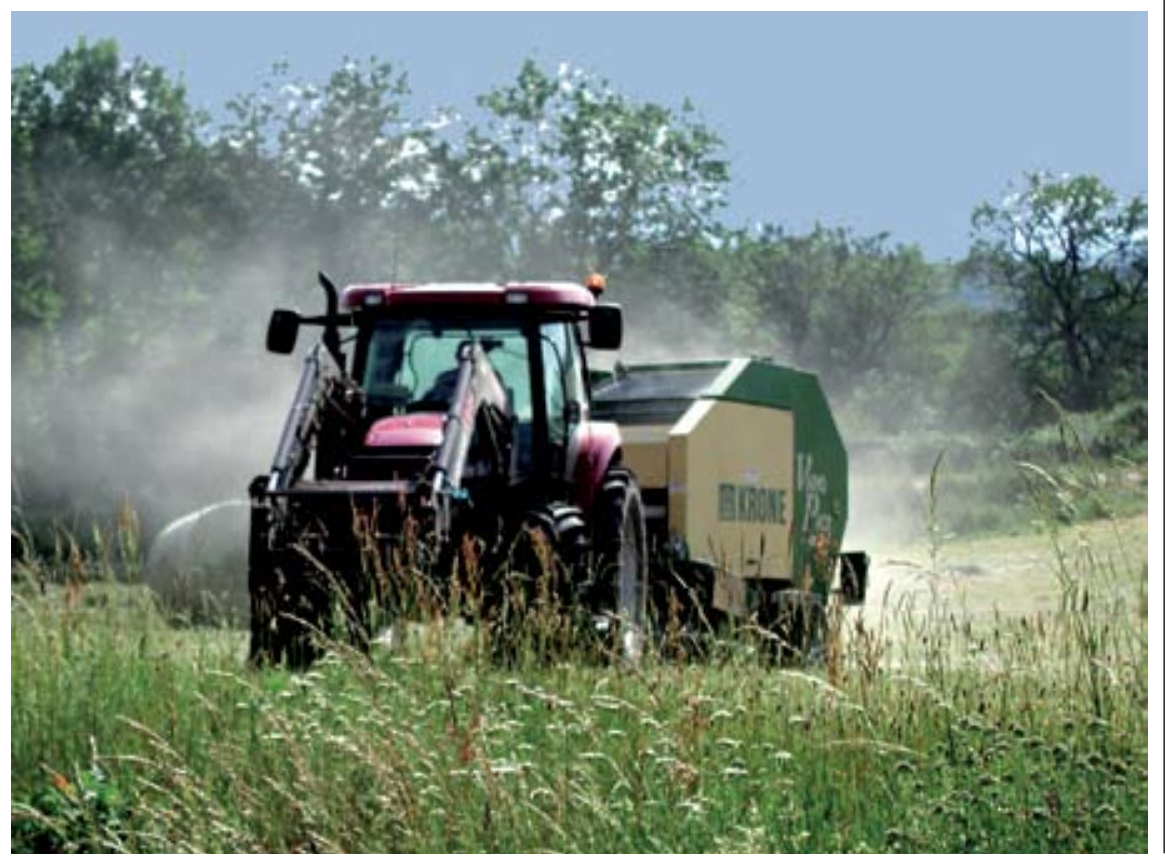

individuellement et collectivement, la perception qu'ils ont de leur territoire, d'en construire des représentations. La démarche se fonde sur la conviction que les acteurs peuvent, dans un processus de concertation et de négociation, définir ensemble les orientations à poursuivre et les moyens à mettre en œuvre. Les données collectées et diffusées par l'observatoire vont, en améliorant et en "objectivant » l'information, contribuer aux décisions et aux négociations nécessaires à l'action collective.

Pour évaluer la faisabilité d'une telle démarche, une méthode a été élaborée et testée sur deux terrains : le bassin de l'Aume-Couture, en Charente, où la question centrale était celle de la gestion quantitative de l'eau, et la vallée de I'Hien, dans I'Isère, où les enjeux étaient liés à la biodiversité et à la qualité de l'eau. Sur chacun de ces sites, le territoire est défini autour d'une action collective qui vise un enjeu particulier. Des collectifs d'acteurs du monde rural y ont été constitués pour construire un observatoire et établir la base d'un système d'information.

\section{Une démarche fondée sur la concertation}

Cinq étapes sont au centre de la démarche. Il s'agit d'abord de caractériser les pratiques au sein des divers systèmes de production du territoire, puis d'analyser les besoins des acteurs pour déterminer la structure de l'observatoire - type d'information à recueillir, procédures de traitement, diffusion auprès des acteurs. 
Ensuite, il est nécessaire de définir les enjeux à privilégier et de choisir les niveaux d'observation et leurs relations, pour construire le système d'information. Enfin, il faut évaluer l'insertion de l'observatoire dans les organisations et ses conséquences sur les processus de négociation.

L'étude de faisabilité a conclu à la pertinence de la démarche, en mettant bien en évidence l'importance de la mobilisation des acteurs et le rôle de la formalisation pour exprimer les objectifs et points de vue de chacun. La mise en œuvre de la méthode dans d'autres situations, au Nord comme au Sud, et sa généralisation sont envisagées.

(1) (1) Michel Passouant, Sandrine Alinat, Umr Territoires, environnement, télédétection et information spatiale (Tetis) michel.passouant@cirad.fr

\section{Partenaires}

Assemblée permanente des chambres d'agriculture (Apca, France), Institut national de la recherche agronomique (Inra, France), Institut de recherche pour l'ingénierie de l'agriculture et de l'environnement (Cemagref, France), ministère de l'Agriculture et de la Pêche, ministère de l'Environnement et du Développement durable, université de Rennes.

\section{Bibliographie}

Benoît M., Passouant M., Thenail C., HubertMoy L., Dupraz P., Brassac C., Le Ber F., Marie J.F., Bockstaller C., Barrière O., King D., Le Bas C., Ruelle P., 2006. Why and how design monitoring processes of farmer practices in European landscape? In : Changing European farming systems for a better future: new visions for rural areas, Langeveld H., Röling N. (éd.). Wageningen, Wageningen Academic Publishers, p. 461-462.

Barzman M., Caron P., Passouant M., Tonneau J.P., 2006. Observatoire agriculture et territoires: étude pour la définition d'une méthode de mise en place d'observatoires. Montpellier, Cirad, 65 p.

\title{
- $\infty$ o Ranema, un module de formation en épidémiologie à distance
}

\begin{abstract}
La formation à distance assistée par ordinateur est une réponse à la diminution des bourses d'études et de stage. Elle permet, en outre, de construire des partenariats avec les établissements du Sud. Un module de formation de ce type, destiné à la remise à niveau en épidémiologie des maladies animales (Ranema), a été conçu sur la base d'activités de simulation. Il est proposé soit seul, lors d'une formation à distance, soit en complément d'une formation traditionnelle.
\end{abstract}

\section{La formation à distance revêt} une importance croissante. Elle répond aux contraintes que rencontre la formation traditionnelle, comme la diminution des crédits alloués aux bourses d'études et de stage, mais offre aussi de nouvelles possibilités de construction de partenariats avec les établissements du Sud. Un module de formation assistée par ordinateur, Ranema, conçu

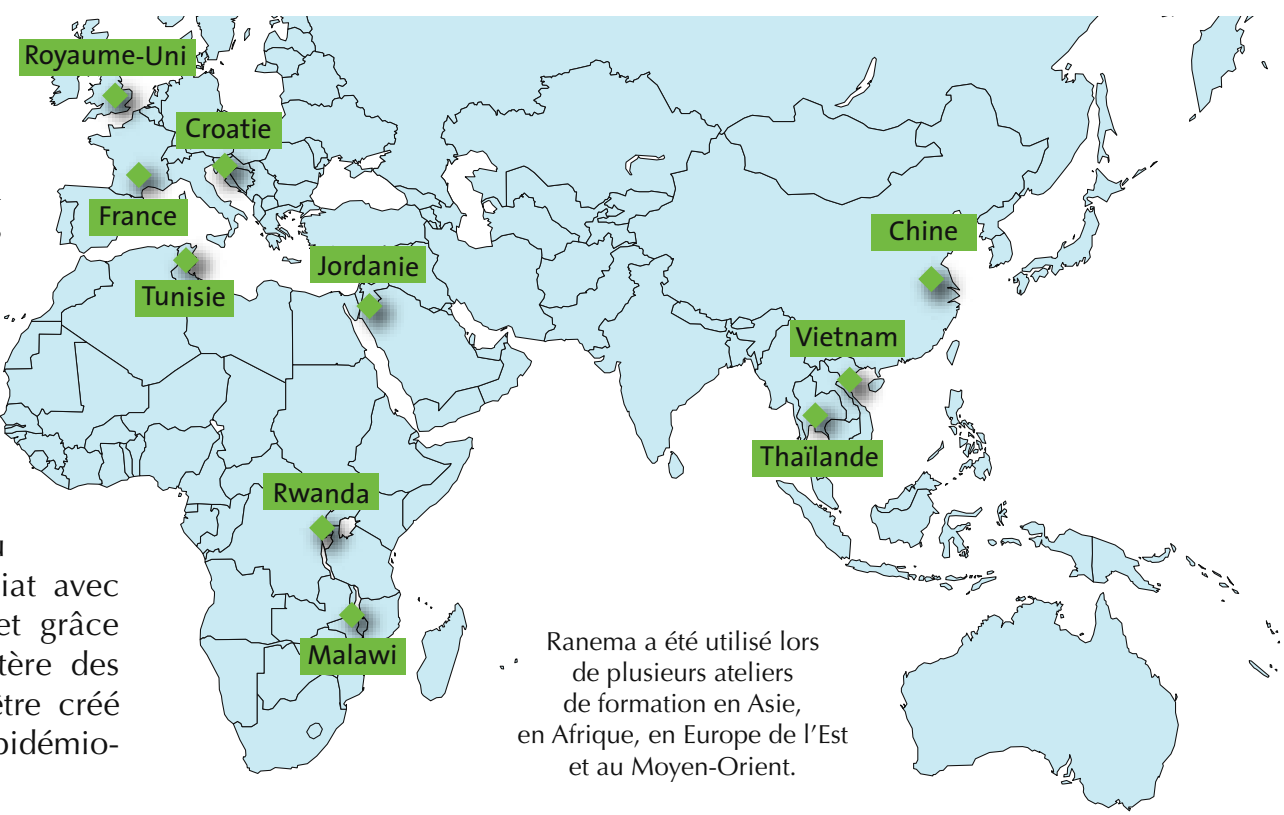
dans le cadre d'un partenariat avec I'Ecole vétérinaire d'Alfort et grâce à un financement du ministère des Affaires étrangères, vient d'être créé pour la remise à niveau en épidémiologie des maladies animales. 


\section{Une formation \\ à la fois interactive et récréative}

Ce module se fonde, en grande partie, sur un manuel d'épidémiologie vétérinaire appliquée, Epidémiologie appliquée à la lutte contre les maladies animales transmissibles majeures, de B. Toma et al. (1999). Il s'organise autour d'activités de simulation destinées à stimuler et à motiver les étudiants. La formation repose sur un scénario simple : le stagiaire est un vétérinaire qui travaille pour les services vétérinaires d'un pays virtuel, Ranema ; pour remplir ses fonctions, il doit remettre à niveau ses connaissances en épidémiologie par un ensemble d'activités.

Ce module peut être proposé seul, lors d'une formation à distance, ou accompagner un enseignement traditionnel et permettre ainsi de réduire la durée des cours théoriques. C'est une nouvelle manière, à la fois interactive et récréative, d'acquérir des bases en épidémiologie.
En 2005 et 2006, le module Ranema a été utilisé lors de plusieurs ateliers de formation sur la grippe aviaire organisés par la Fao, en Asie, en Afrique, en Europe de I'Est et au Moyen-Orient, et par I'Oie, pour l'Asie du Sud-Est. II est désormais décliné sous différentes versions linguistiques (anglais et français) et didactiques (mallettes pédagogiques d'utilisation en semi-présentiel). Une plate-forme permet de l'utiliser à distance.

Les travaux se poursuivent pour produire de nouveaux modules sur des aspects plus spécifiques et dans d'autres versions linguistiques. Ils s'orientent également vers la formation de formateurs, vers l'évaluation de l'impact des formations et vers la simulation du fonctionnement d'un réseau d'épidémiosurveillance par l'application de modèles multiagents.

(1) (1) A) François Roger, Upr Epidémiologie et écologie des maladies animales,

Flavie Goutard, Us Enseignement et formation en élevage francois.roger@cirad.fr flavie.goutard@cirad.fr

\section{Partenaires}

Ecole vétérinaire d'Alfort (France), Institut national de la recherche vétérinaire (Nivr, Vietnam), Organisation mondiale de la santé animale (Oie, France), Organisation des Nations unies pour l'alimentation et l'agriculture (Fao, Italie), Royal Veterinary College (Royaume-Uni), université de Chulalungkorn (Thaïlande).

\section{Bibliographie}

Arnone A., Bénet J.J., Biteau-Coroller F., Dufour B., Etter E., Goutard F., Molia S., Pellecuer M., Queste J., Roger F., Thonnat J., Toma B., Weber L., 2006. Ranema, Remise à niveau en épidémiologie des maladies animales : outils de formation assistée sur ordinateur. Paris, Cirad, Enva, Ministère des Affaires étrangères (cédérom).

Benet J.J., Dufour B., Thonnat J., Weber L., Roger F., Toma B., 2005. Surveys concerning the needs for and evaluation of distance learning in veterinary epidemiology. Journal of Veterinary Medical Education, 32 : 68-71.

Chavernac D., Desvaux S., Goutard F., Roger F., Thonnat J., 2005. Workshop to deliver epidemiology and laboratory training for Hpai diagnostic network. Montpellier, Cirad, Rome, Fao (cédérom).

Goutard F., Thonnat J., Toma B., Dufour B., Queste J., Roger F., 2006. Ranema: a D-L tool for basic epidemiology. In : 11th symposium of the Isvee, Cairns, Australie. Isvee, p. 210.

\section{- ๑ C Cultiver dans les villes : une réponse à l'urbanisation}

L'agriculture des villes joue un rôle socio-économique vital, notamment pour les populations les plus pauvres. Des projets en Afrique et en Asie tentent de conférer une reconnaissance à cette activité et de réconcilier les intérêts contradictoires des acteurs de son développement.

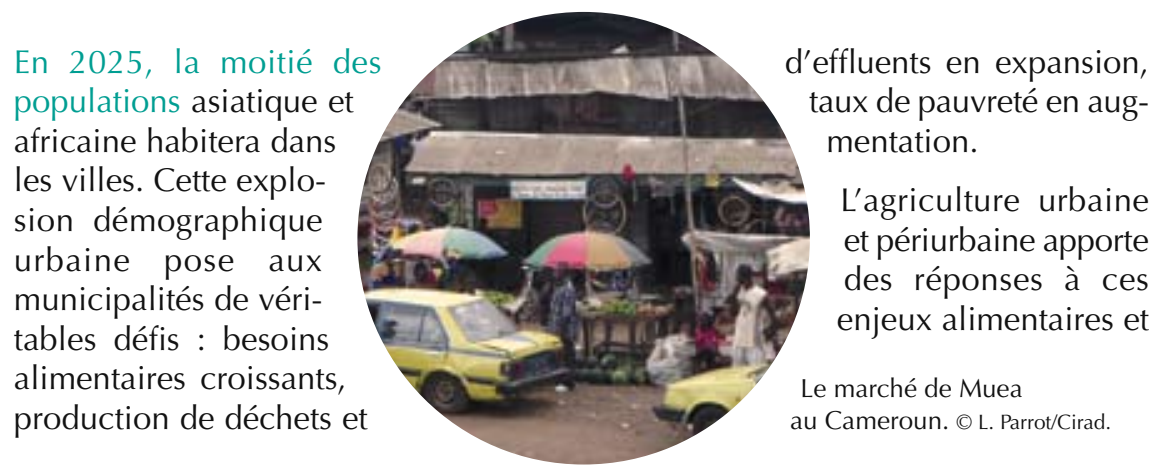

écologiques. D'après la Fao, ce type d'agriculture fournissait en 2005 de la nourriture à près de 700 millions de citadins, soit le quart de la population urbaine mondiale. Elle approvisionne les marchés en produits diversifiés, crée des emplois et rend les villes plus vertes. Pourtant, l'agriculture des villes est l'objet de multiples menaces, que ce soit la concurrence pour le foncier, 
entre usages agricoles, résidentiels et industriels, ou le recours aux importations pour l'approvisionnement des supermarchés.

\section{Prendre conscience des enjeux de l'agriculture urbaine}

Il est important que les institutions publiques locales et nationales, les acteurs privés du développement urbain et le secteur agricole prennent conscience des enjeux de cette agriculture. II s'agit de réconcilier les différentes parties prenantes aux intérêts souvent contradictoires. C'est ainsi que le Cirad et ses partenaires ont lancé deux projets - I'un sur le développement de l'agriculture périurbaine en Asie du SudEst (Susper*), au Cambodge, au Laos et au Vietnam, I'autre sur les supermarchés (M4P**), au Vietnam - et organisé un atelier sur la promotion de l'agriculture urbaine et périurbaine en Afrique de I'Ouest et du Centre, fin 2005, à Yaoundé, au Cameroun.

D'une manière générale, il ressort de ces recherches que, pour assurer la pérennité des activités agricoles urbaines, les différentes parties prenantes, notamment les municipalités, doivent prendre conscience des fonctions de cette agriculture. II est également fondamental que les producteurs et leurs groupements soient reconnus par les pouvoirs publics.

L'atelier de Yaoundé a permis de partager des expériences africaines. Au Bénin, le dialogue entre le gouvernement et I'Union communale des producteurs de Cotonou s'est soldé par l'attribution de 400 hectares aux maraîchers. En Ouganda, le maire de Kampala a, en 2005, accrédité des lois permettant aux citadins de cultiver la terre et de pratiquer l'élevage dans l'enceinte de la ville. Ces diverses expériences ont incité les agriculteurs camerounais présents à I'atelier à créer, avec l'appui des chercheurs, la Coalition pour la promotion de I'agriculture urbaine et périurbaine en Afrique. Ce réseau a pour objectif

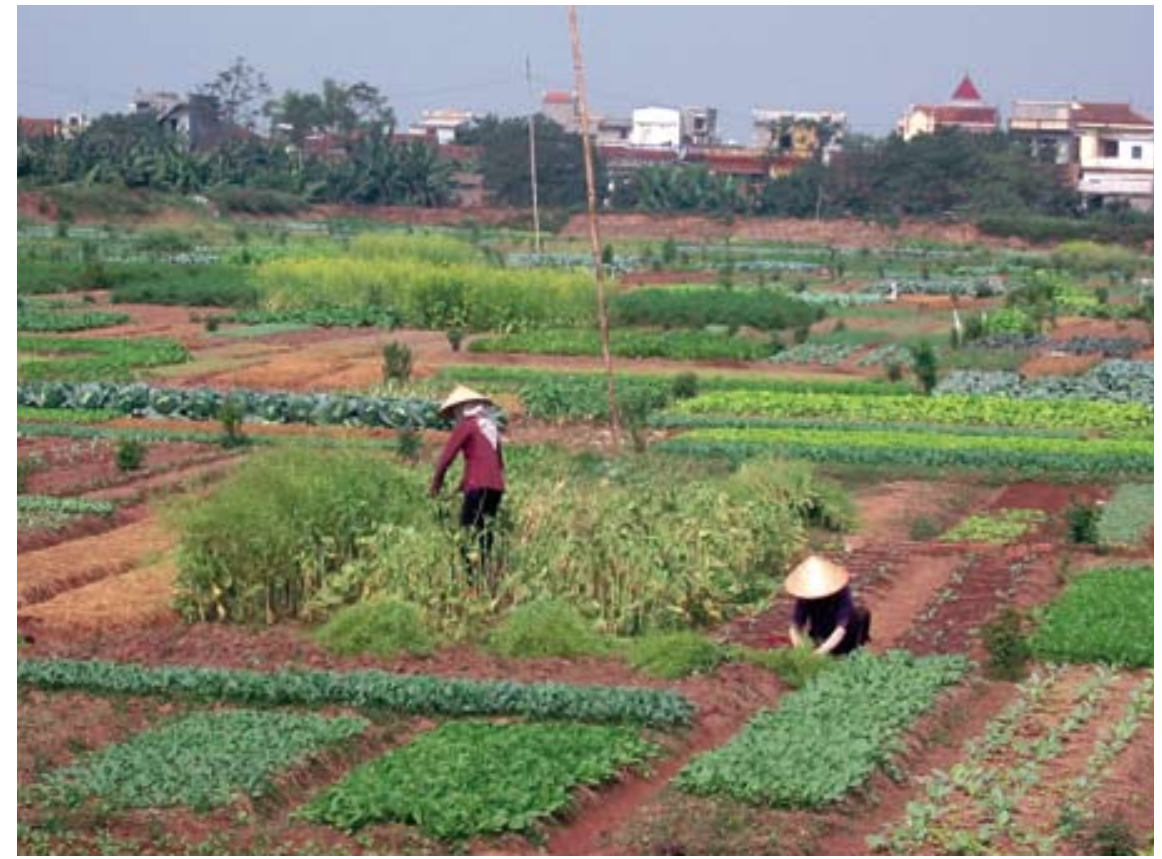

Des cultures de légumes à la périphérie de Hanoi, au Vietnam. ㅇ P. Moustier/Cirad.

de promouvoir le dialogue entre les agriculteurs et les municipalités.

\section{Des solutions}

\section{techniques pour une production marchande}

Le renforcement des compétences des agents privés et publics intervenant dans ce secteur est également indispensable pour pérenniser l'approvisionnement alimentaire. Le projet Susper a ainsi permis à quatre villes asiatiques (Hanoi, Hô Chi Minh-Ville, Phnom Penh et Vientiane) de mieux répondre aux demandes locales en légumes et de s'orienter vers une production marchande. Des solutions techniques ont été trouvées pour satisfaire les besoins du marché et accroître les revenus des paysans, comme la production de contre-saison. De nouveaux modes de certification de la qualité sanitaire des légumes ont été testés. Afin de faciliter la négociation des producteurs avec les commerçants, un système peu coûteux de collecte et de diffusion d'informations journalières sur les prix a été mis au point.
Au Vietnam, le projet M4P a permis d'évaluer l'impact du développement des supermarchés sur les populations pauvres en tant que populations de consommateurs et de commerçants. Les supermarchés représentent moins de $5 \%$ de la distribution des aliments, mais leur croissance se chiffre à plus de $15 \%$ par an. Les conséquences négatives de ce développement pour les consommateurs pauvres sont nombreuses : ils ont peu accès à ces commerces du fait de leurs prix élevés et des contraintes de transport et ne peuvent bénéficier d'un travail dans ce secteur, qui offre nettement moins d'emplois que les marchés traditionnels ou la vente de rue. Par ailleurs, les producteurs pauvres ne peuvent approvisionner les supermarchés en raison de leurs exigences de régularité et de qualité et des délais de paiement. Certaines organisations de producteurs permettent néanmoins aux petits producteurs de développer la qualité gustative ou sanitaire de leurs produits, de la faire reconnaître par un label, et d'intégrer ainsi la filière de la grande distribution avec des revenus plus stables et plus élevés que dans les filières traditionnelles. 
L'urbanisation galopante exige une professionnalisation plus poussée du secteur agricole et une meilleure connaissance des besoins des citadins. La sensibilisation des autorités urbaines sera de plus en plus nécessaire tant pour des raisons sociales que sanitaires ou foncières.

(D) (1) Paule Moustier, Hubert de Bon, Laurent Parrot, Upr Horticulture,

Upr Normes et régulation des marchés agricoles paule.moustier@cirad.fr

\section{Partenaires}

Académie des sciences agronomiques du Vietnam (Vaas, Vietnam), Ecole nationale supérieure du paysage (Ensp, France), Institut national de la recherche agronomique
(Inra, France), Institut national des recherches agricoles du Bénin (Inrab, Bénin), Institut de recherche agricole pour le développement (Irad, Cameroun), Institut de recherche sur les fruits et légumes (Rifav, Vietnam), Institut sénégalais de recherches agricoles (Isra, Sénégal), Institut de sociologie (Ios, Vietnam), Markets and agriculture linkages for cities in Asia (Malica, Vietnam), Pôles de recherche en partenariat Grand Sud et Madagascar, université d'Antananarivo (Madagascar), université de Yaoundé I (Cameroun), The World Vegetable Center (Avrdc, Taiwan).

* Susper (Sustainable Development of Periurban Agriculture in South-East Asia, Cambodge, Laos, Vietnam).

**M4P (Making markets work better for the poor, Vietnam).

\section{Bibliographie}

Cadilhon J.J., Fearne A.P., Phan Thi Giac Tam, Moustier P., Poole N.D., 2006. Traditional versus modern distribution systems: Insights from vegetable supply chains to Ho Chi Minh City. Development Policy Review, 24 : 31-49.

Moustier P., Danso G., 2006. Local economic development and marketing of urban produced food. In : Cities farming for the future: urban agriculture for green and productive cities, van Veenhuizen R. (dir.). Ruaf Foundation, Idrc, lirr, 7, p. 173-208.

Mubarik A., De Bon H., Moustier P., 2006. Pour la promotion d'une agriculture urbaine et périurbaine multifonctionnelle à Hanoi. Magazine agriculture urbaine, $7: 9-11$.

Tixier P., De Bon H., 2006. Urban horticulture. In : Cities farming for the future: urban agriculture for green and productive cities, van Veenhuizen R. (dir.). Ruaf Foundation, Idrc, lirr, 11, p. 315-348.

\section{- 0 ø Le libre accès à la connaissance scientifique}

En 2006, le Cirad a signé, avec les universités, les grandes écoles et sept organismes de recherche, le protocole pour la mise en place d'une plate-forme nationale commune de dépôt sur Internet de documents scientifiques. Un engagement sans précédent pour favoriser l'accès à l'information, dont l'ensemble de la communauté scientifique devrait bénéficier.

Le Cirad s'est engagé dans le mouvement mondial des archives ouvertes en rejoignant les signataires de la déclaration internationale de Berlin en faveur du libre accès à la connaissance et en signant le protocole national $d^{\prime}$ accord pour la mise en place d'une plate-forme commune de dépôt de documents scientifiques. Outre le Cirad, l'ensemble des universités et des grandes écoles, par l'intermédiaire de leur Conférence, et sept organismes de recherche - le Cemagref, le Cnrs, I'Inra, I'Inria, I'Inserm, I'Institut Pasteur et I'Ird - participent à cette initiative nationale, qui vise à favoriser l'accès à I'information scientifique.

\section{Une archive ouverte commune aux institutions françaises}

Parallèlement aux revues scientifiques, Internet a vu se développer un mode direct de communication entre les chercheurs. Les institutions françaises, soucieuses de disposer de ce moyen de diffusion et de valorisation de la production scientifique de leurs chercheurs, ont choisi de se doter d'une plate-forme commune de dépôt de la production scientifique. Cet instrument, relié aux autres dépôts d'archives ouvertes développés dans le monde entier, satisfait aux critères de la communication scientifique directe (open access). Il est construit à partir de Hal (hyperarticle en ligne), outil logiciel développé par le Centre de communication scientifique directe du Cnrs.

Le principe des archives ouvertes s'inspire de cette nouvelle forme de communication scientifique entre chercheurs, qualifiée de directe parce que l'auteur est le propre acteur de la mise en accès libre et gratuit de sa publication. Une archive ouverte permet aux auteurs de faire connaître rapidement leurs travaux et à leurs institutions de rattachement d'être mieux perçues à l'extérieur, en 
offrant un accès universel et gratuit aux publications déposées. En outre, une publication ainsi déposée est soumise ouvertement à la lecture et à la critique des pairs, qui peuvent amener l'auteur à produire et à archiver des versions actualisées de sa publication.

\section{Une visibilité internationale des résultats scientifiques}

Tout chercheur du Cirad peut d'ores et déjà déposer ses publications sur la plate-forme $\mathrm{Hal}$ et la rattacher à son unité de recherche. Un référentiel des principaux domaines scientifiques couverts par Hal permet également à un auteur d'attribuer un ou plusieurs thèmes de recherche à sa publication. Le texte autoarchivé est accessible librement et gratuitement sous 24 heures sur Internet. Le protocole de communica- tion sur lequel Hal repose permet, outre I'interface $\mathrm{Hal}$ et celle de moissonneurs $\mathrm{d}^{\prime}$ archives ouvertes, de rechercher et de visualiser les contenus par les moteurs de recherche classiques. Toute publication déposée dispose $d^{\prime}$ une adresse Internet permanente et $d^{\prime}$ une garantie de conservation.

Une interface de consultation de l'archive ouverte Hal, propre au Cirad, permet de consulter sur Internet I'ensemble des références et des documents scientifiques déposés par des auteurs du Cirad ou d'équipes de recherche associant le Cirad. Fin 2006, 233 documents scientifiques concernant le Cirad avaient été déposés.

Ces archives institutionnelles, tout comme les nouveaux supports de publication et de diffusion que sont les thèses et les revues électroniques en libre accès, facilitent I'accès aux travaux des chercheurs en les rendant consultables gratuitement sur Internet. Un mode de communication original qui devrait bénéficier à l'ensemble de la communauté scientifique, du Nord comme du Sud.

(1) (1) I) Marie-Claude Deboin, Direction de l'innovation et de la communication marie-claude.deboin@cirad.fr

\section{Bibliographie}

Deboin M.C., 2006. Publier et diffuser sa thèse électronique sur Internet : conseils aux doctorants accueillis par le Cirad. Archivesic, 13 p. (http://archivesic.ccsd.cnrs.fr/sic_00001652/ en/)

Deboin M.C, Fily M.F., 2006. Déposer ses publications dans une archive ouverte : information aux auteurs du Cirad et sélection d'entrepôts. Archivesic, 26 p.

(http://archivesic.ccsd.cnrs.fr/sic_00109227/ en/)

Site

http://hal.archives-ouvertes.fr/CIRAD/fr/

\section{Les éditions Quæ, la nouvelle maison d'édition du Cirad}

Depuis le $1^{\text {er }}$ juillet 2006, les éditions du Cirad, du Cemagref, de l'Ifremer et de I'Inra se sont réunies au sein d'un groupement d'intérêt économique appelé Editions Quæ. Avec près de 1000 titres à leur catalogue dans les domaines communs aux quatre organismes — milieux et ressources, environnement, alimentation, sociétés —, les éditions Quæ ont l'ambition de devenir une maison d'édition scientifique de référence, qui réponde aux attentes d'un lectorat exigeant, soucieux d'accéder à une information fiable et de qualité. De nouvelles collections ont été créées, destinées à favoriser les échanges entre scientifiques, transmettre savoirs et savoir-faire, contribuer au débat public et mettre à la disposition de tous les résultats de la recherche. Catalogue, collections, services aux auteurs et aux libraires sont accessibles sur le site www.quae.com, outil de promotion et de diffusion des éditions Quæ.
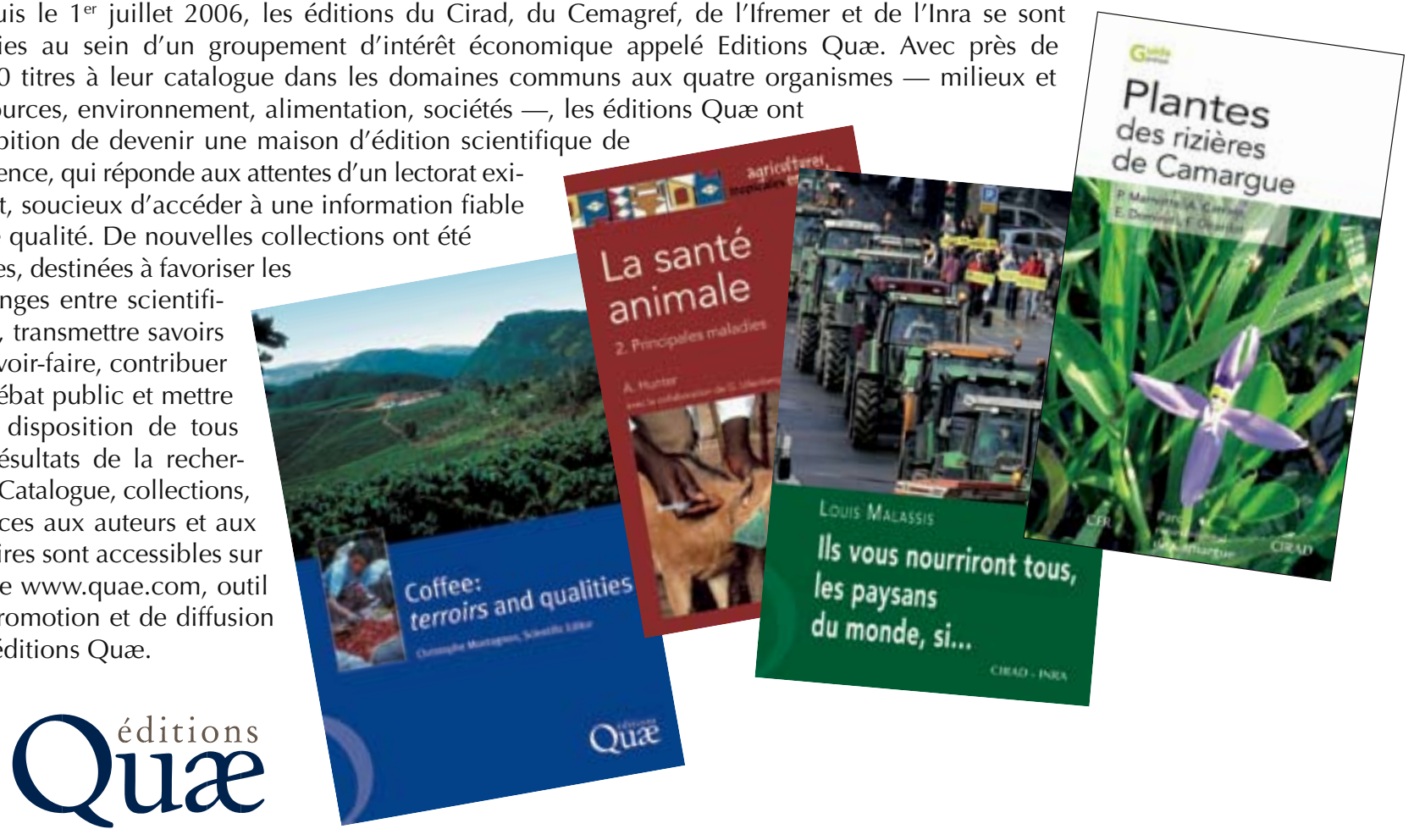


\title{
Innover •••
}

\section{- - Un diagnostic universel et précoce du dépérissement bactérien de l'anthurium}

\begin{abstract}
L'anthurium est cultivé sur l'île de la Réunion pour ses belles fleurs en forme de cœur aux coloris intenses. Cependant, depuis 1997, une bactérie menace les productions réunionnaises. Un outil de détection moléculaire sensible, fiable et rapide de la bactérie est désormais disponible.
\end{abstract}

Les premiers symptômes du dépérissement de l'anthurium sont des taches foliaires d'aspect huileux, qui jaunissent et se nécrosent. L'infection peut devenir rapidement systémique et entraîner la mort du plant. Dans les années 1980, cette maladie infectieuse, due à la bactérie Xanthomonas axonopodis pv. dieffenbachiae, a provoqué aux Antilles l'anéantissement quasi total de la filière de I'anthurium. Sur l'île de la Réunion, la bactérie a été introduite accidentellement en 1997 par l'intermédiaire de plants contaminés en provenance des PaysBas. Une campagne de lutte par éradication a alors été mise en place : destruction de tous les plants des ombrières infectées et interdiction de la commercialisation de plants. L'importation des anthuriums devait s'effectuer sous la forme de vitroplants, avec une quarantaine de 18 mois. Le Cirad a alors lancé un programme de recherche en concertation avec le Service de protection des végétaux de la Réunion et les acteurs de la filière. L'objectif était de disposer de moyens d'inspection plus performants des plants importés.

\section{Une détection à la fois spécifique et sensible}

Deux étapes ont été nécessaires pour mettre au point cet outil. Dans un premier temps, I'objectif a été de constituer une collection représentative de la diversité génétique et pathogénique mondiale de cette bactérie. Des cultures bactériennes provenant de toutes les zones où la maladie est présente ont été collectées et analysées. Les résultats montrent que les bactéries infectant les aracées, famille dont fait partie l'anthurium, constituent un groupe génétiquement hétérogène, dont tous les membres ne sont pas pathogènes pour l'anthurium. Cette diversité a été caractérisée grâce à deux techniques : la technique AFLP (amplified fragment length polymorphism), qui permet de comparer les individus deux à deux pour un grand nombre de caractères de leur génome, et des tests mesurant le pouvoir pathogène sur différentes plantes de la famille des aracées.

Dans un second temps, les travaux ont porté sur un outil de détection fiable et universel, c'est-à-dire capable de détecter toutes les souches bactériennes potentiellement responsables de la maladie quelle que soit leur origine géographique. Les résultats sont probants : I'outil est spécifique - il ne détecte pas les souches non pathogènes — et sensible — il est capable de détecter les souches même lorsque les plants sont faiblement infectés et $n^{\prime}$ ont pas de symptômes visibles. 


\section{Un diagnostic rapide et une quarantaine réduite}

La détection se fonde sur la technique d'amplification génique (PCR, polymerase chain reaction): $\mathrm{C}^{\prime}$ est I'un des gènes de la bactérie qui est détecté. Au préalable, il a donc été nécessaire $d^{\prime}$ identifier un grand nombre de gènes cibles potentiels dans le génome de la bactérie, de déterminer ceux qui lui sont spécifiques et de s'assurer, a posteriori, à partir de la séquence $d^{\prime} A D N$, que le gène ciblé était bien unique et qu'il correspondait à une fonction indispensable de la bactérie. Des amorces nucléotidiques ont ensuite été choisies dans la séquence d'ADN cible afin d'élaborer le test PCR spécifique, puis I'amplification de la séquence cible par ce test a été vérifiée pour toutes les souches pathogènes de l'anthurium.
Les applications de cet outil sont multiples. Il est désormais possible de diagnostiquer rapidement l'infection, mais aussi, à plus grande échelle, de surveiller les ombrières et de contrôler les plants importés à l'entrée du territoire. Les durées de quarantaine imposées aux importateurs peuvent être réduites de moitié. L'outil peut également être utilisé dans le cadre de schémas de certification pour la production de matériel végétal indemne de maladie. Il a fait l'objet de dépôts de brevets en France et aux Pays-Bas. Enfin, il est prévu d'engager une procédure pour son adoption comme méthode officielle de diagnostic auprès de I'Organisation européenne de protection des plantes (Eopp).

- Isabelle Robène-Soustrade, Lionel Gagnevin, Umr Peuplements végétaux et bioagresseurs en milieu tropical (Pvbmt)

lionel.gagnevin@cirad.fr

\section{Partenaires}

Institut national de la recherche agronomique (Inra, Guadeloupe), Service d'inspection vétérinaire, alimentaire et phytosanitaire (Sivap, Nouvelle-Calédonie), Service de la protection des végétaux (Réunion), université de Mauritius (Maurice).

Ce projet a été financé par l'Office de développement de l'économie agricole des départements d'outre-mer (Odeadom, ministère de I'Outre-mer) et le Fonds européen d'orientation et de garantie agricole (Feoga).

\section{Bibliographie}

Jouen E., Laurent P., Robène-Soustrade I., Gagnevin L., Pruvost O., Hostachy B., Gateblé G., Amice R., 2006. First report of bacterial blight of aroids caused by Xanthomonas axonopodis pv. dieffenbachiae in New Caledonia. Plant Disease (sous presse).

Robène-Soustrade I., Laurent P., Gagnevin L., Jouen E., Pruvost O., 2006. Specific detection of Xanthomonas axonopodis pv. dieffenbachiae in anthurium (Anthurium andreanum) tissues by Nested PCR. Applied Environmental Microbiology, 72 : 1072-1078.

Brevets : brevet FR2848222 déposé en France en 2002, étendu aux Pays-Bas (NL1024929C).

\title{
- • Culture in vitro du palmier à huile : un procédé de seconde génération
}

\begin{abstract}
La pérennité des plantations de palmiers à huile repose pour une part sur la qualité du matériel végétal planté : il doit produire en quantité, être adapté aux conditions de culture locales et résister aux maladies. Le matériel clonal peut répondre à ces exigences, mais sa multiplication reste problématique. C'est pourquoi le Cirad développe actuellement un nouveau procédé de production de vitroplants, qui permettra de multiplier rapidement les clones les plus performants.
\end{abstract}

Le palmier à huile est la première source d'huile végétale du monde : I'huile de palme et l'huile de palmiste, toutes deux extraites de son fruit, représentent près de $30 \%$ de la production mondiale d'huiles végétales, avec 37 millions de tonnes produites en 2005. Cette production dépend largement de la qualité du matériel végétal planté : il doit être hautement producteur, pour assurer une rentabilité économique suffisante, adapté aux conditions de culture loca- les et résistant aux principales maladies, pour sécuriser l'investissement du planteur. Les variétés commercialisées de palmier à huile sont des hybrides d'hétérozygotes, ce qui signifie qu'il subsiste une variabilité génétique importante entre les individus d'une même famille. Il est possible de l'exploiter en sélectionnant les individus qui présentent le plus de qualités,

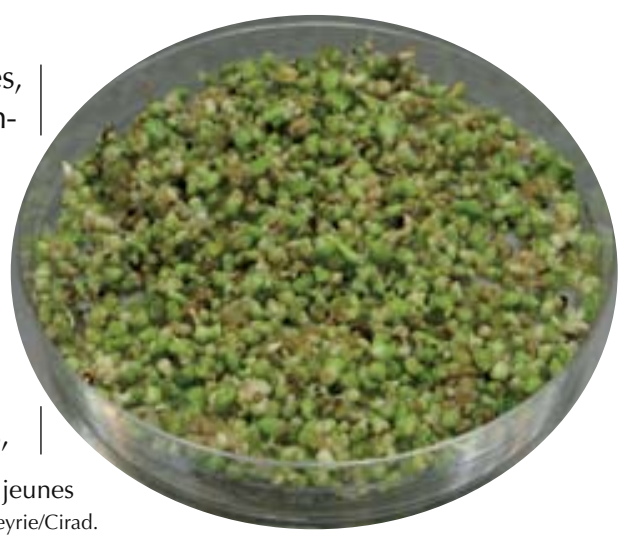


puis de les cloner. Ce clonage ne peut être réalisé que par culture in vitro en exploitant la capacité d'embryogenèse somatique de cette plante. Les premiers procédés développés dans le monde ont fait appel à des cultures sur milieux statiques gélosés. Leurs coûts étaient élevés et leurs capacités de production très limitées pour nombre de génotypes intéressants. Enfin, la conformité des plants produits restait difficile à maîtriser.

En 2001, le Cirad s'est donc engagé, avec I'entreprise Asd du Costa Rica, dans le développement d'un nouveau protocole, qui repose sur la multiplication de suspensions embryogènes en milieu liquide.

\section{Un nouveau protocole de production de clones}

Après cinq années de partenariat, il a été possible de développer un nouveau procédé fondé sur l'exploitation de suspensions embryogènes en milieu liquide. Les bases d'une production à grande échelle ont été posées. Le protocole est performant : en quelques mois, 50000 plants par litre de suspension peuvent être produits, ce qui autorise une bonne synchronisation des productions.
Le caractère prédictible de la production pour un espace, des moyens et des durées donnés est l'un des acquis essentiels de ce travail. Un autre atout majeur de ce procédé est qu'il permet d'utiliser une base génétique très large, y compris certains rétrocroisements d'hybrides interspécifiques impossibles à reproduire par des méthodes conventionnelles. Pour vérifier la qualité du matériel produit et poser les premières bases de la gestion des risques de non-conformité, des vitroplants ont été produits afin de tester différentes étapes du processus de production et plus de 10000 palmiers ont été plantés.

\section{Un test à l'échelle pilote}

Avec I'Ird et des partenaires du Sud, un projet de test à l'échelle pilote a été présenté à l'Agence nationale de la recherche et accepté. II sera mis en œuvre en 2007 et 2008. II se propose de produire 100000 vitroplants, pour recueillir tous les paramètres économiques liés à l'exploitation du procédé, et de suivre par marquage biochimique l'évolution de la qualité des cultures.

Les clones suscitent chez les planteurs de palmier à huile un intérêt croissant, dans la mesure où ce matériel permet de répondre rapidement à des besoins précis, comme la résistance à certaines maladies, ou de produire des huiles aux caractéristiques bien spécifiques. Ce programme devrait permettre, à terme, de leur fournir un matériel fiable et performant.

Tristan Durand-Gasselin,

Axel Labeyrie, Upr Amélioration génétique du palmier à huile tristan.durand-gasselin@cirad.fr

\section{Partenaires}

Agricultural Services and Development (Asd, Costa Rica), Institut de recherche pour le développement (Ird, France).

\section{Bibliographie}

Durand-Gasselin T., 2006. Vitropalm : développement préindustriel d'une production de vitroplants de palmier à huile (E. guineensis) par embryogenèse somatique. Projet Anr du programme Emergence et maturation de projets de biotechnologie à fort potentiel de valorisation.

http://www.agence-nationale-recherche.fr/ documents/aap/2006/selection/empb.pdf

Nouy B., Jacquemard J.C., Edyana Suryana H., Potier F., Konan K.E.P., Durand-Gasselin T., 2006. The expected and observed characteristics of several oil palm (Elaeis guineensis Jacq.) clones. International Oil Palm Conference, Bali, 19-23 juin 2006, 19 p.

\section{Une filiale pour exploiter un champ semencier de palmiers à huile en Thaïlande

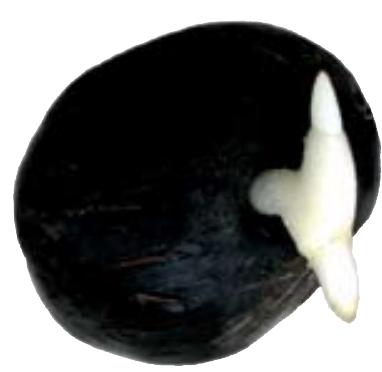 \\ Une graine germée de palmier à huile. (c) T. Durand-Gasselin/Cirad. \\ En Thaïlande, la culture du palmier à huile se développe à un rythme soutenu. Pour accompagner cet essor, le Cirad et l'Inrab, qui sont liés par un programme d'intérêt commun signé en 2001, ont proposé à la société Upoic de réaliser un champ semencier basé sur les tout derniers résultats de recherche. Il s'agit de valoriser au mieux le programme d'amélioration génétique mené par le Cirad et ses par- tenaires. Ce champ semencier entrera en production vers 2015 et sera exploité par la société Siam Elite Palm, créée à parts égales entre le Cirad et Upoic. Elle a reçu de la commission thaïlandaise des investissements I'agrément lié aux investissements étrangers prioritaires. \\ Upoic est la plus grande société de plantation thaïlandaise, avec plus de 7000 hectares de palmiers à huile. Elle achète cependant 40 à $50 \%$ des fruits qu'elle usine à des petits planteurs à qui elle sou- haite proposer en priorité un matériel performant de haute qualité. Ils bénéficieront ainsi de meilleurs revenus et Upoic d'une meilleure productivité.}

Christian Picasso, Tristan Durand-Gasselin, Upr Amélioration génétique du palmier à huile

\section{Partenaires}

Institut national des recherches agricoles du Bénin (Inrab, Bénin), United Palm Oil Industry Public Company Ltd (Upoic, Thaïlande). 
deux systèmes opposés de déterminisme du sexe - l'hétérogamétie femelle puis I'hétérogamétie mâle - et la naissance d'une nouvelle paire de chromosomes sexuels chez $O$. niloticus.

La validation de ces marqueurs de chromosomes sexuels et de leur localisation va fournir, à court terme, une technique pour déterminer le génotype sexuel des géniteurs utilisés : une étape indispensable pour un contrôle génétique du sexe chez le tilapia.

\section{Température et différenciation sexuelle}

Parallèlement, des recherches visent à identifier des marqueurs de la thermosensibilité de la différenciation sexuelle. En effet, un traitement de dix jours à forte température $\left(34{ }^{\circ} \mathrm{C}\right)$ produit, chez certaines descendances, des populations majoritairement mâles (jusqu'à 100 \% de mâles) alors que, pour d'autres, il n'a aucun effet. Des études ont montré que les facteurs de thermosensibilité sont héritables et apportés par les deux parents. Sur la base de ces résultats, le Cirad a mis en place une collaboration avec une équipe allemande pour identifier, par des approches de génomique, des marqueurs de thermosensibilité en utilisant deux lignées de tilapia, I'une insensible à la température et l'autre hypersensible.

L'étude des chromosomes sexuels des deux espèces va se poursuivre dans le cadre d'un nouveau projet de recherche, et un vaste programme international va s'engager avec le séquençage des extrémités des 35000 grands fragments qui couvrent le génome du tilapia et son séquençage complet, qui sera réalisé dans le cadre du Cichlid Genome Consortium.

- Jean-François Baroiller,

Upr Aquaculture et gestion des ressources aquatiques jean-francois.baroiller@cirad.fr

\section{Partenaires}

Centre national de la recherche scientifique (Cnrs, France), Institute of Animal Science
(Israël), Muséum national d'histoire naturelle (Mnhn, France), université du New Hampshire (Etats-Unis), université de Würzburg (Allemagne).

\section{Bibliographie}

Baroiller J.F., D'Cotta H., Bezault E., Coutanceau J.P., Ozouf-Costaz C., Cnaani A., Kocher T., Pepey E., D'Hont A., Hulata G., Volff J.N., Bienvenu D., Chevassus B., 2006. Evolution des systèmes de déterminisme génétique du sexe dans le groupe des tilapias. In : Réunion du groupe transversal différenciation des gonades chez les vertébrés, 3 avril 2006, Paris.

Baroiller J.F., D'Cotta H., Bezault E., Coutanceau J.P., Ozouf-Costaz C., Cnaani A., Kocher T., Pepey E., D'Hont A., Hulata G., Volff J.N., Bienvenu D., Chevassus B., 2006. Basis of sex determination and sex differentiation for sex control in tilapia. In : Proceedings of the joint symposium on animal production, 7-10 novembre 2006, Tainan. Taiwan, Council of Agriculture.

Cnaani A., Lee B.Y., Zilberman N., OzoufCostaz C., Hulata G., Ron M., D'Hont A., Baroiller J.F., D'Cotta H., Penman D.J., Tomasino E., Coutanceau J.P., Pepey E., Shirak A., Kocher T., 2006. Rapid evolution of the sex determination mechanism among closely related cichlid fish species. Journal of Sexual Development (sous presse).

\section{- — Peste bovine et peste des petits ruminants : I'ARN interférent au coeur d'un futur traitement}

La peste bovine et la peste des petits ruminants restent des maladies virales graves malgré la vaccination. Une nouvelle génération d'antiviraux, qui inhibent à plus de $80 \%$ la réplication des morbilivirus responsables de ces maladies, vient d'être mise au point grâce à l'interférence ARN. C'est la voie ouverte au développement de vaccins thérapeutiques, utilisables chez l'animal déjà infecté.

La peste bovine touche les bovins domestiques, les buffles, les yaks, mais aussi les ovins, les caprins, certaines races de porcs et toute une série d'espèces sauvages. Malgré une campagne de vaccination préventive généralisée, qui a presque abouti à l'éradication de la maladie à l'échelle mondiale, des foyers $d^{\prime}$ infection persistent en Somalie. Et il n'existe aucun traitement curatif. Quant à la peste des petits ruminants, elle est présente en Afrique, dans la péninsule arabique, au Moyen-Orient et en Inde. Les vaccins préventifs sont efficaces mais sensibles à la chaleur et, là encore, aucun traitement n'est disponible.

Depuis le début de l'année 2005, le Cirad met au point une nouvelle méthode de lutte contre ces pathologies fondée sur une technique novatrice 
issue de la génétique moléculaire : I'interférence ARN. Ce mécanisme biologique naturel permet aux organismes pluricellulaires de contrôler le niveau $\mathrm{d}^{\prime}$ expression de certains de leurs gènes. Il met en jeu de courts fragments d'ARN - les ARN interférents - capables d'empêcher la lecture et la traduction en protéines du code génétique porté par I'ADN. Ces ARN interférents se lient spécifiquement avec l'ARN messager cible, entraînant sa dégradation et, de ce fait, l'inhibition de la protéine correspondante.

\section{Les ARN interférents inhibent la réplication des virus à plus de $80 \%$}

Les chercheurs du Cirad viennent d'identifier trois ARN interférents de synthèse capables $d^{\prime}$ inhiber in vitro, à plus de $80 \%$, la réplication des virus de la peste des petits ruminants et de la peste bovine. Ils sont ciblés sur l'ARN messager du gène de la nucléoprotéine des virus responsables. Le processus de multiplication virale est alors bloqué. Ces résultats ont fait l'objet d'un dépôt de brevet en décembre 2005.

La deuxième phase de recherche a démarré. Elle consiste à tester in vivo cette nouvelle génération d'antiviraux sur l'animal infecté. Le transfert de ces ARN interférents dans I'animal infecté est envisagé grâce à un vecteur viral, habituellement utilisé comme vaccin. Si l'inhibition de la réplication du virus chez l'animal malade est effectivement observée, il sera possible de développer des vaccins thérapeutiques, sûrs et efficaces, contre les virus des pestes bovines et des petits ruminants.

Ces travaux, très prometteurs, ouvrent $d^{\prime}$ 'autres perspectives en matière de santé animale. Ils pourraient intéresser des virus tels que celui de la grippe aviaire ou celui de la peste porcine africaine. Pour ce dernier, I'application de l'interférence ARN comme méthode de lutte serait alors une avancée majeure, puisqu'il n'existe actuellement aucun vaccin préventif.
Emmanuel Albina,

Dominique Martinez, Upr Contrôle des maladies animales exotiques et émergentes, Umr Biologie et génétique des interactions plante-parasite (Bgpi) emmanuel.albina@cirad.fr

\section{Bibliographie}

Almeida R.S., Keita D., Libeau G., Albina E., 2006. Control of ruminant morbillivirus replication by siRNAs. In : RNAi Europe, 28-29 septembre 2006, Prague, République tchèque.

Keita D., 2006. Utilisation de la PCR quantitative pour évaluer l'efficacité

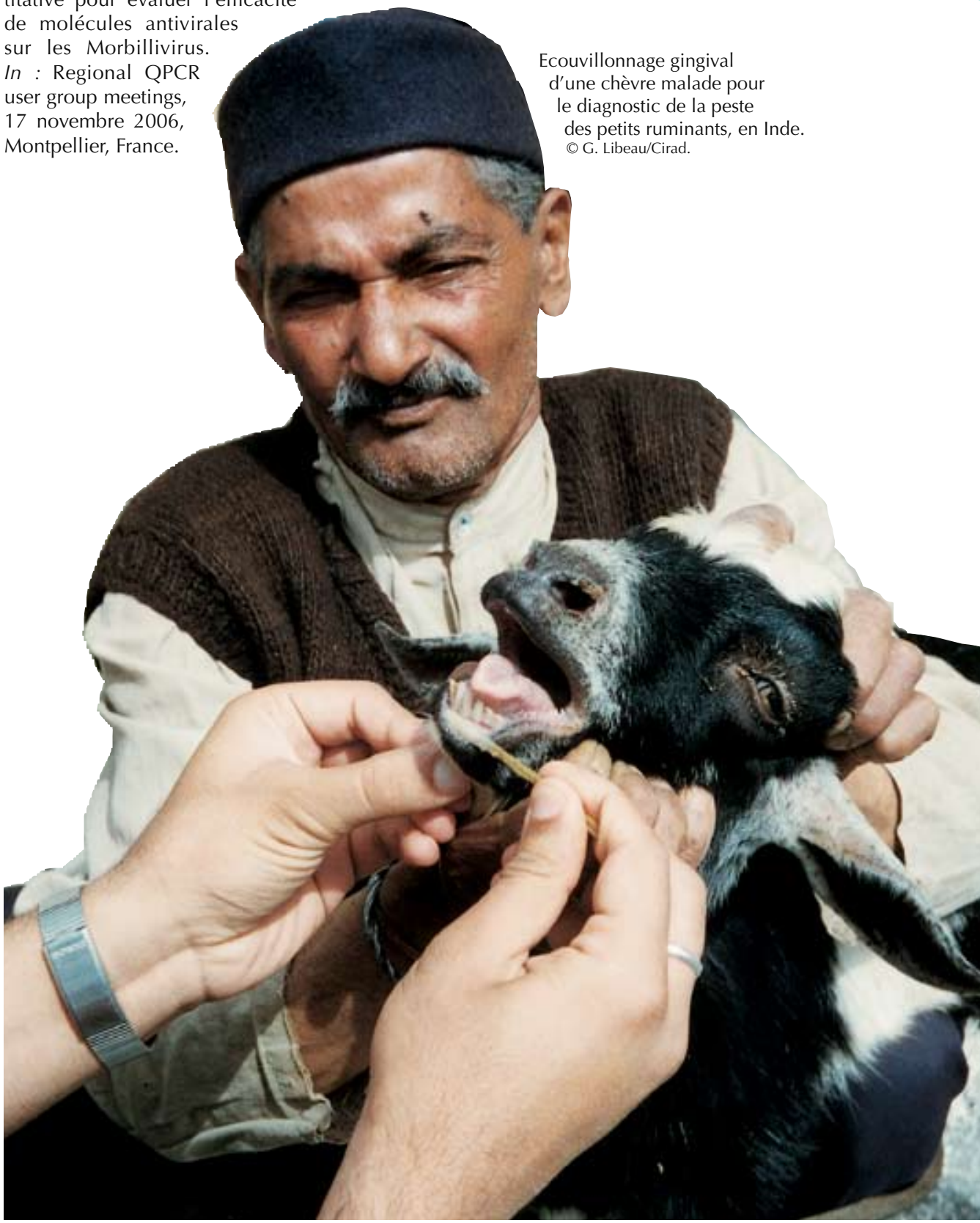

Keita D., Almeida R.S., 2006. RNAi et Morbillivirus. Les ARN messagers, micros et interférents. In : Applied biosystems and ambion, 5 octobre 2006, Lyon, France.

Keita D., Almeida R.S., Libeau G., Albina E., 2006. RNA interference for the control of Morbillivirus infection. In : 7th international congress of veterinary virology, 24-27 septembre 2006, Lisbonne, Portugal. European Society for Veterinary Virology.

Ces résultats font l'objet d'une demande de brevet déposée le 21 décembre 2005 $\left(n^{\circ}\right.$ 0513029), avec une extension internationale ( $n^{\circ}$ PCT/FR2006/002819). 


\title{
—. Les indications géographiques dans les pays émergents
}

\begin{abstract}
Café Antigua du Guatemala, mantecoso péruvien, piment de Mamou en Guinée, agneau du Karoo en Afrique du Sud, riz parfumé Surin Hom Mali de Thaïlande, thé de Darjeeling... Désigner des produits agricoles et agroalimentaires originaux par leur lieu de récolte ou de fabrication est d'un usage ancien et largement répandu. Les pays émergents, conscients que ce signe distinctif leur permettra de mieux valoriser leurs productions, s'engagent dans la mise en place d'un cadre législatif et réglementaire approprié. Le Cirad accompagne plusieurs de ces pays dans cette démarche.
\end{abstract}

La notion d'indication géographique est assez récente. Elle a d'abord été codifiée et transcrite en droit en France au début du $x^{\mathrm{e}}$ siècle. Les appellations d'origine, outil de reconnaissance du patrimoine agricole et agroalimentaire, y ont été placées en 1935 sous la responsabilité de I'Inao (aujourd'hui Institut national de l'origine et de la qualité). Sur le plan européen et international, elles ont fait I'objet de divers accords. En 1994, I'Organisation mondiale du commerce a reconnu les indications géographiques comme un droit de propriété intellectuelle à part entière, au même titre que les brevets ou les marques. Les indications géographiques, qui désignent des produits dont une qualité, une caractéristique ou la réputation est due essentiellement à leur zone d'origine, sont devenues un élément important du débat sur le commerce mondial.

Le fromage frais quesillo sert à fabriquer le mantecoso au Pérou. (C) F. Boucher/Cirad.

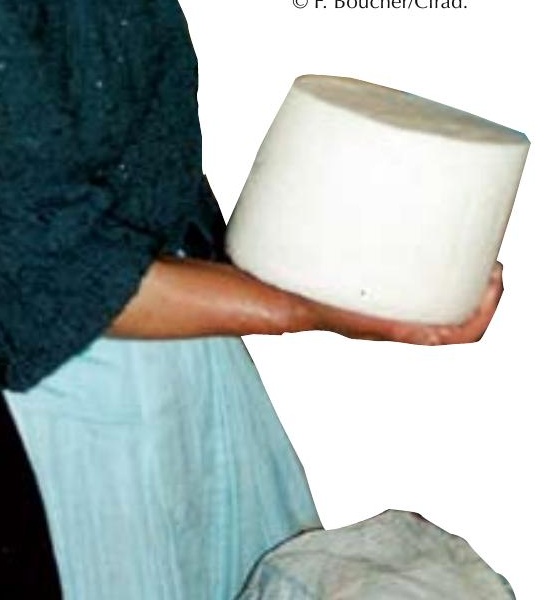

Les pays émergents commencent à s'approprier le concept d'indication géographique, conscients que ce signe distinctif leur permettra, dans le contexte d'un marché de plus en plus ouvert, de mieux valoriser leurs productions originales, tant sur le marché intérieur qu'à l'exportation. Ce qui passe par la définition d'un cadre législatif et réglementaire et par l'identification et la sélection de produits candidats. Le Cirad, qui a signé en 2004 une convention avec I'Inao, accompagne plusieurs pays émergents dans cette évolution.

\section{En Afrique australe et au Brésil, un potentiel à découvrir}

En Afrique du Sud, il n'existe pas de législation spécifique pour la protection des indications géographiques. Cependant, partant du constat de la spécificité de certaines ressources locales, un débat national s'est engagé en 2004 sur l'opportunité de développer cette approche. Deux projets, coordonnés par l'université de Pretoria et le Cirad, ont débuté dans la région, en Afrique du Sud et en Namibie. II s'agit d'explorer le potentiel des indications géographiques comme moyen d'accès aux marchés et de développement rural, mais aussi comme outil de conservation de la biodiversité. Plusieurs produits sont concernés : les plantes à infusions rooibos et honeybush, I'agneau du Karoo, le mohair de Candeboo, I'huile de graines de melon du Kalahari et les fourrures de
Karakul. Par l'intermédiaire de réunions et d'ateliers, le dialogue s'est établi entre les professionnels, les institutions et les acteurs de la recherche. Dans le cas le plus avancé, celui du rooibos, le dossier en vue d'une certification nationale puis européenne a été constitué.

Au Brésil, les indications géographiques sont reconnues par une loi fédérale depuis 1996, mais leur développement est récent. Le Cirad et ses partenaires brésiliens réalisent des recherches sur les conditions de développement de ces signes distinctifs et sur leur intérêt dans la protection des produits d'exportation comme dans la promotion de filières à l'échelon local. Des expériences sont échangées. Des études spécifiques viennent épauler les producteurs dans la gestion ou la création d'indications géographiques pour des produits comme les vins du Vale dos Vinhedos et d'Urussanga, la pomme de São Joaquim ou les huîtres de Florianópolis.

\section{Indonésie et Inde : des indications géographiques mieux reconnues}

En Indonésie, les produits régionaux les plus prestigieux, comme le café toraja ou le poivre blanc de Muntok, sont souvent exportés. Mais il n'est pas rare que les noms géographiques soient déposés par des négociants comme marques commerciales dans les pays d'exportation, sans qu'il y ait de retombées finan- 
cières pour les producteurs. D'où la décision du gouvernement indonésien d'établir un cadre législatif qui organise la reconnaissance des indications géographiques et de lancer un projet pilote sur le café. Le projet sur le café Arabica de Kintamani, dans le nord de Bali, est mené par l'institut indonésien du café et du cacao (Iccri) et les autorités locales en lien avec le Cirad et I'Inao. Il a démontré la forte capacité de mobilisation des acteurs autour de cette notion et s'achève avec la rédaction du cahier des charges de la certification. En amenant les producteurs et transformateurs à définir des règles communes de production et de délimitation, les indications géographiques sont à même de renforcer les processus de développement rural.

Enfin I'Inde, pays émergent très actif dans les négociations internationales sur le commerce, a engagé une politique vigoureuse pour la reconnaissance des indications géographiques. Le cadre juridique adopté permet non seulement à des produits agroalimentaires mais aussi à des produits textiles et artisanaux de bénéficier $d^{\prime}$ une protection de leurs dénominations géographiques. Le Cirad et ses partenaires s'intéressent à la mise en œuvre des indications géographiques dans ce pays de tradition juridique anglo-saxonne. Ils se penchent aussi sur les nouvelles finalités des indications géographiques, telles que la protection de la diversité biologique et des savoirs traditionnels. Le cahier des charges est alors envisagé comme un moyen de codifier des savoirs anciens ou des pratiques respectueuses de l'écosystème. Une analyse comparée avec la situation en Europe permettra de dessiner des perspectives pour le suivi des négociations en vue d'une meilleure reconnaissance internationale des indications géographiques.

- Denis Sautier, Umr Innovation et développement dans I'agriculture et l'agroalimentaire (Innovation) denis.sautier@cirad.fr

\section{Partenaires}

Agridea (Suisse), Association OriGln (Belgique), Ecole nationale des ingénieurs des techniques agricoles de Clermont-Ferrand (France), Empresa Brasileira de Pesquisa Agropecuária (Embrapa, Brésil), Indonesian Coffee and Cocoa Research Institute (Iccri, Indonésie), Institut national de I'origine et de la qualité (Inao, France), Institut national de la recherche agronomique (Inra, France), Réseau SinerGl, Systèmes agroalimentaires localisés (Syal), université agricole de Wageningen (Pays-Bas), universités de Florence et de Parme (Italie), université de Latvia (Lettonie), universités de Newcastle et d'Edimbourg (Royaume-Uni), université fédérale du Santa Catarina (Brésil).

\section{Bibliographie}

Kop P.V.D., Sautier D., Gerz A. (éd.), 2006. Origin-based products: Lessons for pro-poor market development. Amsterdam, Kit, Montpellier, Cirad, Kit Bulletin n 372, 104 p. http://www.mamud.com/originbasedproducts. htm
Marie-Vivien D., Thevenod-Mottet E., 2007. Quelle reconnaissance pour les indications géographiques des pays tiers en Europe? Enjeux découlant de la décision de l'organe de règlement des différends de l'Omc. Economie rurale (sous presse).

Sautier D., Bienabe E., Sallée B., 2005. Les indications géographiques dans les pays du Sud : potentiels et enjeux. In : Produits agricoles et alimentaires d'origine : enjeux et acquis scientifiques, 17-18 novembre 2005, Paris. Paris, Inra, Inao.

Sautier D., Bienabe E., Cerdan C., 2007. Geographical indications in developing countries: potentials and stakes. In : Geographical indications for food: local development and global recognition, Sylvander B., Barham E. (éd.). Wallingford, Cabi (sous presse).

\section{Sites}

http://gis-syal.agropolis.fr

http://www.origin-food.org

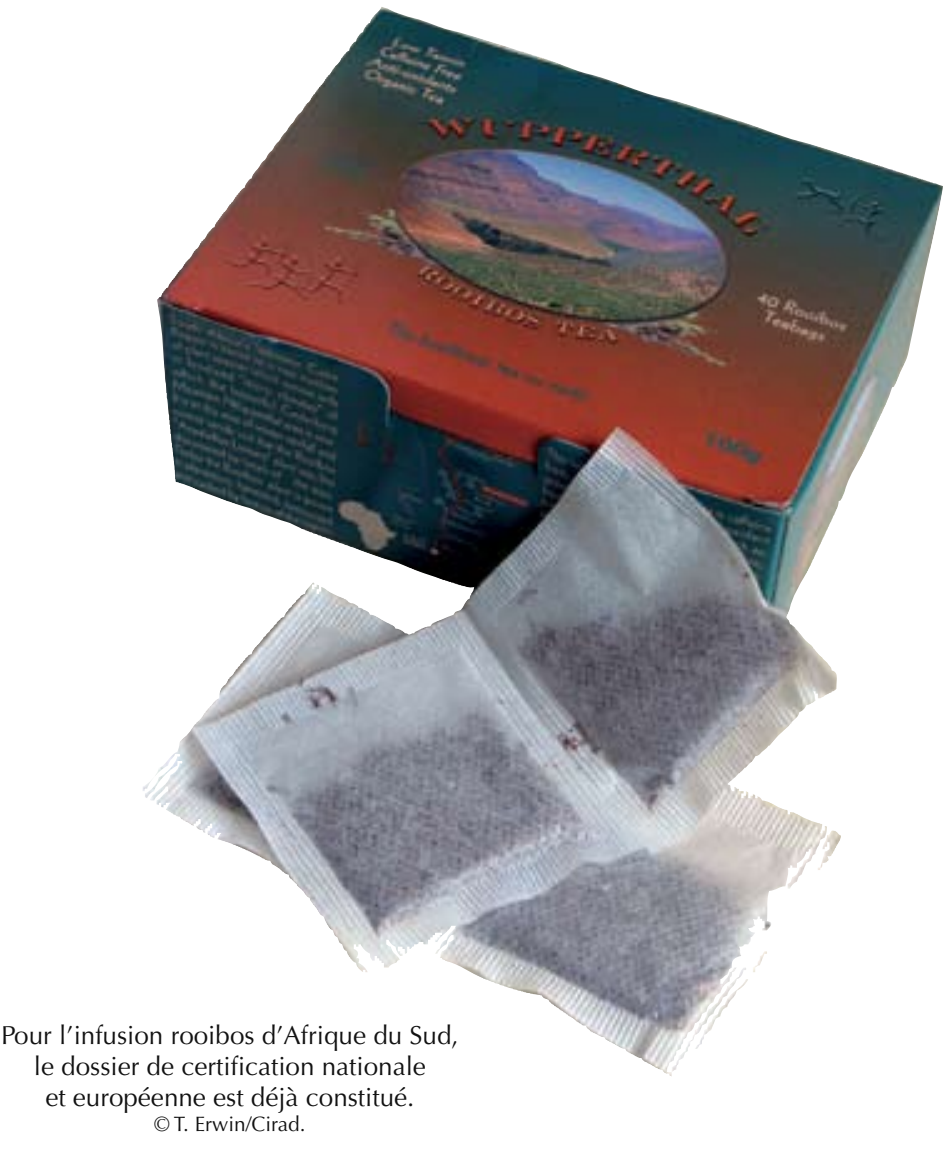




\title{
Anticiper.
}

\section{- Agrimonde : agricultures et alimentations du monde en 2050}

\begin{abstract}
Pour les agricultures du monde, l'un des défis majeurs des prochaines décennies sera de produire plus et mieux pour satisfaire durablement des besoins de biens alimentaires et non alimentaires en forte croissance. Quels scénarios d'évolution peut-on envisager non seulement pour la France et l'Europe, mais aussi pour toutes les grandes régions, en particulier tropicales ? Comment la recherche agronomique peut-elle aider à relever ce défi ? L'exercice prospectif Agrimonde, mené conjointement par l'Inra et le Cirad, devrait permettre de clarifier ces questions, de discuter l'avenir de la recherche publique française et de préciser ses orientations pour lui permettre de mieux se positionner au sein de la communauté scientifique internationale.
\end{abstract}

Les dynamiques en cours — l'augmentation de la population mondiale, les changements de systèmes alimentaires dans les pays émergents, la croissance de la demande en bioénergies et autres produits non alimentaires, la raréfaction ou la dégradation des ressources naturelles — vont bouleverser les offres et demandes nationales. Parvenir à préserver les ressources de la planète tout en réduisant la pauvreté et les inégalités constitue I'un des enjeux majeurs pour le développement durable, mais aussi pour les équilibres géopolitiques planétaires et les relations entre les pays du Nord et ceux du Sud.

\section{Un exercice prospectif à l'horizon 2050}

L'exercice prospectif Agrimonde, Agricultures et alimentations du monde en 2050, qui a débuté en 2006 et se poursuivra en 2007, devrait permettre d'en- visager la place des agricultures dans les différents scénarios de transformation du monde et d'identifier les questions fondamentales auxquelles la recherche agronomique sera confrontée. Il fournira au Cirad et à l'Inra les moyens d'anticiper ces évolutions et de préparer l'avenir en termes de dispositif et d'orientation de la recherche publique, comme en termes de positionnement stratégique international.

L'ensemble du travail a notamment recours aux résultats du Millennium Ecosystem Assessment (Mea), une opération internationale d'évaluation et de prospective sur les écosystèmes commanditée par les Nations unies, qui s'est déroulée entre 2001 et 2005. II s'inscrira dans la perspective des travaux actuels de I'International Agricultural Assessment of Science and Technologies for Development (laastd), une opération de prospective sur l'agriculture lancée en 2002 par les Nations unies et la Banque mondiale.

\section{Une plate-forme de réflexion}

Face à la profusion des analyses et des informations sur les agricultures et les alimentations du monde, Agrimonde se veut d'abord un outil d'aide à la réflexion prospective sur les scénarios d'évolution existants. Son objectif est d'aborder la question des rôles possibles de la recherche, des politiques publiques et des régulations internationales.

L'analyse stratégique de ces scénarios constitue le deuxième volet de l'exercice. II s'agit de croiser les différents scénarios de production et de consommation en matière agricole et alimentaire pour en évaluer les implications environnementales, économiques et politiques, qui elles-mêmes déterminent les questions posées à la recherche agronomique. Les paramètres sont multiples, tant pour la consommation 
que pour la demande. L'analyse critique s'effectue à partir d'une déconstruction et $d^{\prime}$ une reconstruction des scénarios existants, qui permet de signaler leurs impasses et leurs manques éventuels, et de les compléter.
Enfin, les analyses et les réflexions relatives à ces scénarios seront largement débattues, dans une dernière étape, pour aboutir à des recommandations et à des perspectives pour prolonger l'exploitation de la plate-forme.

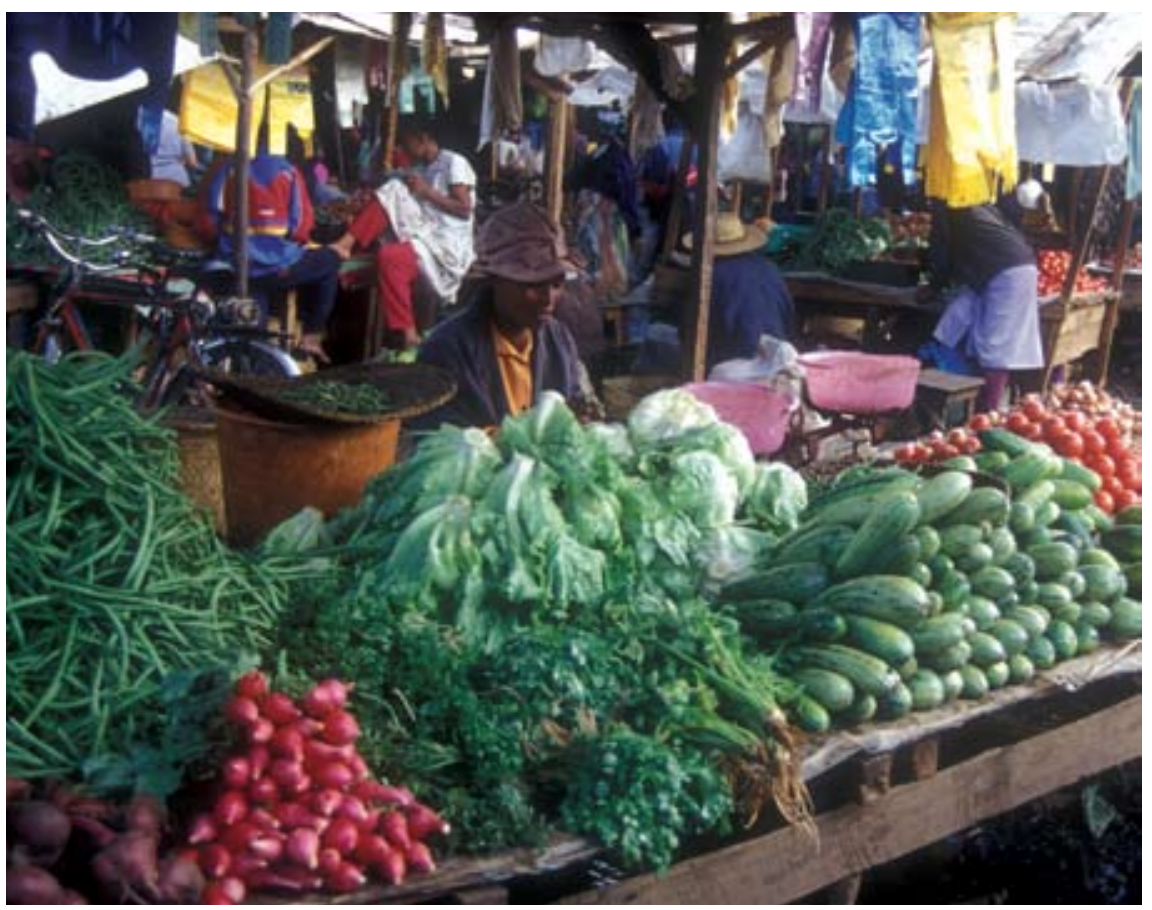

Agrimonde doit permettre aux chercheurs de mieux comprendre les implications des grands changements attendus et de mieux valoriser leurs compétences, en particulier au sein des groupes d'experts internationaux, qui se sont multipliés ces dernières années. Pour l'Inra et le Cirad, I'objectif est de définir leurs orientations scientifiques et de renforcer leur participation aux grands débats internationaux pour mieux répondre aux enjeux agricoles et alimentaires de demain.

- $\bigcirc$ Patrick Caron, Bruno Dorin,

Umr Centre international de recherche sur l'environnement et le développement (Cired)

patrick.caron@cirad.fr bruno.dorin@cirad.fr

\section{Partenaire}

Institut national de la recherche agronomique (Inra).

Un marché sur la côte est de Madagascar. (c) C.Lanaud/Cirad.

\section{- 0 Les maladies émergentes : un défi pour la recherche}

Les changements climatiques, les déséquilibres écologiques et l'intensification des échanges provoquent l'apparition de maladies nouvelles ou la recrudescence d'infections connues, que ce soit dans le domaine de la santé végétale, animale ou humaine. Les crises sanitaires récentes imposent de nouveaux modes d'intervention. Il s'agit maintenant de prévoir, de dépister précocement et d'étudier préventivement, c'est-à-dire dans leurs écosystèmes d'origine, les maladies qui risquent de poser des problèmes dans l'avenir.

Les maladies émergentes tiennent une place de plus en plus importante en santé humaine, animale, mais aussi végétale. Elles correspondent, en fait, à plusieurs situations : ce sont soit des maladies nouvelles, dont l'agent pathogène était inconnu, soit des maladies connues, mais dont le mode de transmission, I'expression ou l'adaptation aux hôtes se sont brusquement modifiés au point de provoquer des affections plus sévères, soit encore des maladies ou ravageurs qui se propagent vers de nouveaux territoires jusqu'alors indemnes. Ces maladies, souvent d'origine 
Les études qu'il mène sur le diagnostic, l'épidémiologie, la modélisation et la gestion intégrée des bioagresseurs dans des contextes diversifiés doivent permettre d'anticiper ces risques et d'apporter des réponses aux problèmes dès leur émergence. Ainsi, par exemple, le Cirad participe au réseau caribéen de surveillance de la maladie des raies noires du bananier qui se met en place pour prévenir l'arrivée de cette maladie, actuellement aux portes des petites Antilles, et pour intervenir rapidement en cas de détection. II fait également partie du réseau d'excellence Endure sur les stratégies durables de protection des cultures. Cette participation permettra d'intégrer les dispositifs de recherche du Sud au sein de ce réseau européen.

Les enjeux sont considérables, pour la santé animale comme pour la protection des cultures. Une réflexion méthodologique commune doit s'engager entre ces deux domaines. Leurs démarches respectives font appel aux mêmes outils - diagnostic, épidémiologie, modélisation, prévision et gestion des risques
- et ne peuvent que s'enrichir l'une l'autre.

Q Renaud Lancelot, Jean-Louis Sarah renaud.lancelot@cirad.fr jean-louis.sarah@cirad.fr

\section{Sites}

Eden (Emerging diseases in a changing European environment) :

http://www.eden-fp6project.net/

Endure (European network for the durable exploitation of crop protection strategies) : http://www.endure-network.eu

\section{Risques phytosanitaires émergents : le Huanglongbing des agrumes}

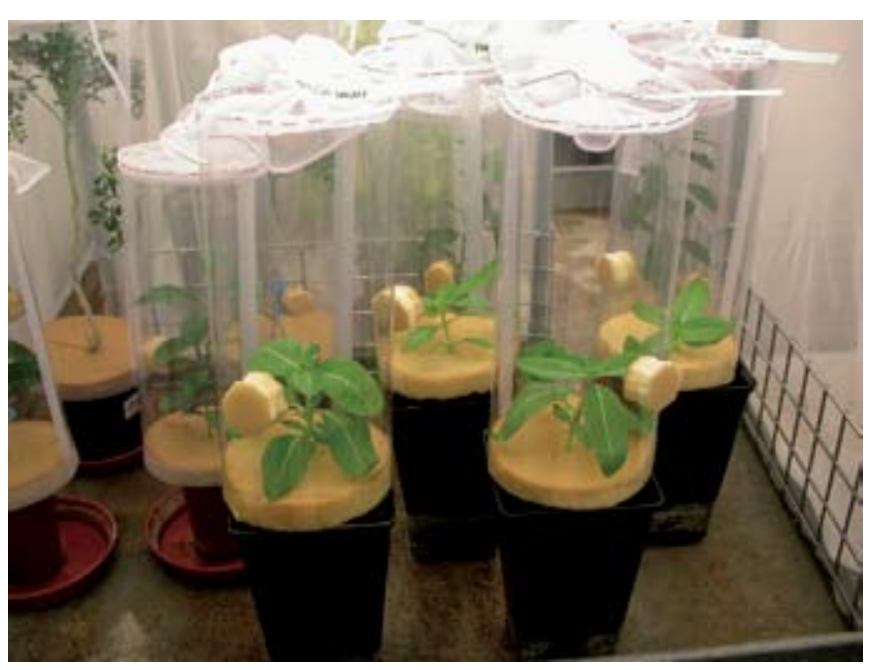

Cage d'élevage de Diaphorina citri en insectarium. (c) F. Gatineau/Cirad.

Le Huanglongbing est une maladie qui affecte tous les agrumes. Il est dû à une bactérie du phloème, Candidatus Liberibacter sp., transmise par des insectes psyllidés. Cette maladie présente en Asie et en Afrique vient d'être identifiée au Brésil et aux Etats-Unis, où elle menace désormais sérieusement la production d'agrumes, première production fruitière au monde. Pour éradiquer ce fléau, le Cirad explore de nouvelles méthodes de lutte.

Jusqu'à présent, les stratégies de lutte contre le Huanglongbing reposaient sur l'éradication ou la réduction des populations des insectes vecteurs, Diaphorina citri et Trioza erytrea, par une lutte insecticide ou biologique, et sur la prophylaxie, aucune résistance ou tolérance naturelle à la maladie n'étant connue chez les Citrus cultivés ou sauvages. Or la transmission de Candidatus Liberibacter sp. par ses vecteurs est une étape capitale dans le schéma épidémiologique de la maladie. Sans cette transmission entomophile hautement spécifique, le contrôle, voire l'éradication, de la maladie pourrait être envisageable.

Compte tenu des récentes avancées dans l'étude des maladies transmises par les insectes et dans les techniques de transformation génétique, le Cirad oriente ses recherches vers une stratégie de lutte qui reposerait, non plus sur l'élimination ou la réduction des populations d'insectes vecteurs, mais sur la modification de leur capacité à transmettre la bactérie. Une série d'études préalables a déjà été engagée sur les mécanismes cellulaires de la translocation de la bactérie dans les tissus du psylle et sur la transgenèse directe ou indirecte des lignées germinales.

D Frédéric Gatineau, Upr Jaunissement mortel du cocotier et greening des agrumes frederic.gatineau@cirad.fr

\section{Bibliographie}

Gatineau F., 2006. Development of an alternative and sustainable strategy to fight Huanglongbing disease: towards modified vector competence of insect vector populations. In : Huanglongbing workshop international, Ribeirão Preto, São Paulo, Brésil, 16-20 juillet 2006.

Gatineau F., Bonnot F., Hien N.T.D., Loc H.T., Tuan T.M., Tuyen N.D., Truc N.T.N., 2006. Effects of 2 insecticide practices on population dynamics of Diaphorina citri and on Huanglongbing incidence in South Vietnam. In : Huanglongbing workshop international, Ribeirão Preto, São Paulo, Brésil, 16-20 juillet 2006. 
Les indicateurs 

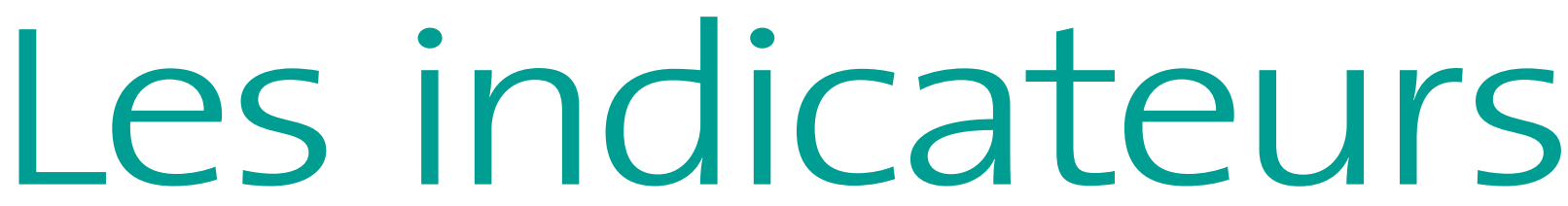

L'année 2006 est une année de transition pour le Cirad, entre la mise en place de ses unités de recherche, qui a eu lieu en 2005, et la réorganisation de ses départements, qui est effective en 2007. Le contrat d'objectifs conclu par le Cirad avec ses ministères de tutelle pour la période 2001-2005 est arrivé à son terme et aucun nouveau contrat n'a été signé en 2006. Les indicateurs, qui sont globalement ceux du précédent contrat, couvrent les aspects les plus significatifs de l'activité du Cirad et présentent, pour certains d'entre eux, l'évolution au cours des six dernières années. Compte tenu de la réorganisation du Cirad et de la mise en place d'un nouveau système d'information pour les ressources humaines, tous les indicateurs n'ont cependant pas pu être rassemblés.

\section{Les moyens humains et l'évolution des compétences}

\section{Les moyens humains}

L'effectif global accuse une légère baisse par rapport à 2005 : il passe de 1850 à 1825 . Cette évolution, sensible depuis 2002, ne touche pas toutes les catégories de personnel, puisque, de 2001 à 2006, I'effectif des cadres progressait de 57 agents, celui des agents de maîtrise de 31 , tandis que le nombre de collaborateurs diminuait de 122 (figure 1). Au cours de cette période, le profil des agents du Cirad s'est profondément modifié, sous l'effet d'une politique visant une meilleure qualification des salariés.

L'effectif diminue surtout en France métropolitaine, avec 31 agents de moins, alors que les affectations outremer progressent de 6 agents. Cette progression profite essentiellement à I'outre-mer français et à l'Amérique latine ; les affectations en Afrique diminuent de 5 agents (figures 2 et 3 ).

En 2006, les missions ont une évolution positive de 8,7 équivalents temps plein et bénéficient surtout à l'Asie et l'Océanie $(+6,3)$ et à l'Afrique $(+3)$. Elles diminuent globalement de 14,1\% par rapport à l'année 2002 (figure 4).
Par rapport à 2001, les effectifs diminuent en Afrique (-21) et dans I'outremer français $(-12)$ et progressent dans toutes les autres affectations, ce qui témoigne d'une politique de diversification, en particulier en direction de I'Asie et de l'Océanie (+ 9).
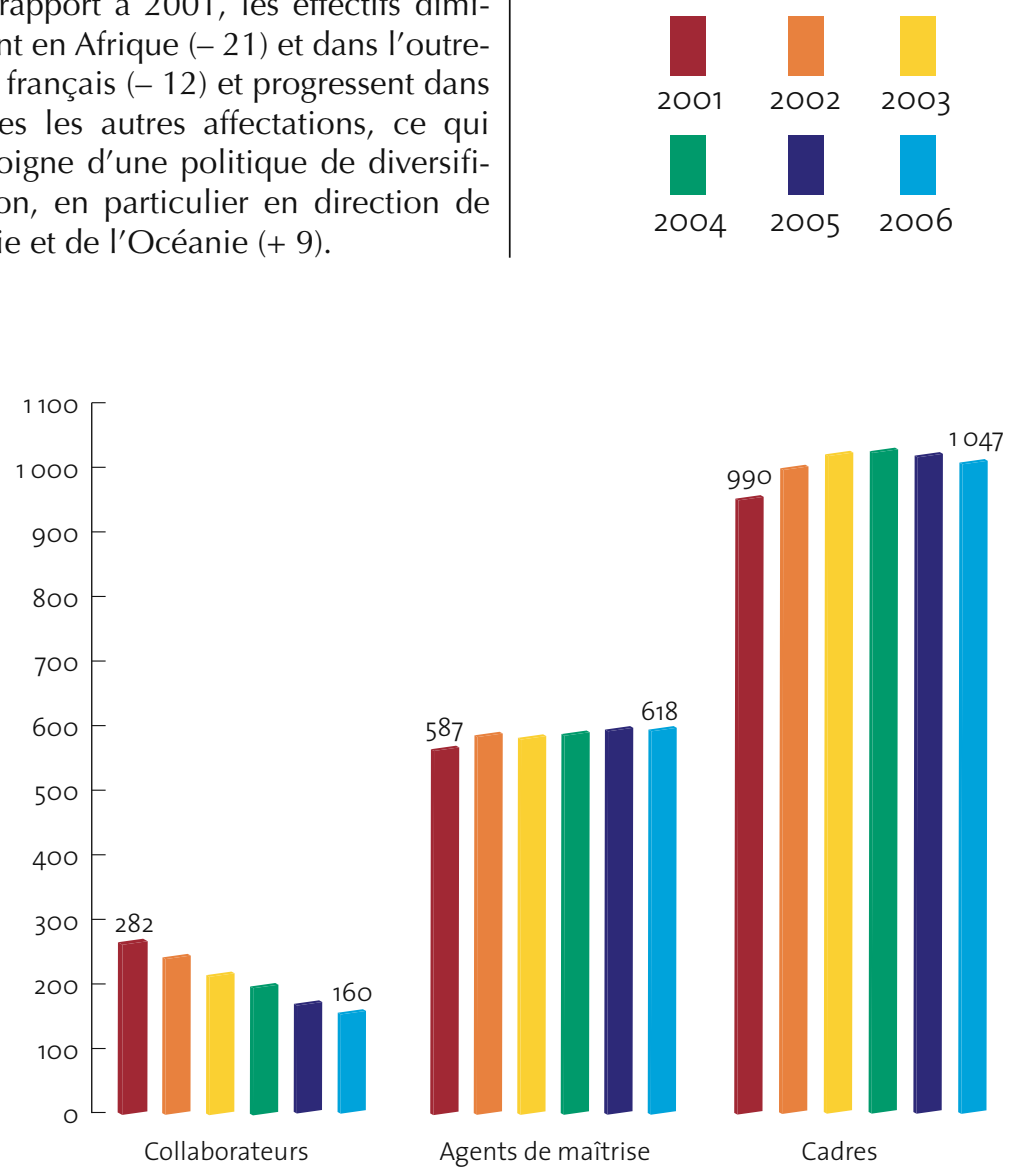

Figure 1. Répartition des effectifs selon les catégories de personnel. 


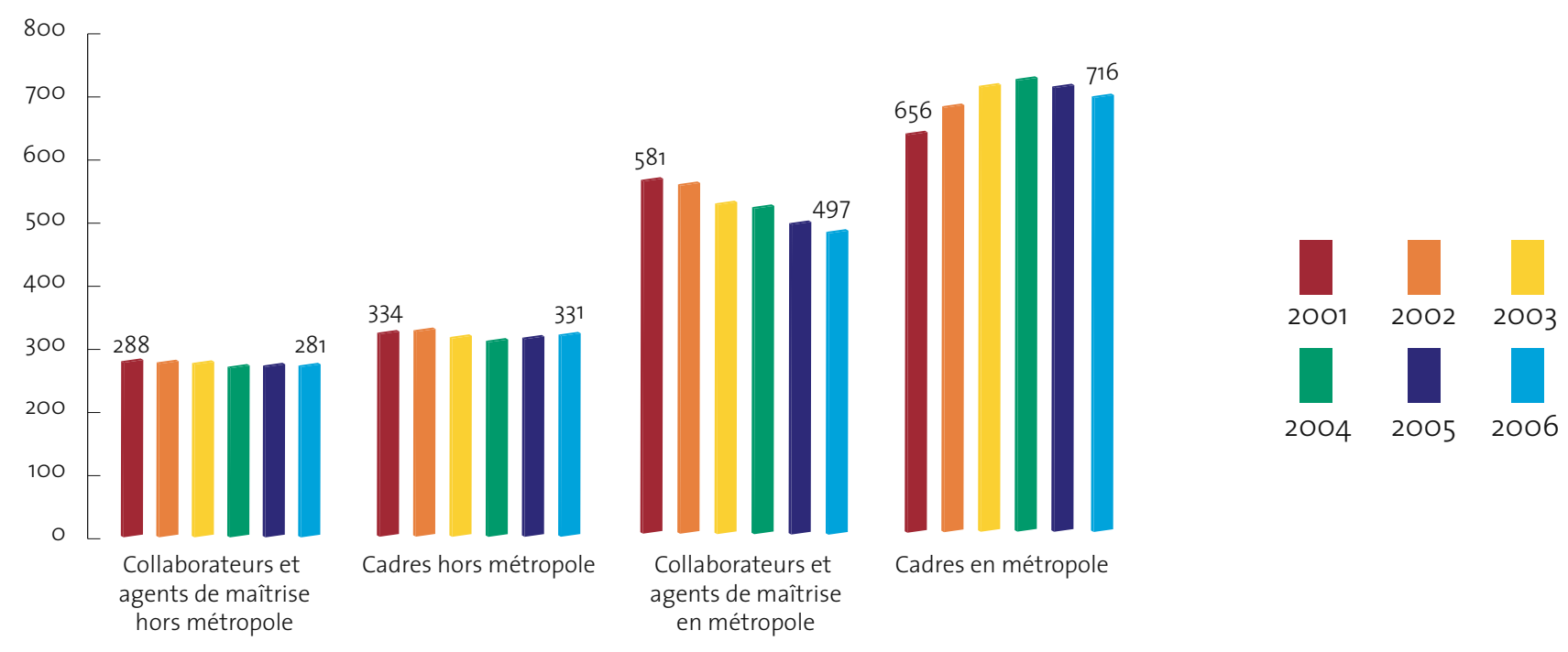

Figure 2. Répartition des effectifs selon la localisation.
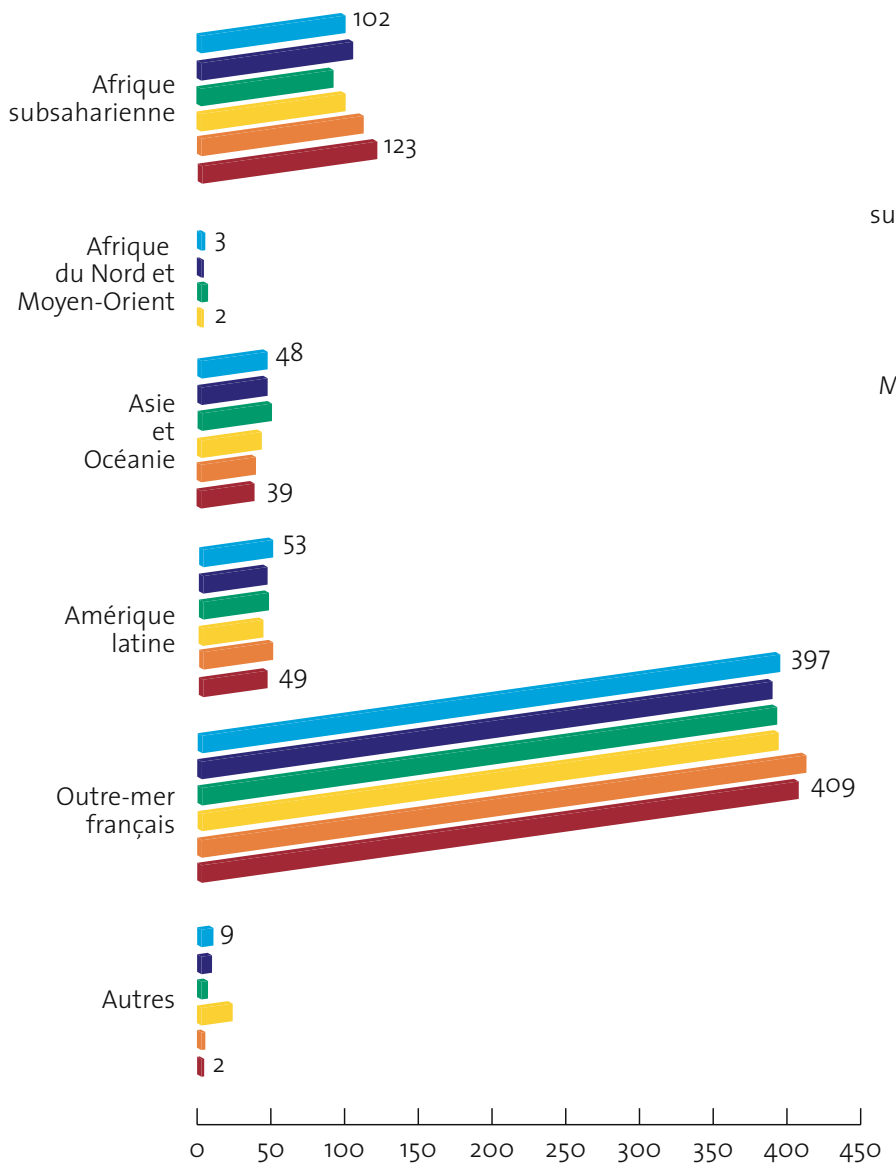

Figure 3. Répartition des effectifs en affectation.

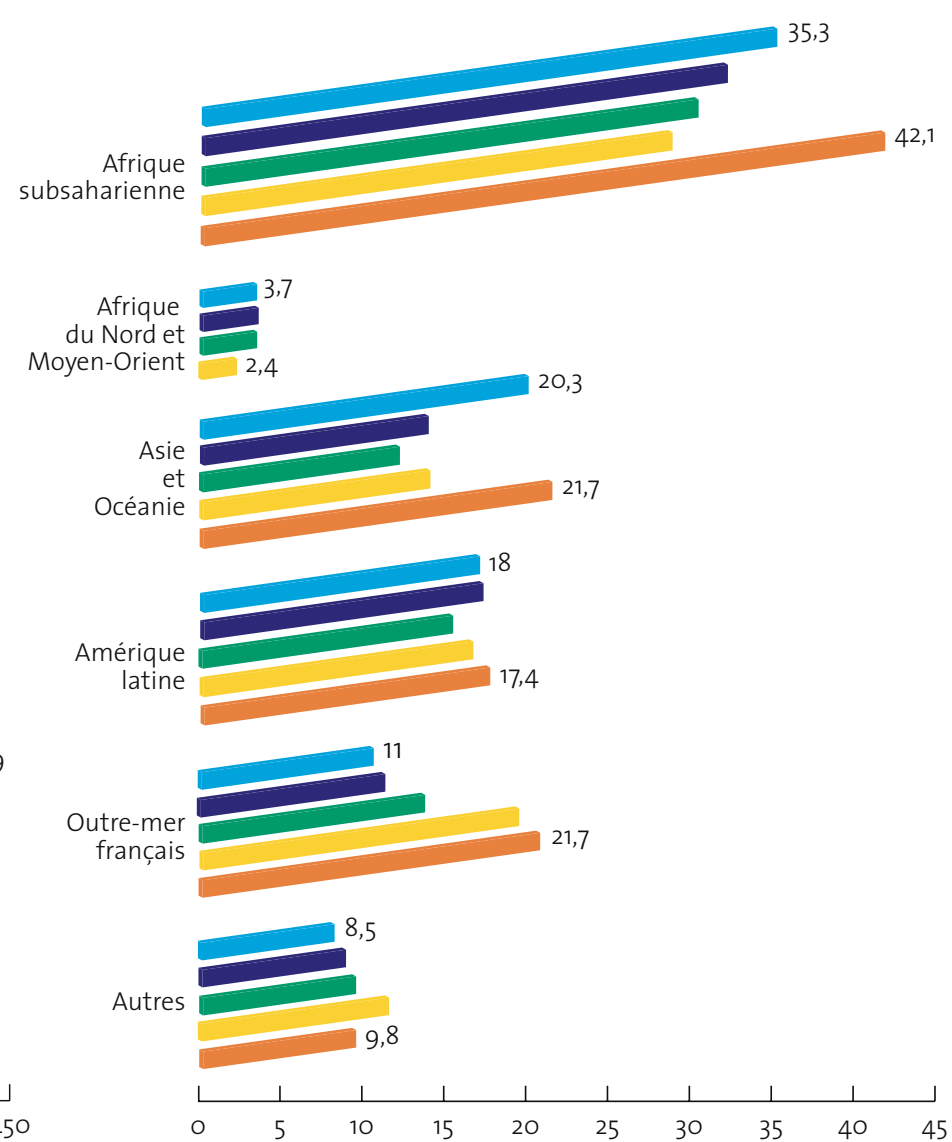

Figure 4. Répartition des missions, en équivalent temps plein. 
Le Cirad salarie 788 cadres scientifiques et bénéficie de la collaboration de 36 cadres associés, dont 8 sont mis à disposition par l'Inra et 11 par le ministère de l'Agriculture. Le ministère des Affaires étrangères met à la disposition du Cirad 10 cadres assistants techniques au développement. Si le Cirad bénéficie de cadres mis à disposition par des organismes extérieurs, il contribue à l'activité de
11 centres du Gcrai (Groupe consultatif pour la recherche agricole internationale), où 20 agents sont affectés en 2006.

Le nombre de cadres d'origine européenne diminue légèrement et ce un peu plus vite que l'effectif global des cadres, ce qui entraîne une baisse en pourcentage de 0,2 \%. Depuis l'année 2000, le nombre de cadres européens est passé de 24 à 37, soit de 2,6\% à 3,5\% (figure 5).

Malgré la baisse générale de l'effectif, la tendance à la féminisation des cadres s'est accentuée en 2006. Ainsi, le nombre de femmes cadres est passé de 266 en 2005 à 274 en 2006, pour atteindre 26,2 \% de l'effectif (figure 6). Cette progression, régulière depuis 2001, est de près de 1 \% par an.

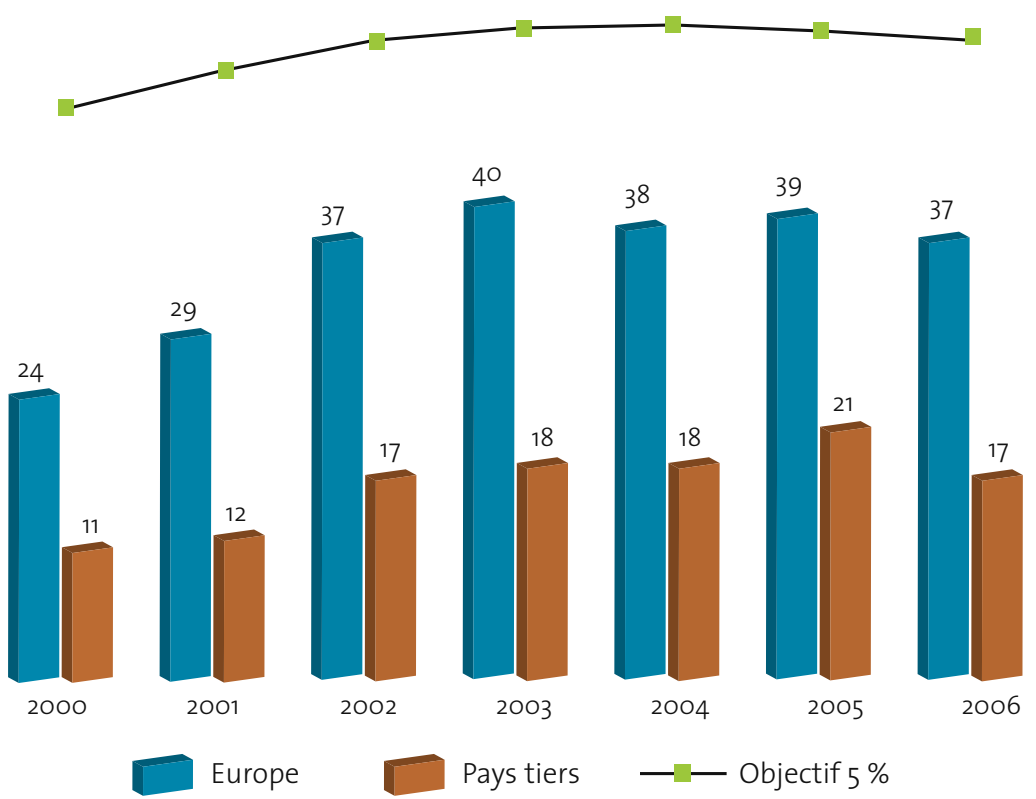

Figure 5. Evolution de l'effectif des cadres étrangers et objectif à atteindre pour les cadres européens.

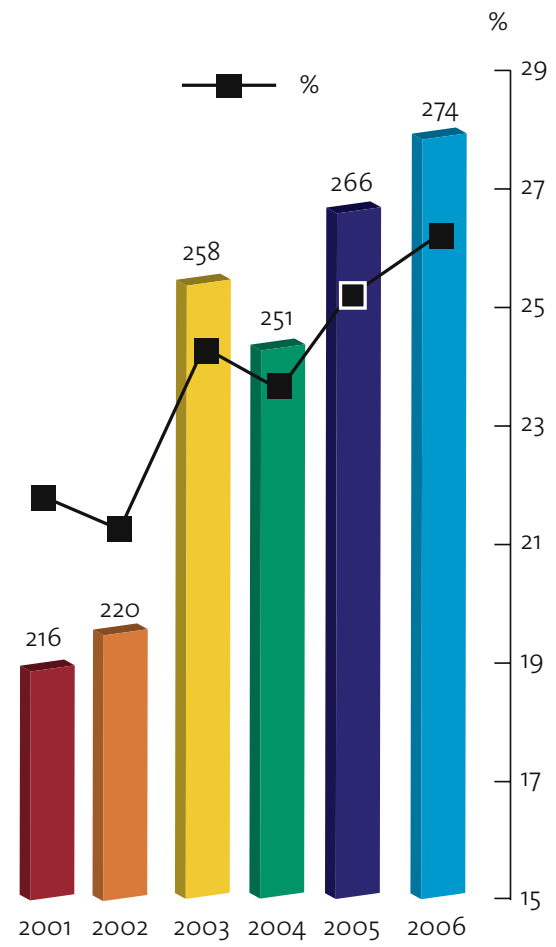

Figure 6. Evolution de l'effectif des femmes cadres.

\section{Lévolution des compétences}

Le nombre d'habilitations à diriger des recherches augmente pour atteindre $8,9 \%$ de l'effectif des cadres scientifiques. Le nombre de docteurs progresse également et passe la barre des $50 \%$. En comparant les chiffres de 2006 à ceux de 2001, on observe une quasistabilité du pourcentage de docteurs, environ $50 \%$, et une augmentation de $1,8 \%$ des habilitations (tableau I).

\begin{tabular}{lcccccc}
\hline \multicolumn{7}{l}{ Tableau I. Evolution des compétences scientifiques de 2001 à 2006. } \\
\hline & 2001 & 2002 & 2003 & 2004 & 2005 & 2006 \\
\hline Cadres scientifiques & 818 & 842 & 899 & 878 & 878 & 856 \\
\hline $\begin{array}{l}\text { Docteurs } \\
\quad \text { nombre }\end{array}$ & 408 & 419 & 465 & 439 & 436 & 430 \\
pourcentage & 49,9 & 49,8 & 51,7 & 50,0 & 49,7 & 50,2 \\
\hline $\begin{array}{l}\text { Habilités à diriger des recherches } \\
\text { nombre }\end{array}$ & 58 & 67 & 72 & 68 & 75 & 76 \\
pourcentage & 7,1 & 8,0 & 8,2 & 7,7 & 8,5 & 8,9 \\
\hline
\end{tabular}




\section{La politique scientifique et partenariale}

Les partenariats

\section{Les projets fédérateurs}

En France, six projets fédérateurs, communs à plusieurs départements, associent des centres de recherche, des établissements d'enseignement supérieur et des centres techniques : Arpège (Architecture racinaire des plantes : facteurs environnementaux et génétiques), Oryzon (Le riz, du gène au champ et du champ au gène), Ecoforbac (Gestion et conservation des écosystèmes forestiers du bassin du Congo), Grenat (Outils d'évaluation et de gestion du risque environnemental lié à l'utilisation de déchets et de produits polluants en agriculture), Labelsud (Qualification et certification des produits), Durabilis (Agriculture durable et innovations sociotechniques). A ces collaborations s'ajoutent de nombreux partenariats européens et internationaux.

Treize actions thématiques programmées (Atp) mobilisent également des chercheurs appartenant à plusieurs départements et unités, sur une durée d'environ trois ans. Ces actions font l'objet d'un appel à propositions, $d^{\prime}$ 'une sélection et d'une restitution collectives.

\section{Les unités mixtes de recherche}

La situation des unités mixtes de recherche n'a pas évolué en 2006. Le Cirad est associé à 20 unités mixtes, où 200 agents sont affectés, ce qui représente plus du quart des cadres scientifiques du Cirad. En 2001, le Cirad participait à seulement 12 unités mixtes de recherche et y affectait 128 scientifiques, soit $15,6 \%$ de son effectif scientifique (figure 7 ).

\section{Les projets européens}

Le $6^{\mathrm{e}}$ programme-cadre de recherche et de développement de la Communauté européenne (Pcrd) s'est achevé

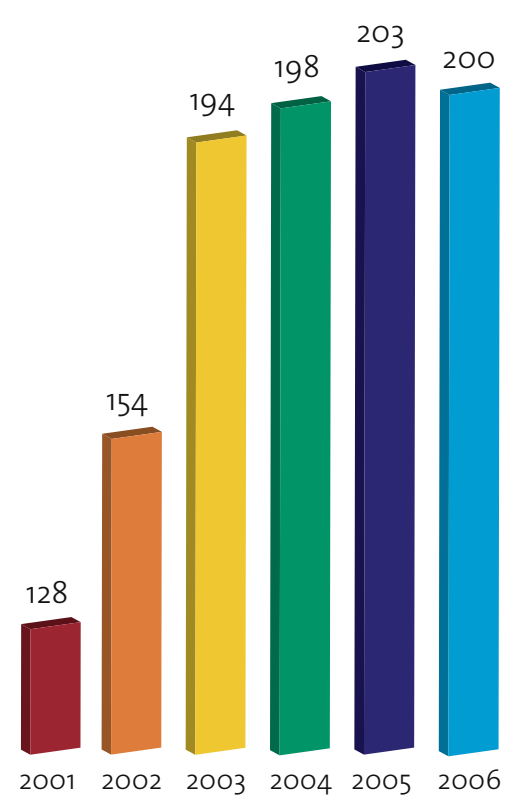

Figure 7. Evolution du nombre de scientifiques du Cirad dans les unités mixtes de recherche. en 2006. Face aux changements apportés à ce programme par rapport aux précédents, le Cirad s'est adapté rapidement, ce qui s'est traduit par une participation accrue et une progression de la contribution des projets européens à ses ressources contractuelles (voir la figure 14 sur l'origine des financements contractuels).

Sur les sept projets financés par la Communauté européenne retenus en 2006, quatre sont coordonnés par le Cirad (tableau II). Le Cirad participe, entre autres, au réseau d'excellence Endure, dont la vocation est de construire une organisation durable autour de la protection des plantes dans une démarche respectueuse de l'environnement. II a ainsi la possibilité de consolider ses propres thématiques de recherche et $d^{\prime} y$ associer ses partenaires du Sud.

Tableau II. Les projets européens retenus en 2006.

European network for the durable exploitation of crop protection strategies (Endure)

Promoting European traceability excellence and research (Peter)

Quantification, understanding and prediction of carbon cycle and other GHG gases in sub-Saharan Africa (Carbo-Africa)

Integrated water resources management by the implementation of improved agro-forestry concepts in arid and semi-arid areas in Latin America (Wafla)

Unravelling pathogenicity of Xanthomonas albilineans, the pathogen causing leaf scald disease of sugarcane (Xagenomics)

Agricultural innovation in dryland Africa (Aida)

Integrating social science research into cotton reform implementation lined with the international outlook (Isscri)
Contact : J.L. Sarah (Bgpi, Pvbmt, Systèmes de culture bananes, plantains et ananas, Dic)

Coordinateur : Inra

Contact : N. Zakhia (late)

Coordinateur : Chambre de commerce et $d^{\prime}$ industrie du Gers

Contact : J.P. Bouillet (Fonctionnement et pilotage des écosystèmes de plantations) Coordinateur : Cirad

Contact : F. Forest (Systèmes de semis direct sous couverture végétale)

Coordinateur : Technologie Transfer Zentrum, Bremerhaven (Ttz, Allemagne)

Contact : P. Rott (Bgpi)

Coordinateur : Cirad

Contact : D. Clavel (Agrobiodiversité des plantes de savanes) Coordinateur : Cirad

Contact : M. Fok (Systèmes cotonniers en petit paysannat) Coordinateur : Cirad 


\section{Les pôles de compétence et les unités de recherche en partenariat}

A l'étranger, six pôles de compétence en partenariat (Pcp) regroupent les chercheurs et les moyens de différentes institutions en un lieu donné, autour d'une thématique commune qui répond à des enjeux de développement (tableau III). Ils ont pour objectif $d$ 'offrir aux chercheurs un environnement optimal et stable pour mener leurs

recherches et se situer au sein de la communauté scientifique internationale. Ils favorisent la production de résultats scientifiques de qualité, l'élaboration d'outils de développement et la formation de jeunes chercheurs de toutes origines. A cela s'ajoute une déontologie du partenariat dont la priorité est de veiller à l'égalité de décision des partenaires. Les partenaires sont associés dès la conception des projets, qui sont inscrits dans les programmations nationales. Le transfert

Tableau IIII. Les pôles de compétence en partenariat.

\begin{tabular}{ll}
\hline $\begin{array}{l}\text { Markets and agriculture } \\
\text { linkages for cities of Asia }\end{array}$ & Partenaires : Asian Institute of Technology (Ait, Thaïlande), \\
(Malica), Vietnam & Centre d'information pour l'agriculture et le développement \\
& rural (Icard, Vietnam), Institut agronomique vietnamien \\
& (Vasi, Vietnam), Institut d'économie agricole (lae, Vietnam), \\
& Institut de recherche sur les fruits et légumes (Rifav, Vietnam), \\
Institut de sociologie (los, Vietnam)
\end{tabular}

Pôle de recherche sur l'intensification des systèmes d'élevage (Prise), Vietnam

Gestion intégrée des agricultures familiales

dans les écosystèmes agroforestiers humides (Grand Sud Cameroun)

Gestion des écosystèmes de savane (Gesed), Mali

Partenaires: Institut d'économie rurale (ler, Mali), Institut polytechnique rural (Ipr, Mali)

Systèmes agroforestiers à base de cultures pérennes, Costa Rica (avril 2007)

Tableau IV. Les unités de recherche en partenariat.

Systèmes de culture et rizicultures durables (Scrid)

Gestion des forêts malgaches et de leur biodiversité (Forêts et biodiversité)

Pastoralisme
Partenaires : Centro Agronómico Tropical de Investigación y Enseñanza (Catie, Costa Rica), Centre for Agriculture and Bioscience International (Cabi, Royaume-Uni), Instituto Centroamericano de Administración de Empresas (Incae, Costa Rica), Programa Cooperativo Regional para el Desarrollo Tecnológico y la Modernización de la Caficultura de Centroamérica (Promecafé, Guatemala, Costa Rica)

Partenaires: Centre national de recherche scientifique (Cnrs, France), National University of Science and Technology (Nust, Zimbabwe), University of Zimbabwe (Uz, Zimbabwe), ambassade de France
Zimbabwe (avril 2007)
Partenaires : Centre national de la recherche appliquée au développement rural (Fofifa, Madagascar), université d'Antanarivo

Partenaires : Centre national de la recherche appliquée au développement rural (Fofifa, Madagascar), université d'Antanarivo

Partenaires : Institut sénégalais de recherches agricoles (Isra, Sénégal), Centre de suivi écologique (Cse, Sénégal), Ecole nationale d'économie appliquée (Enea, Sénégal), Université Cheikh Anta Diop (Ucad, Sénégal) des compétences et l'accès aux informations sont prévus, les publications et I'exploitation en commun des résultats sont facilitées.

Trois unités de recherche en partenariat (Urp), à Madagascar et au Sénégal, viennent compléter ce dispositif (tableau IV). Elles associent des équipes du Cirad à celles d'autres établissements de recherche et d'enseignement supérieur, avec un statut analogue à celui des unités mixtes de recherche. Ce statut renforce l'inscription des équipes dans les systèmes nationaux d'enseignement supérieur et de recherche, leur visibilité internationale et leur reconnaissance par rapport aux standards académiques.

\section{Les pôles et les centres à vocation régionale}

Ces pôles régionaux de coordination scientifique sont des cellules de coordination inter-Etats, qui dépendent des communautés régionales économiques et mobilisent les systèmes nationaux de recherche agricole. Le Prasac, Pôle régional de recherche appliquée au développement des savanes d'Afrique centrale, est ainsi un outil spécialisé de la Cemac, Communauté économique et monétaire d'Afrique centrale. La cellule est basée à N'Djamena, au Tchad, et reçoit une aide budgétaire annuelle de la Cemac. Elle mobilise des financements du ministère des affaires étrangères, de la Banque africaine de développement et coordonne des actions de recherche mises en œuvre par les structures nationales au Cameroun, au Tchad et en République centrafricaine.

Quatre centres régionaux ou à vocation régionale sont partenaires du Cirad en Afrique : le Cirdes, Centre international de recherche-développement sur l'élevage en zone subhumide, au Burkina Faso ; le Carbap, Centre africain de recherche sur bananiers et plantains, au Cameroun ; le Ceraas, Centre d'étude régional pour I'amélioration de l'adaptation à la sécheresse, au Sénégal ; I'Ur2pi, Unité de recherche sur la productivité des plantations industrielles, au Congo. 


\section{Les publications scientifiques et techniques}

Les données concernant les publications scientifiques et techniques sont extraites de la base de données bibliographiques Agritrop, base de référence du Cirad en matière de dépôt institutionnel des publications et rapports. Ces données reflètent l'état de la base au 31 janvier 2007. En raison des délais de parution des documents, seules 50 à $70 \%$ des publications de 2006 sont enregistrées au 31 janvier 2007, d'où une extrapolation des données pour toutes les analyses qui suivent.

Le nombre total de publications (articles de périodiques, ouvrages, chapitres d'ouvrages, actes de congrès, communications et thèses) diminue légèrement depuis 2001 (figures 8 et 9). Cette tendance est principalement due à une diminution du nombre de communications dans les congrès constatée depuis 2003. En revanche, le nombre d'articles de périodiques est en constante augmentation, avec une nette progression des publications dans les revues à facteur d'impact (figure 10).

Pour la période 2005-2006 (hors extrapolation), les articles publiés dans les revues à facteur d'impact sont au nombre de 482. Parmi ceux-ci, 415 articles, soit $86 \%$, sont publiés avec des coauteurs extérieurs au Cirad, principalement issus d'univer- sités ou d'organismes de recherche européens (94\%) ou africains (30\%) (figure 11).

Les organismes de rattachement de ces coauteurs sont particulièrement diversifiés. Cependant, $40 \%$ de ces articles sont publiés avec au moins un universitaire, accueilli en Europe (48 \%), en Afrique (18\%), en Amérique du Nord (13\%), en Asie (13\%) ou en Amérique du Sud $(10 \%)$. En dehors des universités, les organismes les mieux représentés dans ces copublications sont l'Inra, le Cnrs et l'Ird.

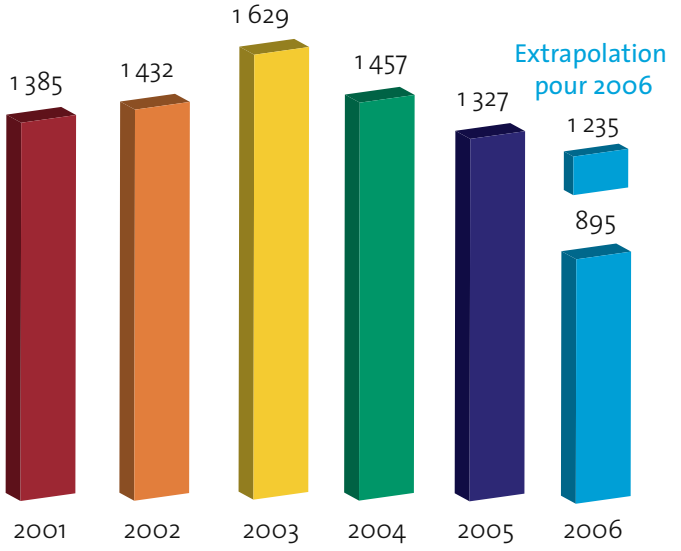

Figure 8. Evolution du nombre total des publications.

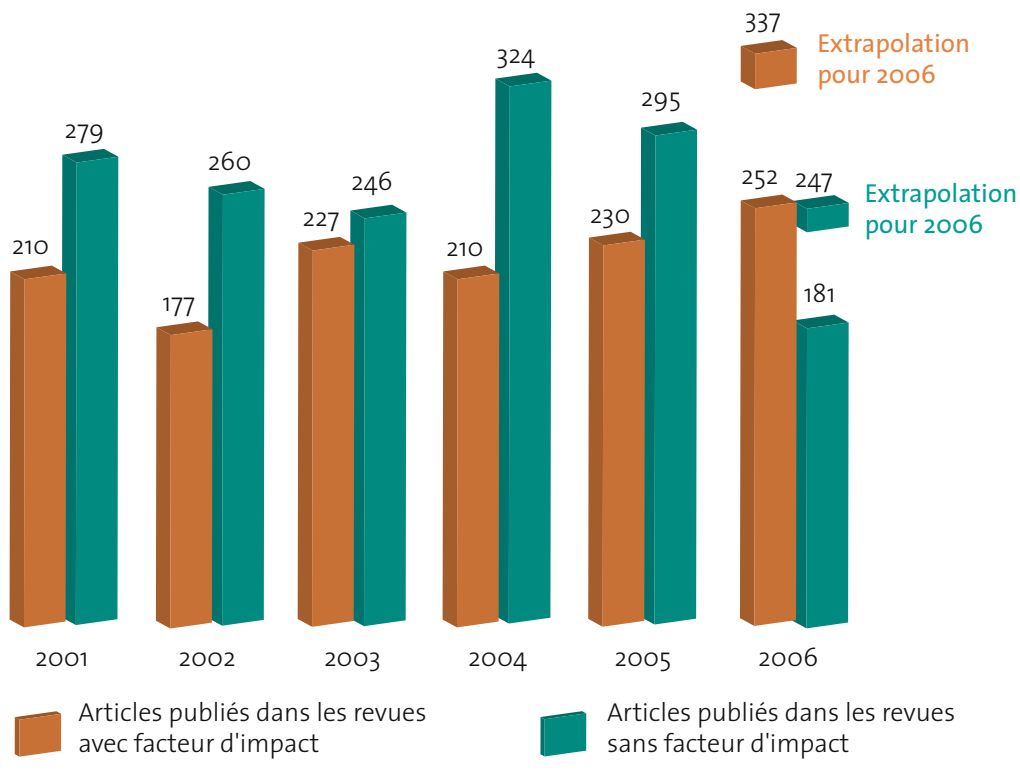

Figure 10. Evolution du nombre d'articles de périodiques.

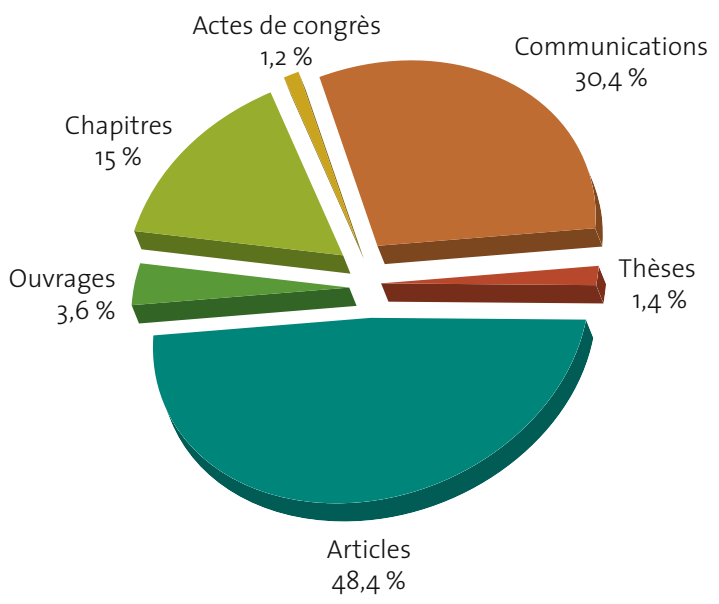

Figure 9. Répartition des publications enregistrées pour 2006 selon le type de document.

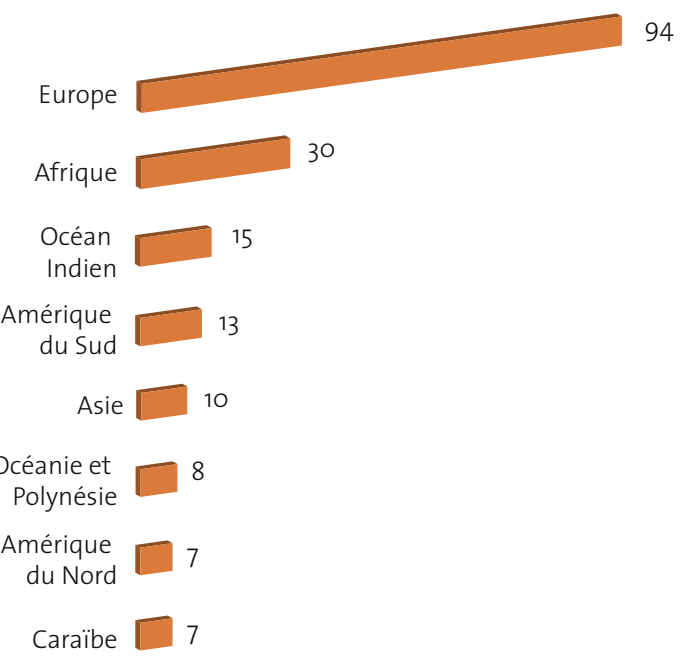

Figure 11. Origine géographique des coauteurs des articles de revue à facteurs d'impact. 


\section{La valorisation}

Le Cirad détient un portefeuille de 35 brevets dont la moitié en copropriété avec au moins un partenaire. A la fin de 2006, le Cirad avait déposé 33 logiciels, 51 variétés végétales protégées par un certificat d'obtention végétale (Cov), 10 marques, un dessin et un dossier technique secret.

\section{Les moyens financiers}

La couverture des charges d'exploitation par la subvention pour charge de service public (Scsp) passe de 62,3\% en 2005 à 62,4\% en 2006 (figures 12 et 13).

Les ressources contractuelles sont en augmentation : 53,5 millions d'euros en 2006 contre 47,4 en 2005 (figure 14). Cette augmentation est, cette année encore, due aux fonds européens, qui passent de 16,1 à 19,3 millions d'euros, soit 19,9\% de plus qu'en 2005. Tous les autres fonds progressent également, mais dans des proportions moindres. A noter, après une période de régression, le redressement des fonds publics français pour la troisième année consécutive, sans toutefois rattraper le niveau de 2002.
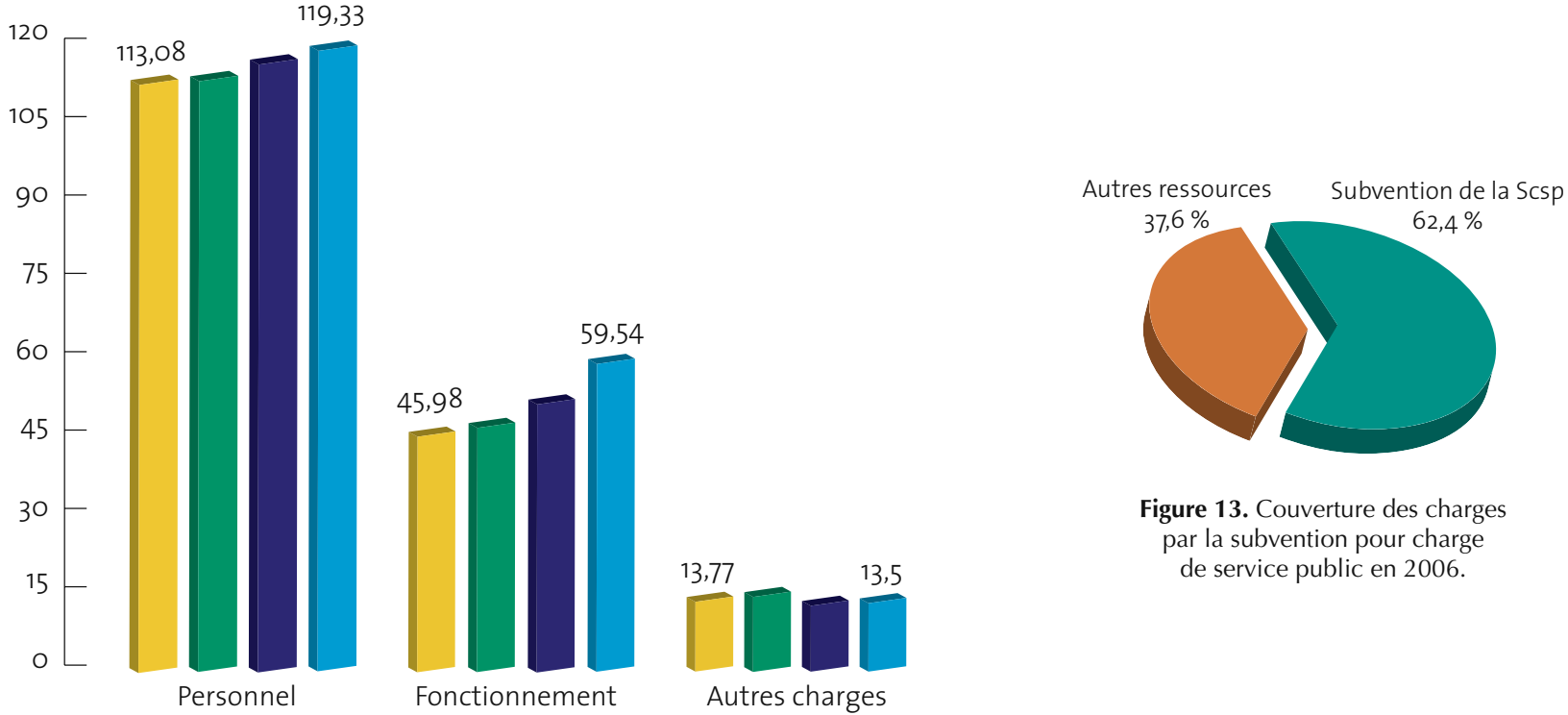

Figure 13. Couverture des charges par la subvention pour charge de service public en 2006.

Figure 12. Dépenses d'exploitation, en millions d'euros.
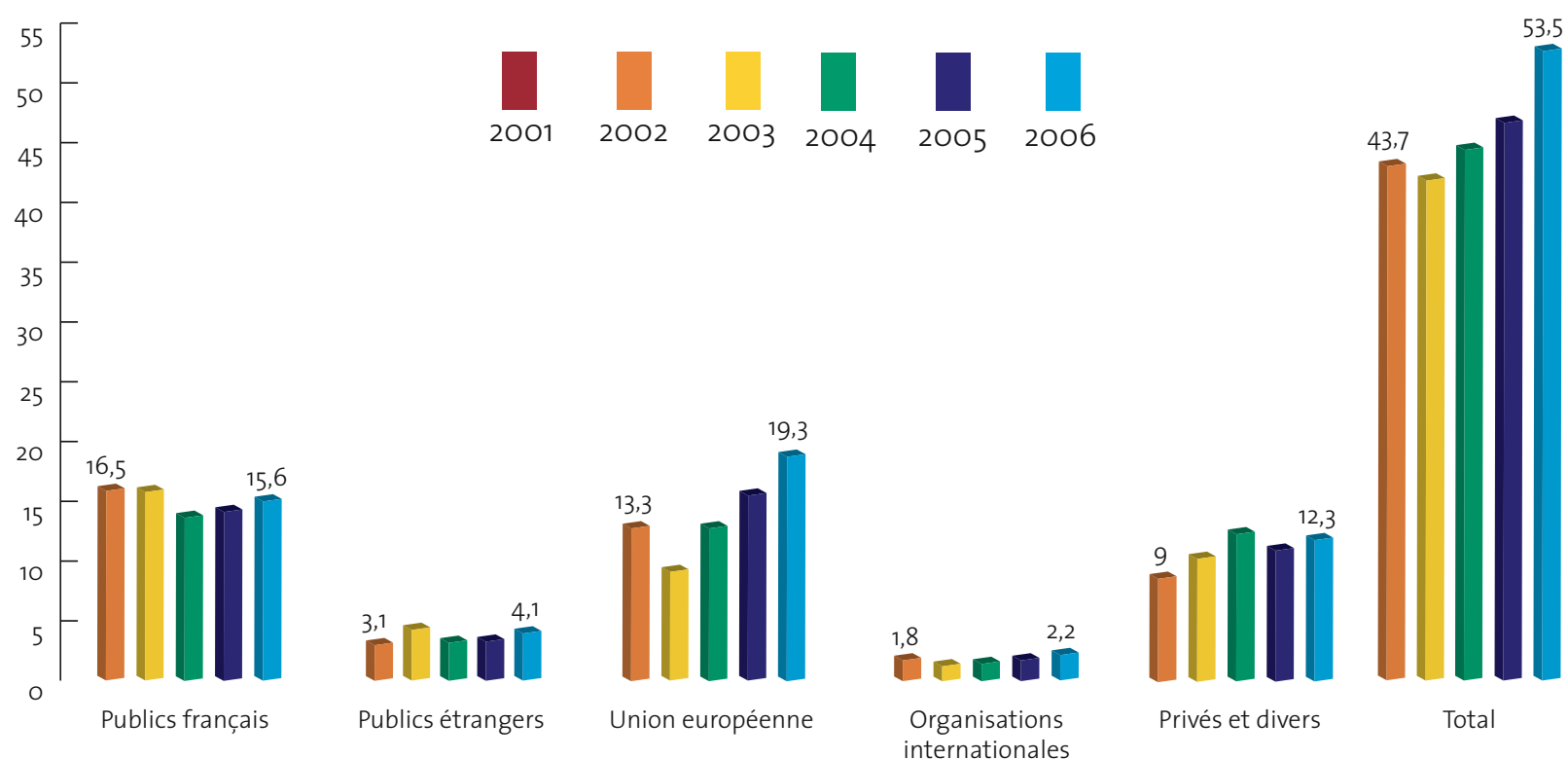

Figure 14. Origine des financements contractuels, en millions d'euros. 


\section{La politique de la qualité}

La démarche de qualité en recherche vise à maîtriser la traçabilité des actions, à améliorer la fiabilité des résultats et à mettre les activités ou les laboratoires en conformité avec des référentiels. Elle a pour objectif prioritaire l'amélioration collective des processus de production scientifique et concerne tous les acteurs de la recherche, y compris les gestionnaires et les agents de l'appui à la recherche.

En 2006, neuf structures, dont huit laboratoires d'unités de recherche, soit 360 personnes $(20 \%$ de l'effectif total), sont engagées dans une démarche de certification ou d'accréditation de niveau 4, c'est-à-dire avec reconnaissance par une tierce partie selon le référentiel international Iso (International Organisation for Standardization) (tableau V).

La démarche de qualité concerne les activités et les laboratoires en métropole et dans l'outre-mer français, mais aussi les structures implantées en partenariat à l'étranger. Des actions spéci- fiques de sensibilisation, d'information et de formation aux démarches et aux outils de la qualité sont organisées. L'ensemble de ces activités au service de la politique générale du Cirad doit contribuer à renforcer la crédibilité et la notoriété de ses équipes de recherche en améliorant la qualité de leurs travaux.

Tableau V. Structures certifiées ou accréditées.

Structures (unité de recherche concernée)

Type de norme

Effectif

\section{Déjà certifiées en 2004}

- Laboratoire d'analyses agronomiques, Montpellier

- Laboratoire d'analyses agronomiques, Réunion

- Laboratoire d'essai en préservation des bois, Montpellier

\section{Certifiées en 2005}

- Laboratoire d'essai en préservation des bois (Production et valorisation des bois tropicaux), Montpellier

- Système de management environnemental à Baillarguet (unités de recherche et de services d'élevage et de médecine vétérinaire), Montpellier

\section{Certifiées en 2006}

- Laboratoire de qualité du caoutchouc naturel (Qualité des produits des cultures pérennes), Montpellier

\section{En cours de certification ou d'accréditation}

- Laboratoire de santé animale, Montpellier

- Laboratoire de santé animale, Guadeloupe

- Umr Biologie et génétique des interactions plantes-parasites pour la protection intégrée

(Bgpi), Montpellier 


$$
\text { L'organisation }
$$




\section{L'organisation \\ en avril 2007}

\section{Conseil d'administration}

Président

Patrice Debré, professeur des universités

Didier Hoffschir, représentant le ministre délégué à l'enseignement supérieur et à la recherche

Antoine Grassin, représentant le ministre délégué à la coopération et au développement

$\mathbf{X}$, représentant le ministre délégué au budget et à la réforme de l'Etat

Jean-Louis Buër, représentant le ministre de l'agriculture et de la pêche

Pierre Brunhes, représentant le ministre des départements et des territoires d'outre-mer

Jean-François Girard, président de l'Institut de recherche pour le développement

Marion Guillou, présidente de I'Institut national de la recherche agronomique

Christiane Lambert, vice-présidente de la Fédération nationale des syndicats d'exploitants agricoles, présidente de Vivea

Haïdara Lansry Nana Yaya, commissaire à la Sécurité alimentaire du Mali

Jean-Michel Severino, directeur général de l'Agence française de développement

Laurence Tubiana, directrice de l'Institut du développement durable et des relations internationales

Représentants élus du personnel

\section{Martine Antona}

Michel Benoit-Cattin

Patrick d'Aquino

Tristan Durand-Gasselin

Laurent Maggia

Philippe Vaast

Secrétaire

Jean-Louis Muron

\section{Comité d'éthique}

En cours de renouvellement

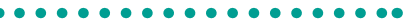 \\ Conseil scientifique}

Président

Bernard Chevassus-au-Louis, Inra, France

Bonnie Campbell, université de Québec, Canada

Marie-Christine Cormier-Salem, Ird, France

Bernard Delay, Cnrs, France

Maria Fernanda Espinosa, Uicn, Equateur

Yaye Kene Gassama Dia, ministère

de la Recherche, Sénégal

Gnissa Konate, Inera, Burkina Faso

Yves Savidan, Ird, France

Claudine Schmidt-Lainé, Cemagref, France

Serge Svizzero, université de la Réunion,

France

Représentants élus du personnel

Marie-Line Caruana

Jacques Lançon

Raphaël Morillon

Laurence Ollivier

Vincent Ribier

\section{-..................... \\ Direction générale}

Gérard Matheron, directeur général

Michel Griffon, conseiller

Jean-Louis Muron, conseiller

Léandre Mas, délégué à la qualité

\section{Direction de la recherche}

et de la stratégie

Etienne Hainzelin, directeur

Michel Benoît-Cattin, fonds incitatifs et budget

Claudie Dreuil, fonds incitatifs et budget

Dany Griffon, délégué à l'évaluation

Martin-Eric Loffeier, coordination et stratégie Hubert Omont, filières

\section{Direction de l'innovation et de la communication}

Alain Weil, directeur

Joël Sor, directeur adjoint et délégué aux systèmes d'information

Didier Chabrol, délégué à l'information scientifique et à la communication

Véronique Vissac-Charles, déléguée

à la valorisation

\section{Direction des relations européennes} et internationales

Gilles Saint-Martin, directeur

Hubert Guérin, délégué pour l'Afrique et l'océan Indien

$\mathbf{X}$, délégué pour l'Asie et le Pacifique

André de Courville, délégué pour l'Amérique latine et la Caraïbe

Catherine Marquié, déléguée pour l'Europe communautaire

Christian Hoste, délégué pour le système européen et international de la recherche agricole pour le développement

Mireille Mourzelas, déléguée aux échanges scientifiques internationaux

Michel Trebel, délégué pour les pays méditerranéens et le Proche-Orient

\section{Secrétariat général}

Hervé Deperrois, secrétaire général Patrick Herbin, secrétaire général adjoint Marc Gélis, directeur de la comptabilité et des affaires financières

Vincent Fabre-Rousseau, directeur de la gestion des ressources humaines (par intérim)

Didier Servat, directeur technique de I'aménagement et de la maintenance

Gilles Mandret, directeur de l'outre-mer français

Patrick Herbin, délégué juridique

André Nau, délégué au contrôle de gestion

Marie-Gabrielle Bodart, déléguée aux archives

Aleth de Sartiges, ingénieur sécurité 
Départements et unités de recherche

Département Systèmes biologiques

Jean Christophe Glaszmann, directeur

Dominique Berry, directeur adjoint

Xavier Mourichon, adjoint à la direction

Francis Ercole, chef du service d'appui

à la gestion

Unités de recherche*

Agrobiodiversité des plantes de savanes

(Upr), Jacques Chantereau

Amélioration génétique d'espèces

à multiplication végétative (Upr),

\section{Robert Domaingue}

Amélioration génétique du palmier à huile (Upr), Tristan Durand-Gasselin

Biologie et génétique des interactions plantes-parasites pour la protection intégrée (Umr Bgpi), Jean-Loup Notteghem, SupAgro (SupAgro, Inra)

Botanique et bio-informatique

de I'architecture des plantes (Umr Amap),

Daniel Barthélémy, Inra (Cnrs, Inra, Ird,

université Montpellier 2)

Centre de biologie et gestion des populations (Umr Cbgp), Denis Bourguet, Inra (SupAgro, Inra, Ird, université Montpellier 2)

Commercialisation du matériel végétal (Us), Christian Picasso

Contrôle des maladies animales exotiques et émergentes (Upr), Dominique Martinez

Création variétale et peuplements de riz

(Upr), Nourollah Ahmadi

Développement et amélioration des plantes

(Umr Dap), Françoise Dosba, SupAgro

(SupAgro, Inra, Ird, université Montpellier 2, Cnrs)

Diversité génétique et amélioration des espèces forestières (Upr), Jean-Marc Bouvet Ecologie et maîtrise des populations d'acridiens (Upr), Michel Lecoq

Enseignement et formation en élevage (Us), Christophe Dalibard

Epidémiologie et écologie des maladies animales (Upr), François Roger

Gestion des ressources génétiques et dynamiques sociales (Upr), Hélène Joly Jaunissement mortel du cocotier et greening des agrumes (Upr), Michel Dollet

Laboratoire des symbioses tropicales et méditerranéennes (Umr Lstm),

Bernard Dreyfus, Ird (SupAgro, Inra, Ird, université Montpellier 2)

Maîtrise des bioagresseurs des cultures pérennes (Upr), Christian Cilas

Peuplements végétaux et bioagresseurs en milieu tropical (Umr Pvbmt),

Bernard Reynaud (université Réunion)
Plasticité phénotypique et performances des cultures (Upr), Michael Dingkuhn

Résistance des plantes aux bioagresseurs (Umr Rpb), Michel Nicole, Ird (Ird, université Montpellier 2)

Trypanosomes (Umr), Gérard Cuny, Ird (Ird)

Unité de service agricole en Guyane (Us), Jean-Louis Pradon

\section{Département Performances}

des systèmes de production

et de transformation tropicaux

Robert Habib, directeur

Marcel de Raïssac, directeur adjoint

Jacques Nolin, chef du service d'appui

à la gestion

Unités de recherche*

Aide à la décision et biostatistique (Upr), Philippe Letourmy

Analyses des eaux, sols et végétaux (Us), Alain Aventurier

Aquaculture et gestion des ressources aquatiques (Upr), Jérôme Lazard Biomasse-énergie (Upr), Philippe Girard

Démarche intégrée pour l'obtention d'aliments de qualité (Umr Qualisud), Jean-Pierre Pain, université Montpellier 2 (universités Montpellier 1 et 2, SupAgro)

Elevage des ruminants en régions chaudes (Umr Errc), François Bocquier, SupAgro (SupAgro, Inra)

Fonctionnement et conduite des systèmes de culture tropicaux et méditerranéens (Umr System), Jacques Wery, SupAgro

(SupAgro, Inra)

Fonctionnement et pilotage des écosystèmes de plantations (Upr), Jean-Pierre Bouillet

Génie des procédés d'élaboration des bioproduits (Umr Gpeb), Alain Grasmick, université Montpellier 2 (Ensia, Siarc, universités Montpellier 1 et 2)

Horticulture (Upr), Philippe Vernier

Ingénierie des agropolymères

et technologies émergentes (Umr late),

Stéphane Guilbert, SupAgro (SupAgro, Inra, université Montpellier 2)

Performance des systèmes de culture des plantes pérennes (Upr), Jean-Luc Battini

Production et valorisation des bois tropicaux (Upr), Jean Gérard

Production fruitière intégrée (Upr),

Hubert De Bon

Qualité des fruits et légumes tropicaux (Umr Qualitrop), Louis Fahrasmane, Inra (Inra, université Antilles-Guyane)

Qualité des productions cotonnières (Upr), Bernard Hau

Risque environnemental lié au recyclage (Upr), Hervé Saint Macary

Systèmes canniers (Upr), Pascal Marnotte
Systèmes cotonniers en petit paysannat (Upr) Bernard Hau

Systèmes de culture bananes, plantains et ananas (Upr), François Côte

Systèmes de culture et rizicultures durables (Urp Scrid), Alain Ratnadass

(Fofifa, université d'Antanarivo)

Systèmes de semis direct sous couverture végétale (Upr), Francis Forest

\section{Département Environnements et sociétés}

Patrick Caron, directeur

Bernard Mallet, directeur adjoint

Brigitte Nésius, chef du service d'appui

à la gestion

Unités de recherche*

Actions collectives, politiques et marchés

(Upr), Jacques Marzin

Centre international de recherche sur l'environnement et le développement (Umr Cired), Jean-Charles Hourcade, Cnrs-Ehess (Cnrs, Ehess, Engref, Enpc)

Innovation et développement dans I'agriculture et l'agroalimentaire

(Umr Innovation), Hubert Devautour

(SupAgro, Cnearc, lamm, Inra)

Dynamique des forêts naturelles (Upr), Sylvie Gourlet-Fleury

Ecologie des forêts de Guyane (Umr Ecofog), Bernard Thibaut, Cnrs (Cnrs, Engref, Inra, université Antilles-Guyane)

Gestion de l'eau, acteurs et usages (Umr G-eau), Patrice Garin, Cemagref (Cemagref, Engref)

Gestion des forêts malgaches et de leur biodiversité (Urp Forêts et biodiversité), Pascal Danthu (Fofifa, université d'Antanarivo)

Gestion des ressources renouvelables et environnement (Upr), Jean-Pierre Müller

Gestion intégrée de la faune (Upr),

François Monicat

Marchés, organisations, institutions et stratégies d'acteurs (Umr Moisa),

Jean-Louis Rastoin, SupAgro (SupAgro, Inra, Ciheam, Ird)

Pastoralisme (Urp), Amadou Tamsir Diop, Isra (Isra, Ucad, Cse, Enra)

Ressources forestières et politiques publiques (Upr), Robert Nasi

Systèmes d'élevage et produits animaux (Upr), Didier Richard

Territoires, environnement, télédétection et information spatiale (Umr Tetis),

Pascal Kosuth, Cemagref (Cemagref, Engref)

\footnotetext{
* Umr : Unité mixte de recherche • Upr : Unité propre de recherche $\bullet$ Urp : Unité de recherche en partenariat $\bullet$ Us : Unité de service
} 


\section{Dispositif géographique}

\section{France}

\section{Corse}

Dominique Agostini, directrice

Station de recherche agronomique Inra 20230 San Giuliano

Tél. : +33495595921

agostini@corse.inra.fr

\section{Guadeloupe}

Patrice Guillaume, directeur régional Station de Neufchâteau, Sainte-Marie 97130 Capesterre-Belle-Eau

Tél. : +590 590861790 patrice.guillaume@cirad.fr

\section{Guyane}

Philippe Godon, directeur régional BP 701, avenue de France 97387 Kourou Cedex Tél. : +594594327352 philippe.godon@cirad.fr

\section{Ile-de-France}

Patrick Herbin, directeur régional

42, rue Scheffer

75116 Paris

Tél. : +33153702001

patrick.herbin@cirad.fr

\section{Languedoc-Roussillon}

Emmanuel Camus, directeur régional Avenue Agropolis

34398 Montpellier Cedex 5

Tél. : +33467615801

emmanuel.camus@cirad.fr

\section{Martinique}

Thierry Goguey-Muethon, directeur régional BP 214

97285 Le Lamentin Cedex 2

Tél. : +596596423000

thierry.goguey-muethon@cirad.fr

\section{Mayotte}

Bernard Dolacinski, correspondant BP 1304

97000 Mamoudzou

Tél. : +269269612121

cirad.mayotte@wanadoo.fr

\section{Nouvelle-Calédonie}

Gilles Mandret, directeur régional

42, rue Scheffer

75116 Paris

Tél. : +33153702179

gilles.mandret@cirad.fr

\section{Réunion}

Jean-Pierre Gay, directeur régional

Station de La Bretagne, BP 20

97408 Saint-Denis Messageries Cedex 9

Tél. : +262 262528002

cirad-reunion@cirad.fr

\section{Afrique}

\section{Afrique centrale}

Sylvie Lewicki-Dhainaut, directrice régionale BP 2572

Yaoundé

Cameroun

Tél. : +23722 212541

$$
\text { +23796337537 }
$$

cirad-cm@cirad.fr

Philippe Deleporte, correspondant BP 1292

Pointe-Noire

Congo

Tél. : +242944795

+2425246948

philippe.deleporte@cirad.fr

\section{Afrique orientale et australe}

Denis Depommier, directeur régional

C/o Icraf, United Nations Avenue

Gigiri, PO Box 30677

00100 Nairobi

Kenya

Tél. : +25420722 4653

+254723274069

cirad-afora@cgiar.org

Stefano Farolfi, correspondant

Ceepa, University of Pretoria

0002 Pretoria

Afrique du Sud

Tél. : +27 124204659

$+27794952155$

\section{Afrique de l'Ouest continentale}

Jacques Pages, directeur régional 01 BP 596

Ouagadougou 01

Burkina Faso

Tél. : +22650307070

$$
\text { +25670205745 }
$$

draoc.cirad@fasonet.bf

Patrick Prudent, correspondant 08 BP 1077, Centre de tri postal Cotonou

Bénin

Tél. : +2292138 8086 +22997445775

patrick.prudent@cirad.fr

Alain Renou, correspondant

BP 1813

Bamako

Mali

Tél. : +2232211015

+2236750150

alain.renou@cirad.fr

\section{Didier Snoeck}

Sccs Regional Project

Ambassade de France au Ghana Valise diplomatique

128 bis, rue de l'Université

75351 Paris SP7

Tél. : +23321513142

\section{Afrique de l'Ouest côtière}

Georges Subreville, directeur régional 37, avenue Jean XXIII, BP 6189

Dakar-Etoile

Sénégal

Tél. : +221822 4484

+2216371878

dreg.cirad@sentoo.sn

Patrice de Vernou, correspondant C/o SCAC, Ambassade de France BP 570

Conakry

Guinée

Tél. : +22430455052 +22463352495

patrice.de_vernou@cirad.fr 


\section{Madagascar}

Michel Partiot, directeur régional Ampandrianomby, BP 853

Antananarivo

Madagascar

Tél. : +261202240623

+261320711422

dregion@cirad.mg

\section{Amérique}

\section{Amérique centrale}

Philippe Vaast, correspondant Catie, 7170 Apartado 3

Turrialba

Costa Rica

Tél. : +5065587830

philippe.vaast@cirad.fr

\section{Brésil}

Philippe Petithuguenin, directeur régional SHIS-QI 23, BI. B. Ed. Top 23

71660-120 Brasilia DF

Brésil

Tél. : +556133661132

+556181389865

philippe.petithuguenin@cirad.fr

\section{Etats-Unis}

Jill Barr, correspondante auprès de la Banque mondiale et de la Banque interaméricaine de développement

Development Research Associates 8313, Woodhaven bvd, Bethesda, 20817 Maryland

Etats-Unis

Tél. : +1 3013656855

jbarr@cirad.fr
Asie

\section{Asie du Sud-Est continentale}

Gabriel Taffin de Tilques, directeur régional Cirad Representative Office,

19 Han Thuyen street, Hai Ba Trung District Hanoi

Vietnam

Tél. : +84 49720625 +84903215792

ciradvn@hn.vnn.vn

Antoine Leconte, correspondant Cirad office

Research and Development Building 4th Floor, Kasetsart University 10900 Bangkok

Thaïlande

Tél. : +6629427627 +66898885415

antoine.leconte@cirad.fr

\section{Asie du Sud-Est insulaire}

Jean-Guy Bertault, directeur régional Plaza Bisnis Kemang, 3rd Floor

Jalan Kemang Raya 2

Jakarta Selatan 12730

Indonésie

Tél. : +62 217199067

$$
\text { +628161910012 }
$$

jean-guy.bertault@cirad.fr

\section{Chine}

Zheng Li, représentant permanent Inra-Cirad 507 Tower A, Fuhua Mansion 8 Chaoyangmen North Avenue 100027 Beijing

Chine

Tél. : +861065541871

zhengliinra@sohu.com

\section{Océanie}

\section{Pacifique Sud}

Gilles Mandret, directeur régional 42, rue Scheffer

75116 Paris

Tél. : +33153702179

gilles.mandret@cirad.fr 


\section{Le Cirad dans le monde}

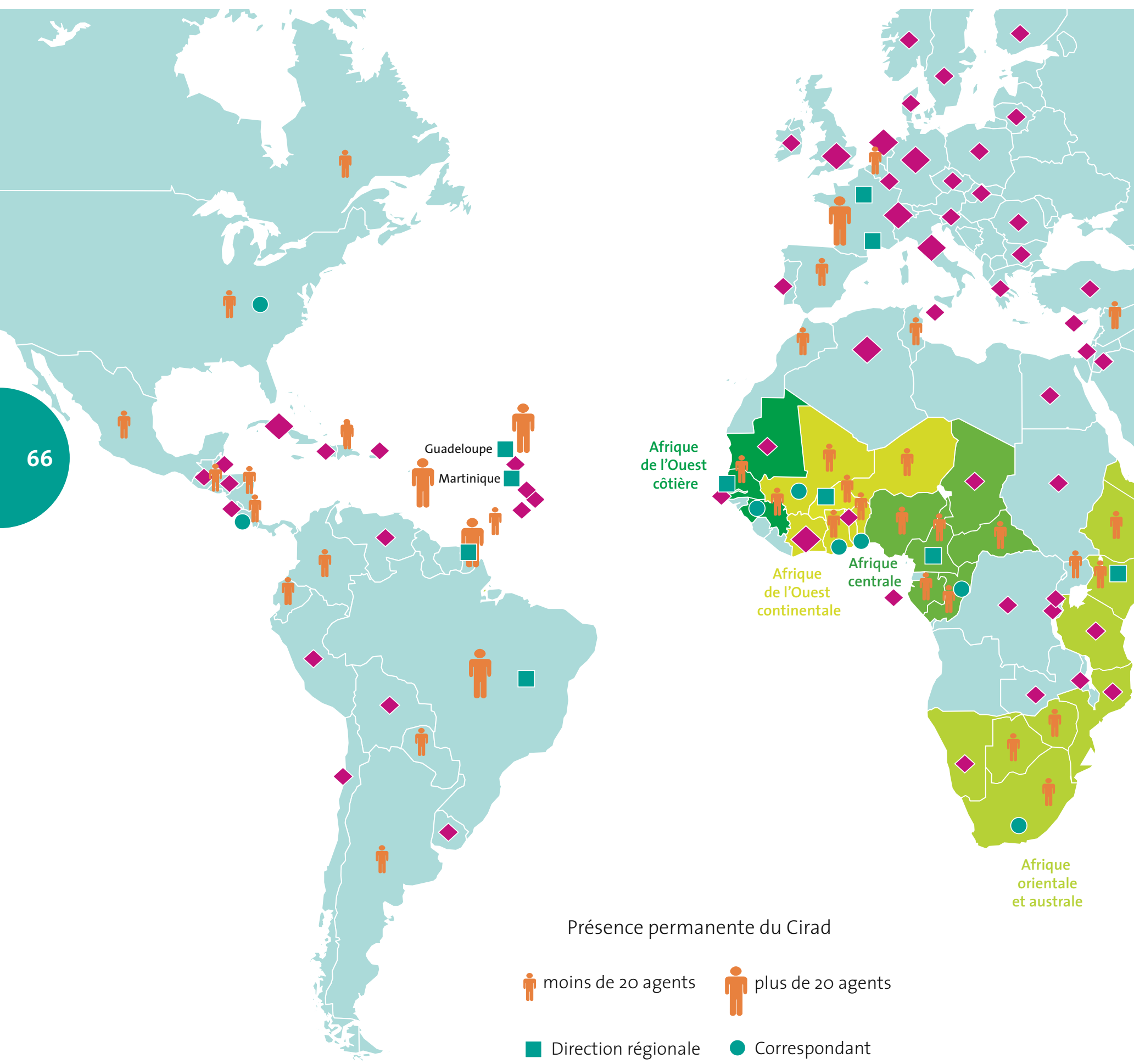




\section{Photographies}

Couverture : Rizières des hauts plateaux de Madagascar. (c) C. Lanaud/Cirad.

Page 7 (c) Cirad, V. Dollé, T. Durand-Gasselin, B. Pioch, V. Porphyre, G. Trébuil, I. Vagneron.

Pôle images du Cirad.

Réalisation

Direction de l'innovation et de la communication

\section{Coordination}

Martine Lemaire

\section{Rédaction}

Martine Lemaire, Elsa Bru

avec la collaboration de Cécile Fovet-Rabot, Christine Rawski, Nicole Pons

\section{Correction}

Jacques Bodichon, Aniane (34)

\section{Maquette et infographie}

Patricia Doucet

\section{Diffusion}

Renée Graulières

Impression

Impact Imprimerie, Saint-Gély-du-Fesc (34)

Dépôt légal : juin 2007 


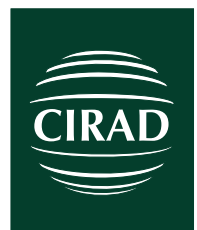

Centre

de coopération internationale en recherche agronomique pour le développement

42, rue Scheffer 75116 Paris France

www.cirad.fr

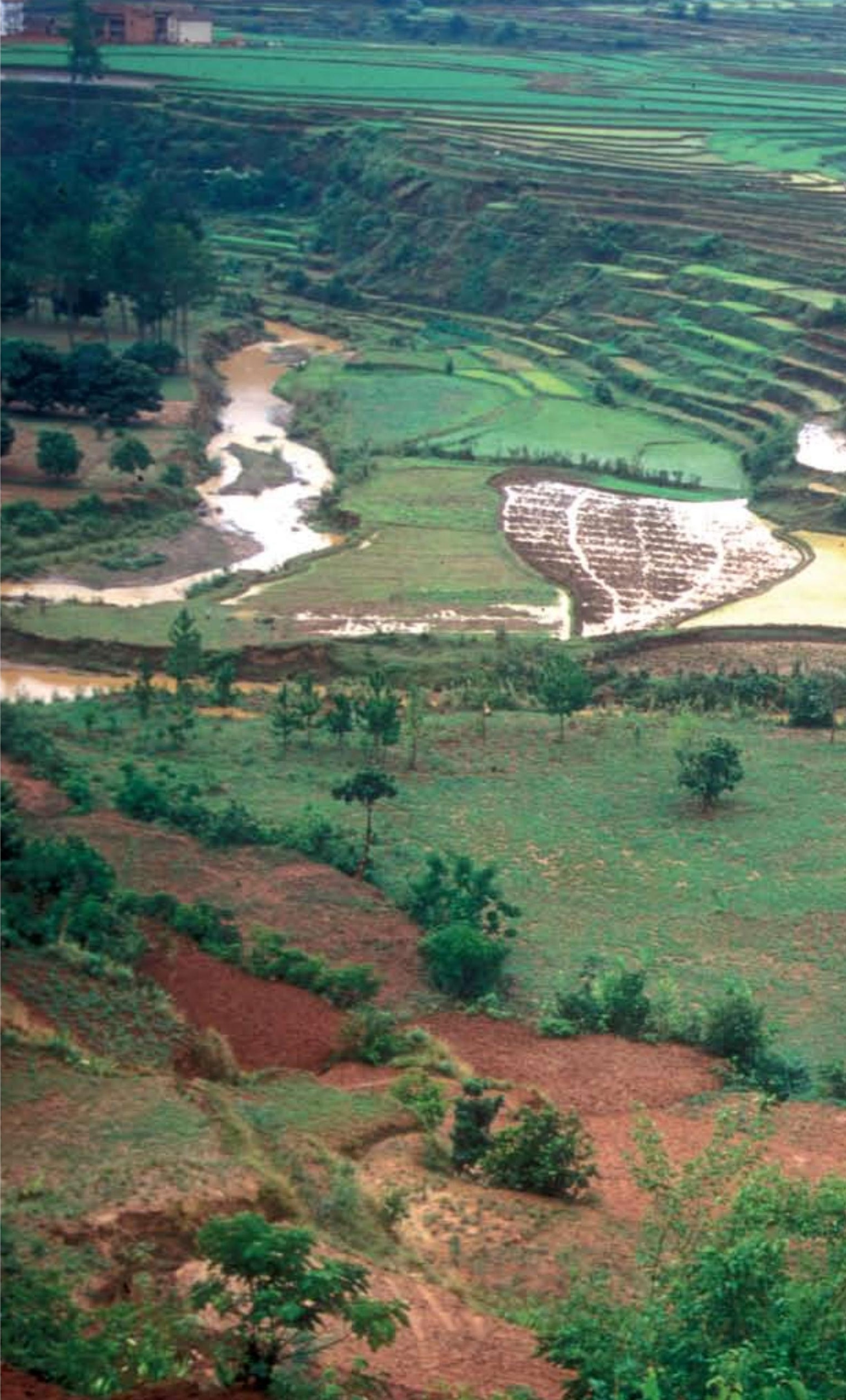

